\title{
Um ambiente computacional para um teste de significância bayesiano
}

Silvio Rodrigues de Faria Junior

\author{
DISSERTAÇÃO APRESENTADA \\ $\mathrm{AO}$ \\ Instituto DE MATEMÁticA e EstatísticA \\ DA \\ UnIVERSIDADE DE SÃO PAUlO \\ PARA \\ OBTENÇÃO DO TÍTULO \\ DE \\ Mestre EM CiênCIAS \\ Programa: Estatística \\ Orientador: Prof. Dr. Julio Michael Stern
}

Durante o curso de mestrado, o autor recebeu apoio financeiro da Pró-Reitoria de Pós Graduação da USP

São Paulo, novembro de 2006 


\title{
Um ambiente computacional para um teste de significância bayesiano
}

\author{
Esta dissertação contém as correções e alterações \\ sugeridas pela Comissão Julgadora durante a defesa \\ realizada por Silvio Rodrigues de Faria Junior em 09/10/2006. \\ O original encontra-se disponível no Instituto de \\ Matemática e Estatística da Universidade de São Paulo.
}

Comissão Julgadora:

- Prof. Dr. Julio Michael Stern (Orientador) - IME - USP

- Prof. Dr. Francisco Louzada Neto - UFSCar

- Prof. Dr. Eduardo Jordão Neves - IME - USP 


\section{Agradecimentos}

Gostaria de dedicar este trabalho a todas as pessoas que conviveram comigo ao longo deste período da minha vida onde muito além de teoria e técnica, aprendi a valorizar ainda mais os bons relacionamentos e a verdadeira amizade. Pessoas dentre as quais ensinaram-me que a dedicação, o empenho e a busca pelo aperfeiçoamento só podem produzir bons frutos em nossas vidas e que as intempéries pelas quais passamos são parte importante do nosso desenvolvimento pessoal, e portanto, devemos enfrentá-las com alegria em nossos corações.

Meus sinceros agradecimentos aos professores Eduardo Jordão Neves, meu primeiro incentivador em minha jornada no mestrado; Carlos Alberto de Bragança Pereira, um ser humano fantástico, motivador e dono de uma simpatia e bom-humor inigualáveis; ao meu orientador Julio Michael Stern, sou muito grato por todo o apoio e dedicação, sem os quais a conclusão deste trabalho teria sido inimaginável para mim.

Gostaria de lembrar também meus amigos e companheiros de pesquisa Marcelo de Souza Lauretto, Fábio Nakano e Elisa Sayuri Shimabukuro, que me ajudaram imensamente na elaboração deste texto, apoiando, opinando, discutindo e corrigindo meus erros de grafia e texto. Aprendi e ainda estou aprendendo muito com vocês também. Muito obrigado a Ricardo Zorzetto Nicoliello Vêncio por ter contribuído com as ilustrações e a Ricardo Luiz Andrade Abrantes pela ajuda com a interface ALGENCAN no R.

Meu muito obrigado ao casal Daniel Vainsencher de Maya Monteiro e Fabiana Bittencourt Fevorini, pela oportunidade de aprender e crescer como programador e pelo pragmatismo. Obrigado ao Sr. Hélio Canhato e á D. Lourdes Canhato que me acolheram em São Paulo e sempre me apoiaram e incentivaram em meus estudos mesmo nos momentos difíceis.

Agradeço aos meus amigos que sempre estiveram do meu lado, Rodnei Roberto da Silva, Mickail Monteiro Lopes Ribeiro Gonçalves, Ailton de Andrade Oliveira, Alexandre Lymberopoulos, Roberto Masaishi dos Santos Yoshikawa, Henry Kyoshi Oyagawa, Edward Mitsuo Iwanaga Iamamoto, Daniel de Oliveira Dantas, Fábio Grezele, Patrip Roy Chowdhurry, Rodrigo Nonamur Pereira Mariano de Souza, e tantos outros.

E finalmente á minha família, minhas irmãs Patrícia Buzatto de Faria e Natália Aparecida de Faria, minha avó Cleufe Cipolla Buzatto, muito obrigado por tudo. E a meus pais Silvio Rodrigues de Faria e Lenamara Buzatto de Faria que nunca mediram esforços pela educação e bem-estar de seus filhos com muito amor e carinho.

Agradeço a Deus por vocês todos terem participado da minha vida. 


\section{Resumo}

Em 1999, Pereira e Stern [Pereira and Stern, 1999] propuseram o Full Bayesian Significance Test (FBST), ou Teste de Significância Completamente Bayesiano, especialmente desenhado para fornecer um valor de evidência dando suporte a uma hipótese precisa $H$.

Apesar de possuir boas propriedades conceituais e poder tratar virtualmente quaisquer classes de hipóteses precisas em modelos paramétricos, a difusão deste método na comunidade científica tem sido fortemente limitada pela ausência de um ambiente integrado onde o pesquisador possa formular e implementar o teste de seu interesse.

O objetivo deste trabalho é apresentar uma proposta de implementação de um ambiente integrado para o FBST, que seja suficientemente flexível para tratar uma grande classe de problemas. Como estudo de caso, apresentamos a formulação do FBST para um problema clássico em genética populacional, o Equilíbrio de Hardy-Weinberg.

Palavras-chave: equilíbrio de Hardy-Weinberg, estatística bayesiana, FBST, métodos computacionais. 


\section{Abstract}

In 1999, Pereira and Stern [Pereira and Stern, 1999] introduced the Full Bayesian Significance Test (FBST), developed to give a value of evidence for a precise hypothesis $H$.

Despite having good conceptual properties and being able to dealing with virtually any classes of precise hypotheses under parametric models, the FBST did not achieve a large difusion among the academic community due to the abscence of an computational environment where the researcher can define and assess the evidence for hypothesis under investigation.

In this work we propose an implementation of an flexible computational environment for FBST and show a case study in a classical problem in population genetics, the Hardy-Weinberg Equilibrium Law.

Keywords: Hardy-Weinberg equilibrium, bayesian statistics, FBST, computational methods. 


\section{Sumário}

1 Introdução 10

2 Full Bayesian Significance Test (FBST) 12

2.1 Algumas definições . . . . . . . . . . . . . . . . . . . . . 12

2.2 Consistência e Níveis de Significância . . . . . . . . . . . . . . 14

2.3 Procedimento para o teste

e FBST Ilustrado . . . . . . . . . . . . . . . . . . . . 15

2.3.1 Teste de Proporção . . . . . . . . . . . . . . . 16

2.3.2 Teste de Homogeneidade . . . . . . . . . . . . . 17

2.3.3 Modelo Normal . . . . . . . . . . . . . . . . 18

3 Construindo um Ambiente Computacional para o FBST 23

3.1 Otimização . . . . . . . . . . . . . . . . . . . 24

3.1.1 ALGENCAN . . . . . . . . . . . . . . 24

3.2 Integração . . . . . . . . . . . . . . . . . . . 25

3.2.1 Monte Carlo Importance Sampling . . . . . . . . . . . 25

3.2.2 Importance Sampling no FBST . . . . . . . . . . 27

3.2 .3 Exemplo: Modelo Normal . . . . . . . . . . . . 28

3.2.4 Método da Variável Indicadora . . . . . . . . . . . . . . . . 29

3.3 Biblioteca FBST para o Ambiente R . . . . . . . . . . . . 30

3.3.1 Plataforma de Desenvolvimento . . . . . . . . . 30

3.3 .2 Exemplo passo-a-passo . . . . . . . . . . . 30

3.3.2.1 scriptModeloNormal.r . . . . . . . . . 30

3.4 Considerações . . . . . . . . . . . . . . . . . . . . 33

4 O Equilíbrio de Hardy-Weinberg e a Evolução Darwiniana $\quad 35$

4.1 Equilíbrio de Hardy-Weinberg . . . . . . . . . . . . . . . . . 36

4.2 Teste de Equilíbrio de Hardy-Weinberg com FBST . . . . . . . 37

4.2.1 Otimização . . . . . . . . . . . . . . . . . . . . . . . . . . . . . . 38

4.2 .2 Integração . . . . . . . . . . . . . . . . . 39 
4.3 Evolução Darwiniana . . . . . . . . . . . . . . . . . . 39

5 Contribuições $\quad 42$

5.1 Teste de Paternidade . . . . . . . . . . . . . . . . . . . . . 42

5.2 Hipóteses Separadas . . . . . . . . . . . . . . . . 42

A Scripts Desenvolvidos $\quad 51$

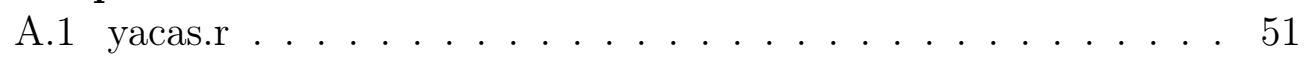

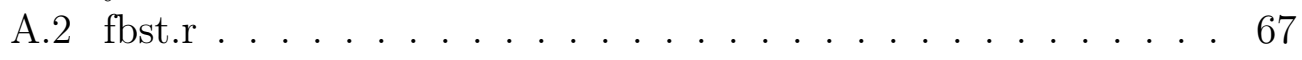

A.3 fitdistr2.r . . . . . . . . . . . . . . . . . 79

A.4 plotasurf.r . . . . . . . . . . . . . . . . 84

A.5 gompertz.r........................ . . 93

A.6 truncatedNormal.r . . . . . . . . . . . . . . . 94 


\section{Lista de Tabelas}

2.1 Valores Críticos de $\overline{e v}$. . . . . . . . . . . . . . . . 15

2.2 Evidências contra hipóteses do modelo . . . . . . . . . . . . 18

2.3 Pontos de máxima posteriori sob as hipóteses do modelo . . . 22

3.1 Médias e variâncias de $\overline{e v}$ e do total de pontos avaliados. . . . 29

4.1 Freqüências genotípicas esperadas no Equilíbrio de Hardy-Weinberg . . . . . . . . . . . . 36

5.1 Erros dos Tipos I e II para testes de hipóteses separadas Weibull vs. Log-Normal . . . . . . . . . . . . . . . . 44 


\section{Lista de Figuras}

2.1 FBST para proporção, $(x, y)=(12,24) \ldots \ldots . . \ldots 16$

2.2 Visão do plano $\left(\pi_{1}, \pi_{2}\right)$ para o teste de homogeneidade . . . . 17

2.3 Densidade posteriori de $f(\mu, \tau)$ :

Curvas das Hipóteses 0,1 e 2 . . . . . . . . . . . . . . . 19

2.4 Cortando a posteriori para definir o conjunto $T_{0} \ldots \ldots$. . . 20

2.5 Cortando a densidade posteriori para definir os conjuntos $T_{0}$ e $T_{1} \ldots \ldots \ldots \ldots \ldots$

2.6 Cortando a densidade posteriori para definir os conjuntos $T_{0}$ e $T_{1}$ e $T_{2} \ldots \ldots \ldots \ldots . \ldots \ldots$

2.7 Curvas de Nível:

Conjuntos Tangentes $T_{0}, T_{1}, T_{2}, T_{3}, T_{4}$, e $T_{5} \ldots \ldots 22$ 


\section{Capítulo 1}

\section{Introdução}

O FBST, Full Bayesian Significance Test, ou Teste de Significância Completamente Bayesiano, foi especialmente desenhado para fornecer um valor de evidência dando suporte a uma hipótese precisa $H$.

Das referências para este texto, podemos listar diversas propriedades do FBST, dentre as quais:

1. Fornece uma medida de significância estatística da hipótese em teste, idealmente uma medida de probabilidade no espaço paramétrico original ou natural do problema;

2. Tem uma definição intrinsecamente geométrica, independente de qualquer aspecto não geométrico, como a particular parametrização da hipótese sendo testada, ou o particular sistema de coordenadas escolhido para o espaço paramétrico, i.e., ser um procedimento invariante;

3. Fornece uma função de suporte suave, i.e., contínua e diferenciável, nos parâmetros da hipótese e nas estatísticas da amostra, dentro de condições apropriadas de regularidade do modelo;

4. Obedece ao princípio da verossimilhança, i.e. a informação obtida das observações deve ser representada pela, e apenas pela, função de verossimilhança;

5. Não requer qualquer artifício $a d$ hoc, como dar probabilidades positivas a conjuntos de medida nula, ou estabelecer razões de crença iniciais arbitrárias entre hipóteses;

6. É uma função de suporte possibilística, onde o suporte a uma disjunção lógica é o máximo entre o suporte dos disjuntos; 
7. É um procedimento exato, i.e., não utilizar no cálculo do e-valor qualquer aproximação assintótica;

8. Fornece um teste consistente para uma dada hipótese precisa;

9. Permite a incorporação de experiência prévia ou opiniões de especialistas via distribuições a priori;

O FBST tem se mostrado um teste robusto em diversas aplicações, vide [Irony et al, 2001], [Lauretto et al, 2003], [Pereira and Stern, 2001], [Stern, 2001], [Stern, 2003].

Apesar de possuir boas propriedades conceituais e poder tratar virtualmente quaisquer classes de hipóteses precisas em modelos paramétricos, a difusão deste método na comunidade científica tem sido fortemente limitada pela ausência de um ambiente integrado onde o pesquisador possa formular e implementar o teste de interesse. Assim, a construção de um ambiente computacional capaz de calcular a estatística do teste, para a maior variedade de modelos possíveis, é um passo natural no desenvolvimento do FBST.

O objetivo deste trabalho é apresentar uma proposta de implementação de um ambiente integrado para o FBST, que seja suficientemente flexível para tratar uma grande classe de problemas. Neste ambiente cabe ao pesquisador implementar as rotinas computacionais específicas do seu problema - função de densidade, função de amostragem para a integração via Monte Carlo e as restrições que definem a hipótese precisa. Os passos centrais do método desenvolvidos nesta implementação garantem o cálculo da estatística de teste.

No Capítulo 2 apresentamos a formulação geral, conceitos do FBST e sua aplicação em alguns problemas clássicos. No Capítulo 3 desenvolvemos os passos centrais do método e abordamos algumas propostas para o cálculo da estatística de teste. No Capítulo 4 abordamos um problema clássico em genética populacional: o teste de Equilíbrio de Hardy-Weinberg. O Capítulo 5 comentamos algumas contribuições e desenvolvimentos conjuntos feitos ao longo deste trabalho. 


\section{Capítulo 2}

\section{Full Bayesian Significance Test (FBST)}

Assumindo que o conjunto de dados $x$, observado em um experimento é proveniente de uma variável aleatória $X$ com um determinado modelo probabilístico paramétrico, o FBST, apresentado por [Pereira and Stern, 1999], é um teste intuitivo que possui uma interpretação geométrica.

Para maior clareza, introduziremos algumas definições importantes para a construção do teste na primeira seção. Em seguida falaremos sobre a consistência do estimador e níveis de confiança. Passaremos por alguns exemplos para mostrar a caracterização geométrica do FBST e finalmente apresentamos o procedimento para execução do teste.

\subsection{Algumas definições}

Posteriori: Seja $\theta \in \Theta \subset \boldsymbol{R}^{p}$, o vetor de parâmetros do modelo que descreve a variável aleatória $X$ e $L(x \mid \theta)$ a verossimilhança associada aos dados observados $x$. Pelo Teorema de Bayes, assumindo uma distribuição a priori $p_{0}(\theta)$ para os parâmetros do modelo de $X$, a densidade a posteriori $p(\theta)$, é proporcional ao produto da verossimilhança pela priori $p_{0}(\theta)$.

$$
p(\theta) \propto L(x \mid \theta) p_{0}(\theta) .
$$

A constante de normalização $m(x)$, que define a identidade dos elementos expressos acima é dada por:

$$
m(x)=\int_{\Theta} L(x \mid \theta) p_{0}(\theta) d \theta .
$$

A consideração de informações prévias sobre a distribuição dos parâmetros caracterizada pela escolha da priori $p_{0}$ fica a critério do pesquisador. 
Uma análise do impacto da escolha de prioris sobre o poder do FBST é descrita em [Stern, 2004a], mas neste trabalho não abordaremos esse tema. Em todos os problemas utilizaremos prioris uniformes sobre $\Theta$.

Hipóteses Precisas: Uma hipótese é um subconjunto do espaço $\Theta$, que pode ser definido por uma coleção de funções com domínio em $\Theta$ e imagem em $\boldsymbol{R}$, limitadas por igualdades ou desigualdades. Um conjunto de hipóteses precisas $H$ formulada sobre o espaço paramétrico $\Theta$, define um conjunto $\Theta_{0} \subset \Theta$, de forma que:

$$
\Theta_{0}=\{\theta \in \Theta: g(\theta) \leq 0 \wedge h(\theta)=0\} .
$$

onde $g$ e $h$ são os vetores de restrições sobre $\Theta$ e há pelo menos uma restrição de igualdade. Nosso interesse é testar uma hipótese precisa $H$ contra a hipótese alternativa $\bar{H}=\Theta \backslash \Theta_{0}$.

Credibilidade: Vamos considerar para $\varphi$ na imagem da densidade a posteriori, o seguinte conjunto:

$$
T_{\varphi}=\{\theta \in \Theta: p(\theta)>\varphi\} .
$$

Denominamos $T_{\varphi}$ como o conjunto dos parâmetros tangente à hipótese, que possuem imagem em $p$ acima do nivel $\varphi$ (i.e., densidade a posteriori), a sua credibilidade $\kappa(\varphi)$ é dada por:

$$
\kappa(\varphi)=\int_{T_{\varphi}} p(\theta) d \theta=\int_{\Theta} p_{\varphi}(\theta) d \theta
$$

com

$$
p_{\varphi}(\theta)=\left\{\begin{array}{ll}
p(\theta) & \text { se } p(\theta)>\varphi \\
0 & \text { c.c. }
\end{array} .\right.
$$

Para o caso em que a posteriori admite um ponto de máximo único, podemos notar que $\kappa(\varphi)$ define uma medida de distância no intervalo [0;1], entre o ponto de máximo da posteriori e o complementar do conjunto tangente a $\varphi$, denotado por $\bar{T}_{\varphi}$, pois:

1. Se $\varphi^{*}$ for o valor máximo de $p, \kappa\left(\varphi^{*}\right)=0$;

2. Se $\varphi=0$, então $\bar{T}_{\varphi}=\varnothing$ e $\kappa(\varphi)=1$;

3. Se $0<\varphi_{1}<\varphi_{2}<\varphi^{*}$, então $\kappa\left(\varphi_{1}\right)<\kappa\left(\varphi_{2}\right)$.

Da mesma maneira, para posterioris não-normalizadas, $\kappa(\varphi)$, define uma medida de distância, na escala do intervalo $[0, m(x)]$, onde o conjunto $\bar{T}_{\varphi}$ está mais próximo de $\varphi^{*}$, se $\kappa(\varphi)$ estiver próximo de 0 . 
Evidência: Considere $\theta^{*}$ como sendo o ponto de máximo da densidade a posteriori sob a hipótese precisa $H$, e seu respectivo valor na imagem de $p$, isto é,

$$
\theta^{*} \in \arg \max _{\theta \in \Theta_{0}}(p(\theta)), \quad p^{*}=p\left(\theta^{*}\right) .
$$

Definimos as evidências a favor e contra a hipótese nula $H$ como:

$$
e v(H)=1-\kappa\left(p^{*}\right) \quad \text { e } \quad \overline{e v}(H)=\kappa\left(p^{*}\right) .
$$

Assim sendo, $\overline{e v}$ caracteriza uma medida de distância entre o máximo irrestrito da posteriori $\left(\varphi^{*}\right)$ e o conjunto $\bar{T}_{\theta^{*}}$. É importante observar que $\Theta_{0} \subset \bar{T}_{\theta^{*}}$, e portanto, se $\widehat{\theta}=\arg \max _{\theta \in \Theta}(p(\theta))$, $\overline{e v}$ mede na escala do intervalo $[0,1]$ a "distância" entre $\widehat{\theta}$ e a hipótese $H$.

\subsection{Consistência e Níveis de Significância}

Vamos considerar a distribuição acumulada da evidência contra a hipótese, $\bar{V}(c)=\operatorname{Pr}(\overline{e v} \leq c)$. Dado $\theta^{0}$, o verdadeiro valor do parâmetro, sob condições apropriadas de regularidade, em [Stern, 2005] demonstra-se que, para tamanhos crescentes de amostra, $n \rightarrow \infty$, as seguintes afirmações são verdadeiras:

- Se $H$ é falsa, $\theta^{0} \notin \Theta_{0}$, então $\overline{e v}$ converge em probabilidade para 1 , isto é, $\bar{V}(0<c<1) \rightarrow 0$. Logo, $\overline{e v}$ é uma estatística consistente;

- Se $H$ é verdadeira, $\theta^{0} \in \Theta_{0}$, então $\overline{e v}$ converge em distribuição para uma $\chi^{2}(t)$, onde $t$ é o número de graus de liberdade do espaço paramétrico. O nível de confiança $\bar{V}(c)$ (que também denotaremos por $\alpha$ ) pode ser aproximado pela função:

$$
Q Q(t, h, c)=\chi^{2}\left(t-h,\left(\chi^{2}\right)^{-1}(t, c)\right) .
$$

sendo,

- $h$ : número de graus de liberdade do espaço $\Theta_{0}$,

- $\chi^{2}$ : a densidade chi-quadrado,

- $\left(\chi^{2}\right)^{-1}$ : é o quantil da chi-quadrado.

Note que pelo fato de trabalharmos com conjuntos de hipóteses precisas bem definidas, $\operatorname{dim}\left(\Theta_{0}\right)<\operatorname{dim}(\Theta)$, portanto os graus de liberdade $t-h \geq 1$. 
A seguir, apresentamos uma tabela com os valores críticos de $\overline{e v}$ calculados fixando os níveis de significância de 0,10 e 0,05.

Tabela 2.1: Valores Críticos de $\overline{e v}$.

\begin{tabular}{|cc|c|c|}
\hline $\operatorname{dim}(\Theta)$ & $\operatorname{dim}\left(\Theta_{0}\right)$ & $c(\alpha=0,10)$ & $c(\alpha=0,05)$ \\
\hline 1 & 0 & 0,900 & 0,950 \\
\hline 2 & 0 & 0,900 & 0,950 \\
\hline 2 & 1 & 0,741 & 0,853 \\
\hline 3 & 0 & 0,900 & 0,950 \\
\hline 3 & 1 & 0,769 & 0,887 \\
\hline 3 & 2 & 0,560 & 0,720 \\
\hline 4 & 0 & 0,900 & 0,950 \\
\hline 4 & 1 & 0,818 & 0,901 \\
\hline 4 & 2 & 0,669 & 0,800 \\
\hline 4 & 3 & 0,391 & 0,572 \\
\hline
\end{tabular}

Note, a medida em que as dimensões de $\Theta$ e $\Theta_{0}$ aumentam, os valores críticos diminuem.

\subsection{Procedimento para o teste e FBST Ilustrado}

O critério de decisão para a rejeição da hipótese no FBST pode ser baseado apenas no valor da evidência contra a hipótese $\overline{e v}$.

Porém, as definições e propriedades da evidência, apresentadas anteriormente, delineiam um procedimento para FBST, que consiste em calcular $\overline{e v}(H)$ e confrontá-lo com o valor crítico encontrado invertendo a função $Q Q$ para um nível fixado arbitrariamente.

Para isso temos que resolver dois problemas básicos:

1. Encontrar o ponto de máximo $\theta^{*}$ da posteriori $p$ no conjunto $H$;

2. Avaliar a integral definida por $\overline{e v}$.

O detalhamento destes procedimentos, intuitivamente simples mas que na prática requerem esforços consideráveis, será feito no próximo capítulo.

Como foi dito no início, o FBST possui uma caracterização geométrica. Nesta seção apresentaremos problemas clássicos de Testes de Hipóteses em Estatística com a metodologia apresentada anteriormente. 


\subsubsection{Teste de Proporção}

Vamos mostrar o problema clássico do lançamento de moedas com o FBST. Seja:

- n: o número de lançamentos,

- $x$ : o número de caras,

- y: o número de coroas.

Tomamos o caso $n=36, x=12, y=24$ e usamos como priori $p_{0}$ a densidade uniforme $U[0 ; 1]$. Nesta situação, a estatística utilizada para o teste é o kernel da verossimilhança (o fator que depende dos resultados amostrais): $L(\pi \mid x, y)=\pi^{x}(1-\pi)^{y}$. A hipótese nula que se deseja testar é $H: \pi=\frac{1}{2}$. A hipótese alternativa neste caso é $A: \pi \neq \frac{1}{2}$.

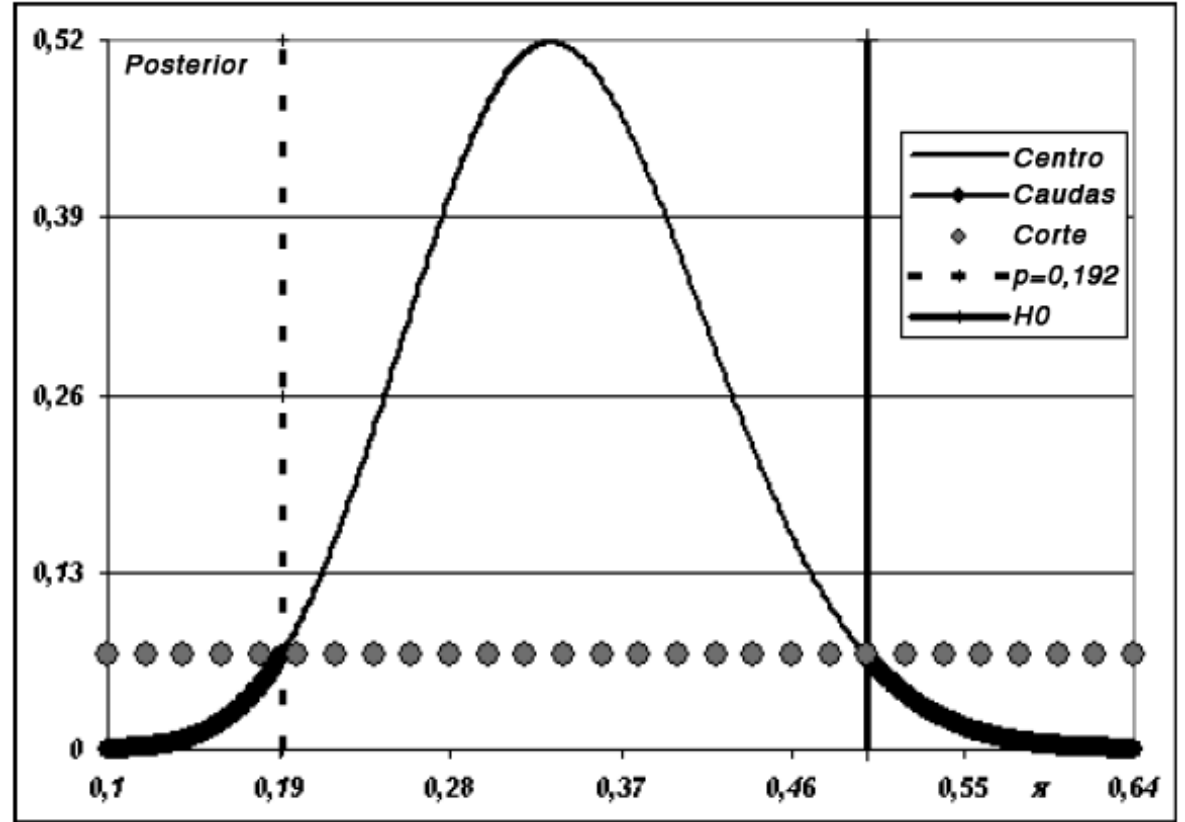

Figura 2.1: FBST para proporção, $(x, y)=(12,24)$

A hipótese nula $H: \pi=\frac{1}{2}$ é representada pela linha vertical contínua que passa pelo ponto $\pi=0,5$ nas abcissas. A curva de nível que caracteriza o conjunto tangente à hipótese é a legendada como Corte e ela define o conjunto $T=\{\pi \mid 0,19<\pi<0,5\}$. Note que, neste exemplo, a hipótese nula está em uma região de baixa densidade posterior e, assim, $\overline{e v}_{H}=95,9 \%$. Confrontando com o valor crítico de $95 \%$, encontrado na Tabela 2.1 para $\operatorname{dim}(\Theta)=1$ e $\operatorname{dim}\left(\Theta_{0}\right)=0$, rejeitamos a hipótese $H$. 


\subsubsection{Teste de Homogeneidade}

O presente exemplo considera duas amostras independentes em que observouse para cada uma o número de sucessos e fracassos, $(x, y)_{i}$, onde $i$ é índice da população. O objetivo é testar se as proporções populacionais de sucesso são iguais.

A seguir listamos as diversas etapas do trabalho estatístico.

\section{- Parâmetros de Interesse:}

$\pi_{i}$ : proporção de sucessos na população $i, i=1,2$.

- Densidade Posteriori: Observamos as seguintes freqüências em duas amostras, sendo uma de cada população. $(x, y)_{1}=(4,16)$ e $(x, y)_{2}=$ $(10,10)$

$$
f\left(\pi_{1}, \pi_{2}\right) \propto \pi_{1}^{x_{1}}\left(1-\pi_{1}\right)^{y_{1}} \pi_{2}^{x_{2}}\left(1-\pi_{2}\right)^{y_{2}}
$$

- Hipótese e Evidência: $H: \pi_{1}=\pi_{2}$ e $\overline{e v}_{H}=98,8 \%$

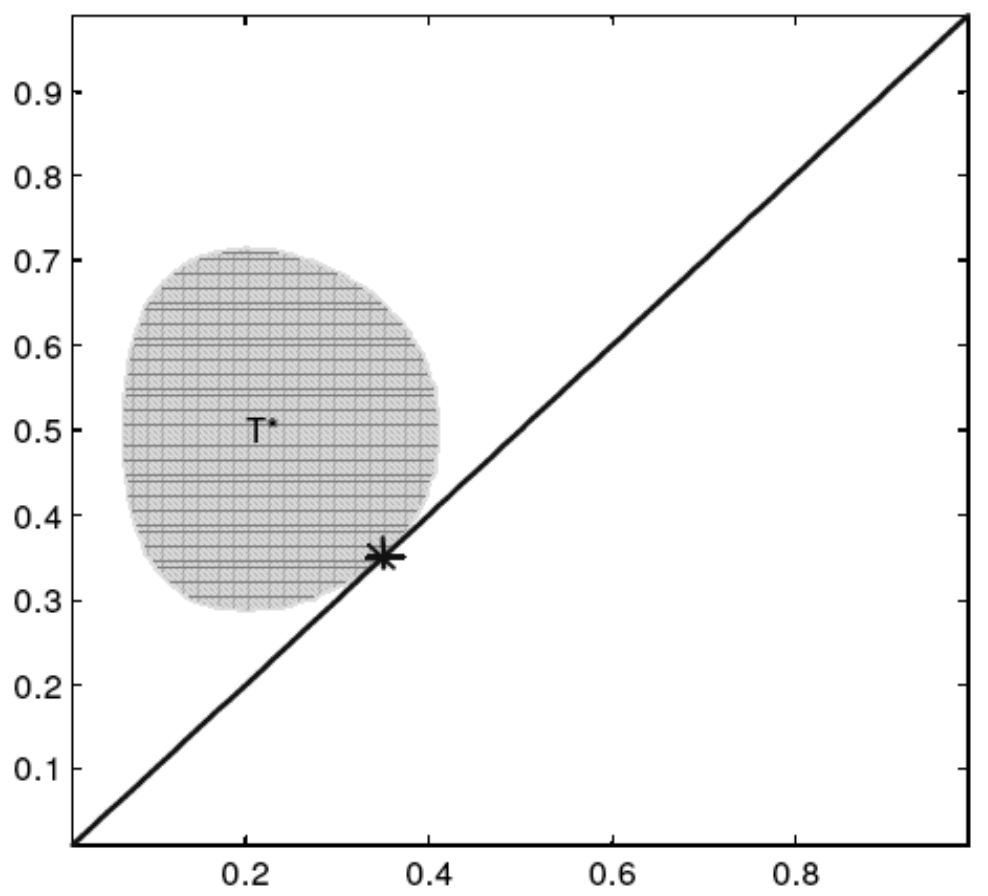

Figura 2.2: Visão do plano $\left(\pi_{1}, \pi_{2}\right)$ para o teste de homogeneidade

A FIgura 2.2 ilustra o conjunto tangente (área sombreada), que dá origem ao cálculo da evidência. A hipótese é representada pela linha contínua que corta o quadrado, e o ponto de máximo da hipótese é o ponto representado 
pelo asterisco. Neste problema a $\operatorname{dim}(\Theta)=2$ e $\operatorname{dim}\left(\Theta_{0}\right)=1$, o que nos leva ao valor crítico de $85,3 \%$ para $\overline{e v}$ com nível de significância de $5 \%$, e portanto, rejeitamos $H$.

\subsubsection{Modelo Normal}

Vamos aplicar o FBST ao modelo mais frequentemente utilizado na Estatística, o do conjunto de dados com distribuição normal com média e variância desconhecidas. O presente exemplo foi extraído de [Pereira, 2005]. Serão apresentadas para este problema, 3 exemplos de hipóteses compostas, cujo tratamento decorre naturalmente da formulação do FBST. A seguir listamos as diversas etapas do trabalho estatístico.

\section{- Parâmetros de Interesse:}

- $\mu$ : média,

$-\tau$ : precisão, definida como o inverso da variância, ou seja, $\tau=\frac{1}{\sigma^{2}}$.

- Densidade Posteriori: A partir de um conjunto de dados observados de um experimento, chegamos ao seguinte kernel para o modelo normal $N(\mu, \tau)$

$$
f(\mu, \tau) \propto \tau^{6,5} \exp \left\{-\frac{\tau\left[4+11(\mu-0,9)^{2}\right]}{2}\right\}
$$

\section{- Hipóteses e Evidências:}

Tabela 2.2: Evidências contra hipóteses do modelo

\begin{tabular}{lll}
\hline$H_{0}:$ & $\mu=1,1$ & $\overline{e v}_{0}=0,49$ \\
\hline$H_{1}:$ & $\tau=2,5$ & $\overline{e v}_{1}=0,19$ \\
\hline$H_{2}:$ & $c v=\sqrt{\mu^{2} \tau}=\frac{1}{2}$ & $\overline{e v}_{2}=0,31$ \\
\hline$H_{3}:$ & $\mu=1,1$ e $\tau=2,5$ & $\overline{e v}_{3}=0,53$ \\
\hline$H_{4}:$ & $\mu=1,1$ e $c v=\frac{1}{2}$ & $\overline{e v}_{4}=0,52$ \\
\hline$H_{5}:$ & $\tau=2,5$ e $c v=\frac{1}{2}$ & $\overline{e v}_{5}=0,87$ \\
\hline
\end{tabular}

Neste exemplo, as hipóteses $H_{0}, H_{1}$ e $H_{2}$ possuem dimensão 1 no espaço paramétrico. FIxando o nível de significância de $5 \%$ e comparando com o valor crítico de 0,853 dado pela Tabela 2.1, não as rejeitamos. 
As hipóteses $H_{3}, H_{4}$ e $H_{5}$ são conjuntos pontuais e possuem dimensão 0 no espaço paramétrico. Neste caso também não as rejeitamos para o nível de significância de 0,05 .O valor crítico de $\overline{e v}$ neste caso, é de 0,950 .

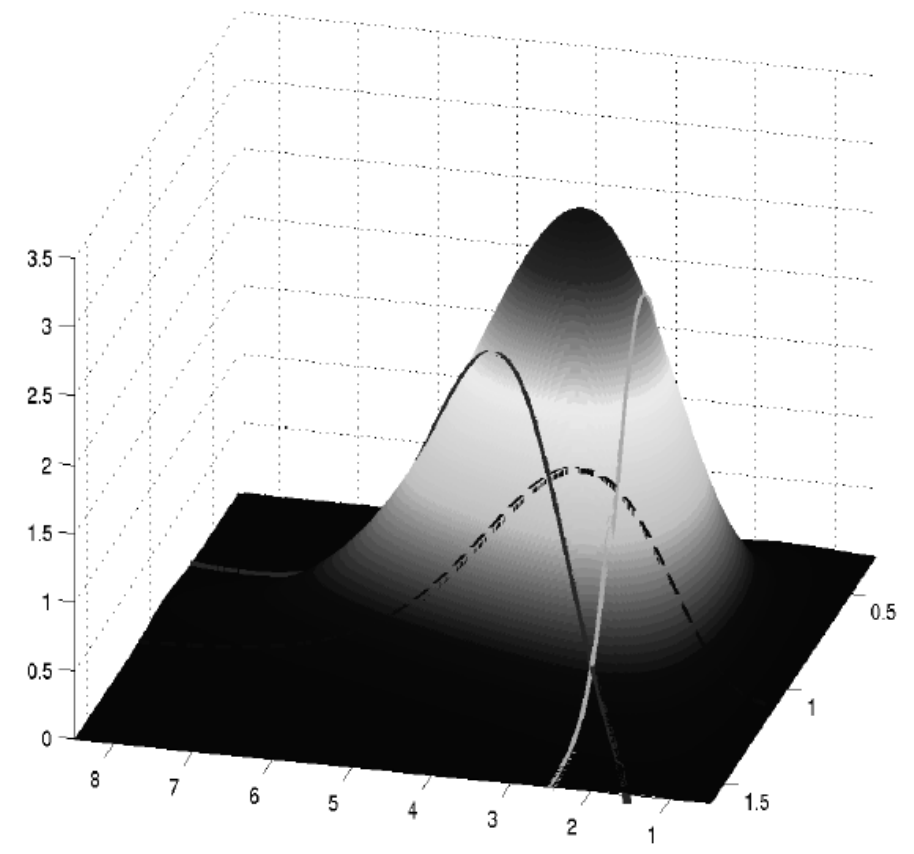

Figura 2.3: Densidade posteriori de $f(\mu, \tau)$ : Curvas das Hipóteses 0, 1 e 2

A FIgura 2.3 apresenta a densidade a posteriori de $(\mu, \tau)$ e as curvas correspondentes ao espaço paramétrico sob as hipóteses: $H_{0}: \mu=1,1$ (linha tracejada), $H_{1}: \tau=2,5$ (linha contínua clara) e $H_{2}: c v=\sqrt{\mu^{2} \tau}=\frac{1}{2}$ (linha contínua escura). 


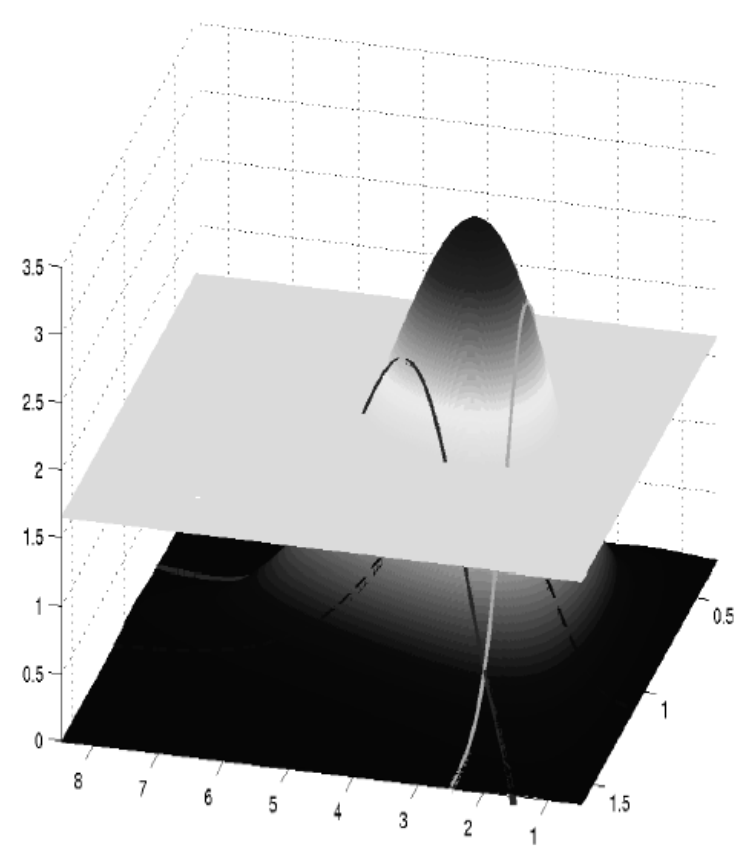

Figura 2.4: Cortando a posteriori para definir o conjunto $T_{0}$

Na FIgura 2.4, observamos o plano tangente à hipótese $H_{0}: \mu=1,1$; definido pela curva de nível $f(\mu, \tau)=f\left(\theta_{H_{0}}^{*}\right)$. A superfície acima do plano corresponde à imagem de $f$ no conjunto $T_{\Theta_{0}} \subset \Theta=\left\{(\mu, \tau): \mu \in \boldsymbol{R}, \tau \in \boldsymbol{R}_{*}^{+}\right\}$

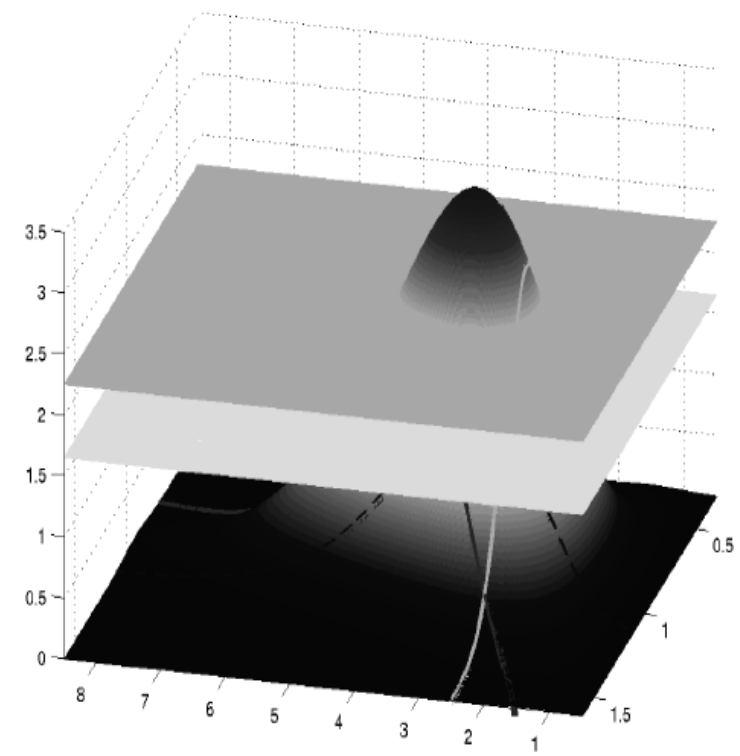

Figura 2.5: Cortando a densidade posteriori para definir os conjuntos $T_{0}$ e $T_{1}$ 


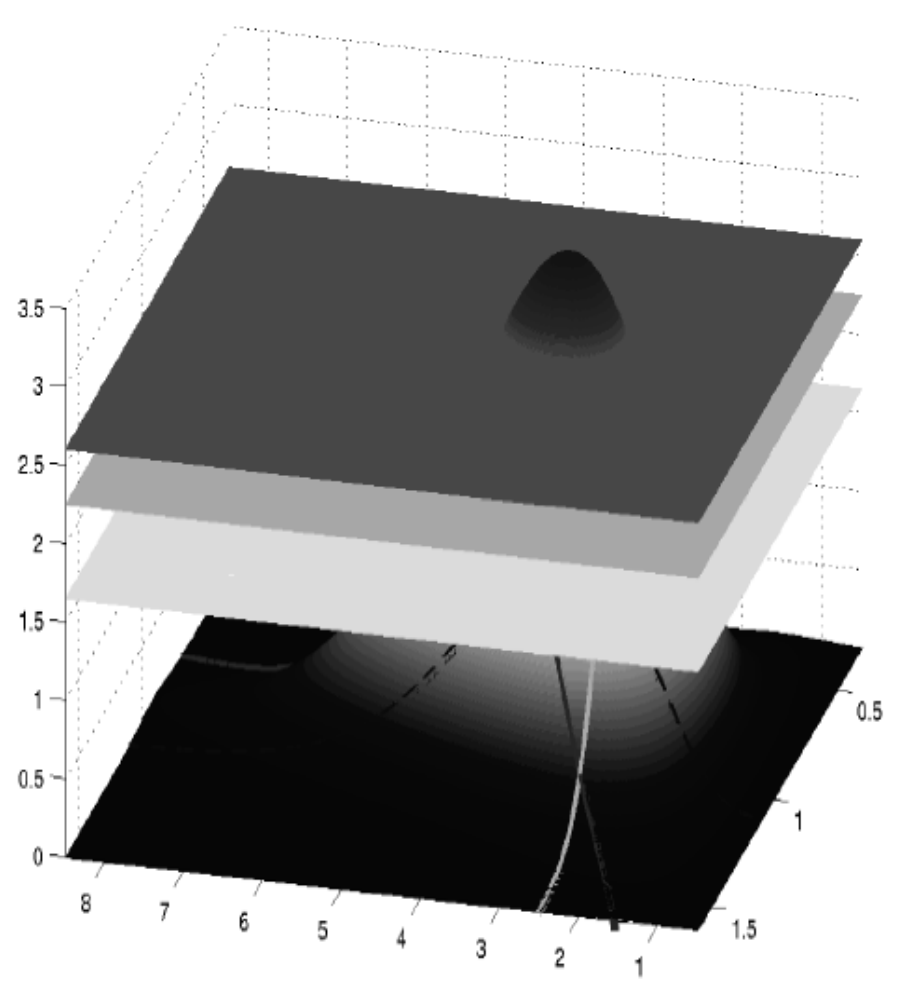

Figura 2.6: Cortando a densidade posteriori para definir os conjuntos $T_{0}$ e $T_{1}$ e $T_{2}$

A FIgura 2.7 representa o espaço paramétrico $\Theta$ e as curvas de nível tangentes às hipóteses apresentadas. Os pontos $\theta^{*}$ de cada hipótese estão listados na Tabela 2.3. 

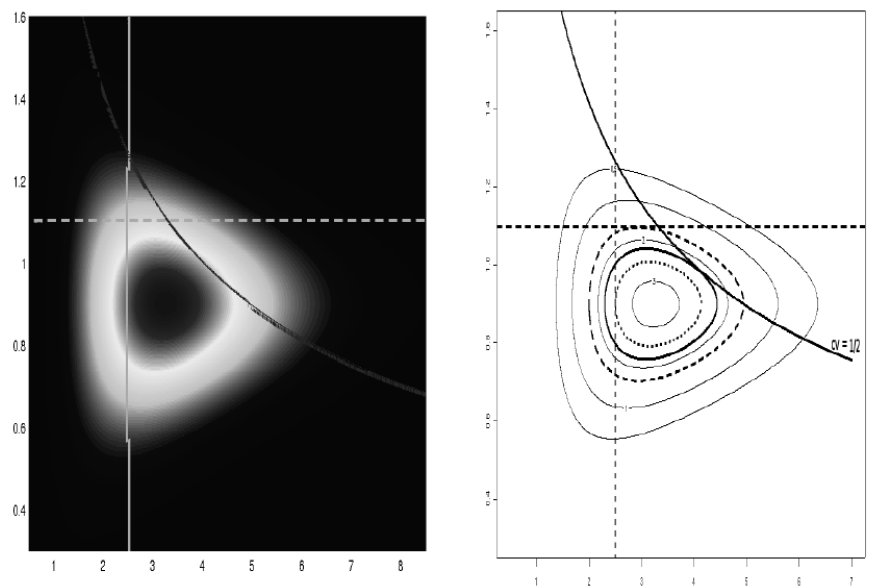

Figura 2.7: Curvas de Nível:

Conjuntos Tangentes $T_{0}, T_{1}, T_{2}, T_{3}, T_{4}$, e $T_{5}$

Tabela 2.3: Pontos de máxima posteriori sob as hipóteses do modelo

\begin{tabular}{lll}
\hline$H_{0}:$ & $\mu=1,1$ & $\theta_{H_{0}}^{*}=(1,1 ; 2,92)$ \\
\hline$H_{1}:$ & $\tau=2,5$ & $\theta_{H_{1}}^{*}=(0,9 ; 2,5)$ \\
\hline$H_{2}:$ & $c v=\sqrt{\mu^{2} \tau}=\frac{1}{2}$ & $\theta_{H_{2}}^{*}=(0,98 ; 4,12)$ \\
\hline$H_{3}:$ & $\mu=1,1$ e $\tau=2,5$ & $\theta_{H_{3}}^{*}=(1,1 ; 2,5)$ \\
\hline$H_{4}:$ & $\mu=1,1$ e $c v=\frac{1}{2}$ & $\theta_{H_{4}}^{*}=(1,1 ; 3,30)$ \\
\hline$H_{5}:$ & $\tau=2,5$ e $c v=\frac{1}{2}$ & $\theta_{H_{5}}^{*}=(1,26 ; 2,5)$ \\
\hline
\end{tabular}




\section{Capítulo 3}

\section{Construindo um Ambiente Computacional para o FBST}

Por possuir boas propriedades conceituais e abranger uma classe grande de testes que envolvem modelos paramétricos, a construção de um ambiente computacional capaz de calcular a estatística $\overline{e v}$ para a maior variedade de modelos possíveis é um passo natural no desenvolvimento de aplicações que o FBST pode oferecer. Neste capítulo discorremos sobre a implementação do FBST no ambiente R.

Amplamente conhecido no meio acadêmico, o $\mathrm{R}$ é um ambiente computacional de estatística, desenvolvido por uma grande equipe de profissionais ligados a instituições de pesquisa renomadas sob a filosofia do "free-software", ele pode ser distribuído livremente e utilizado de acordo com os termos da licença GPL da Free Software Foundation.

Por possuir uma extensa biblioteca de rotinas e procedimentos que podem ser estudados e melhorados pela livre iniciativa do usuário e a popularidade que ele vem conquistando nas áreas de pesquisa que utilizam largamente a estatística aplicada, o $\mathrm{R}$ caracteriza um ambiente de desenvolvimento promissor para a implementação do FBST.

Na seção de otimização discutiremos essa questão dentro do ambiente $\mathrm{R}$, e em seguida, apresentaremos sem detalhamento teórico, a rotina de otimização $A L G E N C A N$ utilizada para encontrar o ponto $\theta^{*}$ na hipótese $H$. Feito isso, discutiremos o método de Monte Carlo Importance Sampling para resolver problemas de integração genéricos, para abordarmos em seguida o problema de integração da posteriori restrita ao conjunto $T_{\theta^{*}}$ na estimação de $\overline{e v}$. Mostraremos o estimador de $\overline{e v}$, sua consistência e variância para controle de parada do algoritmo. Para ilustrar o impacto da escolha adequada da distribuição de amostragem no desempenho do Importance Sampling, exibiremos resultados obtidos por simulação nos problemas descritos no Capí- 
tulo 2. Continuando, apresentamos o Método da Variável Indicadora para estimação de $\overline{e v}$ nos casos em que deparamos com insuficiência da precisão de máquina. E finalmente fazemos algumas considerações respeito de todo o processo discutido neste capítulo.

\subsection{Otimização}

A procura pelo ponto de ótimo da posteriori, restrita á hipótese testada, é fundamental para avaliarmos a evidência contra a mesma $(\overline{e v})$.

No ambiente $\mathrm{R}$, a carência de um otimizador capaz de tratar restrições não-lineares que envolvem igualdades e desigualdades, foi motivação para o desenvolvimento de uma interface com uma rotina capaz de tratar genericamente problemas desse tipo.

A seguir apresentaremos a opção desenvolvida para esta questão, porém é necessário ressaltar que, no desenvolvimento do ambiente de FBST, levamos em consideração a liberdade do usuário para utilizar outras formas de otimização sob restrições, de acordo com a conveniência e necessidade do seu problema.

\subsubsection{ALGENCAN}

O ALGENCAN é uma rotina originalmente escrita em Fortran, desenvolvida pelo grupo do Projeto Tango (Trustable Algorithms for Nonlinear General Optimization), capaz de resolver problemas de otimização na seguinte forma:

$$
\text { minimizar } f: R^{n} \rightarrow R, f \text { de classe } C^{1}
$$

sujeita a

$$
\left\{\begin{array}{l}
c_{j}(x)=0, \quad j \in E \\
c_{j}(x) \leq 0, \quad j \in I \\
l \leq x \leq u
\end{array}\right.
$$

tal que:

- $c: \boldsymbol{R}^{n} \rightarrow \boldsymbol{R}^{m}$ define o vetor de restrições do problema,

- E é o conjunto de índices das restrições de igualdade,

- I é o conjunto de índices das restrições de desigualdade do problema.

ALGENCAN é uma implementação do Método do Lagrangeano Aumentado, descrito em [Andreani et al, 2005, Birgin et al, 2004], que requer a avaliação dos jacobianos e hessianas da função objetivo $f$, e da função de restrições $c$. 
Para os jacobianos e hessianas, a rotina possui um método de aproximação que é utilizado de acordo com os parâmetros de execução fornecidos pelo usuário, mas para obtenção de melhor performance o usuário deve fornecer esses objetos à rotina.

O ALGENCAN possui interface para várias linguagens, entre elas o R. Em todas, o usuário precisa editar um script que contém todas as definições do seu problema (função objetivo, restrições, jacobianos e hessianas), além de parâmetros opcionais da rotina como as ordens de grandeza admitida para a distância do ponto de ótimo até a região de viabilidade e a diferença absoluta entre o valor ótimo real e o obtido pelo algoritmo.

Do ponto de vista de interface com o usuário, no caso de problemas com funções definidas por expressões algébricas grandes o suficiente, e/ou com várias restrições, torna-se difícil a geração e a manutenção dos scripts de input para o ALGENCAN. Para contornar essa dificuldade, construímos uma interface do R com o Yacas (Yet Another Computer Algebra System), que como o nome diz, trata-se de um ambiente computacional que trabalha com álgebra simbólica desenvolvido inicialmente por Ayal Pinkus dentro dos moldes do software livre. Além de ser capaz de manipular algebricamente expressões envolvendo derivadas, integrais, equações diferenciais, possui uma linguagem de programação flexível para o desenvolvimento de algoritmos de manipulação simbólica, podendo ser executado em modo shell, ou via linha de comando pelo terminal.

De posse destas ferramentas, criamos uma rotina capaz de resolver o primeiro problema que FBST exige, com uma interface amigável ao usuário.

\subsection{Integração}

Uma vez encontrado o ponto de máximo sob a hipótese precisa $H$, chegamos ao segundo problema do FBST: avaliar a integral definida na Equação 2.8.

Como a curva de nível descrita por $p(\theta)=\theta^{*}$ geralmente não define uma região de integração simples de ser parametrizada para a utilização de métodos numéricos determinísticos, o Monte Carlo Importance Sampling pode prover aproximações satisfatórias para $\overline{e v}$, mesmo para posterioris definidas em espaços paramétricos de grandes dimensões.

\subsubsection{Monte Carlo Importance Sampling}

Antes de discutir como resolvemos o segundo problema que o procedimento do FBST exige, precisamos entender como funciona a técnica do importance sampling para a estimação de integrais, [Robert, 1996]. Considere $f: R^{n} \rightarrow$ 
$R$, estritamente positiva, de classe $L^{2}$, e o valor

$$
\phi=\int_{D} f(y) d y
$$

tal que $D \subset R^{n}$, e $q$ é uma densidade de probabilidade da variável aleatória $Y$ com suporte em $D$. Deste modo:

$$
E\left(\frac{f(Y)}{q(Y)}\right)=\int_{D} \frac{f(y)}{q(y)} q(y) d y=\phi
$$

Assim, o estimador:

$$
\bar{\phi}=\frac{1}{r} \sum_{i=1}^{r} \frac{f\left(Y_{i}\right)}{q\left(Y_{i}\right)} \stackrel{\text { q.c. }}{\longrightarrow} \phi,
$$

pela Lei Forte dos Grandes Números, e como $\int_{D}|f(y)|^{2} d y$ existe, sua variância possui a seguinte expressão:

$$
\sigma_{\hat{\phi}}=\int_{D}\left(\frac{f(y)}{q(y)}-\phi\right)^{2} q(y) d y
$$

Observe que se $q=c f, c>0$, então, $c=1 / \phi$ e,

$$
\sigma_{\hat{\phi}}=\int_{D}\left(\frac{1}{c}-\phi\right)^{2} c f(y) d y=0
$$

O que teoricamente nos levaria a um estimador de erro zero, isso se soubéssemos definir a constante $c$ função de $\phi$, que é exatamente a grandeza que procuramos.

Isso indica um caminho para estimar $\phi$ : se conseguimos uma distribuição $q$, capaz de fazer com que a razão $\frac{f(y)}{q(y)}$ possua uma pequena variação para os pontos $y \in D$, o estimador $\hat{\phi}$ terá uma variância reduzida.

Para controlar a razão, precisamos de uma distribuição $q$, onde os maiores valores dela são assumidos num subconjunto de $D$, que assumem os maiores valores de $f$, ou seja, atribuímos um peso maior aos pontos de $D$ em torno de seu ponto de máximo. Este é o conceito do chamado Importance Sampling.

Um cuidado que devemos tomar ao definir a distribuição $q$, é o de garantir que a amostragem de $Y$ não fique concentrada na região do ponto de máximo de $f$, pois isso traria um vício ao estimador $\hat{\phi}$. 


\subsubsection{Importance Sampling no FBST}

A discussão que segue nesta seção foi apresentada em [Stern, 2001, Stern, 2003].

Escolhendo uma densidade de probabilidade $q$ sobre $\Theta$ adequada para aplicar o Importance Sampling, podemos reescrever $\overline{e v}$, deste modo:

$$
\overline{e v}(H)=\frac{\int_{\Theta} \mathbf{1}_{\left\{\theta \in T\left(\theta^{*}\right)\right\}}(\theta) L(\theta \mid x) p_{0}(\theta) d \theta}{\int_{\Theta} L(\theta \mid x) p_{0}(\theta) d \theta}=\frac{\int_{\Theta} \frac{g(\theta)}{q(\theta)} q(\theta) d \theta}{\int_{\Theta} \frac{h(\theta)}{q(\theta)} q(\theta) d \theta} .
$$

Denotando $\overline{e v}(H)$ por $\psi$, vamos tomar uma amostra aleatória $Y_{1}, \ldots, Y_{n}$ com densidade $q$, e seu respectivo estimador $\hat{\psi}$

$$
\hat{\psi}=\frac{\bar{Z}_{n}^{*}}{\bar{Z}_{n}}
$$

onde,

$$
\bar{Z}_{n}^{*}=\frac{1}{n} \sum_{i=1}^{n} \frac{g\left(Y_{i}\right)}{q\left(Y_{i}\right)} \quad \text { e } \quad \bar{Z}_{n}=\frac{1}{n} \sum_{i=1}^{n} \frac{h\left(Y_{i}\right)}{q\left(Y_{i}\right)} .
$$

Da seção anterior, sabemos que $\bar{Z}_{n}^{*}$ e $\bar{Z}_{n}$ convergem respectivamente para $\int_{\Theta_{H}} L(\theta \mid x) p_{0}(\theta) d \theta$ e $\int_{\Theta} L(\theta \mid x) p_{0}(\theta) d \theta$

Stern e Zacks (2003) demonstraram que o estimador $\hat{\psi}$ é consistente.

Tomando $Z_{i}=\frac{g\left(Y_{i}\right)}{q\left(Y_{i}\right)}$, e $Z_{i}^{*}=\frac{h\left(Y_{i}\right)}{q\left(Y_{i}\right)}$, o vetor $\left(Z_{i}, Z_{i}^{*}\right)$ é geralmente dependente, enquanto os vetores $\left(Z_{i}, Z_{i}^{*}\right)$ e $\left(Z_{j}, Z_{j}^{*}\right)$ são independentes para $i \neq j$, e pela Lei Forte dos Grandes Números, a convergência de $\hat{\psi}$ para $\psi$ é garantida.

Vamos considerar a quantidade pivotal

$$
U_{n}=\bar{Z}_{n} \psi-\bar{Z}_{n}^{*}
$$

podemos notar que $E\left(U_{n}\right)=0$, e sua respectiva variância dada por

$$
V\left(U_{n}\right)=\frac{1}{n}\left(V\left(\bar{Z}_{n}^{*}\right)+\psi^{2} V\left(\bar{Z}_{n}\right)-2 \psi \operatorname{Cov}\left(\bar{Z}_{n}^{*}, \bar{Z}_{n}\right)\right)
$$

é finita, pelo fato de $g$ e $h$ serem $L^{2}$ integráveis, e os estimadores consistentes para as variâncias e covariância acima são:

$$
\begin{aligned}
\hat{\sigma}_{n}^{* 2} & =\frac{1}{n} \sum_{i=1}^{n}\left(Z_{i}^{*}-\bar{Z}_{n}^{*}\right) \\
\hat{\sigma}_{n}^{* 2} & =\frac{1}{n} \sum_{i=1}^{n}\left(Z_{i}-\bar{Z}_{n}\right) \\
\hat{\sigma}_{g, h, n}^{2} & =\frac{1}{n} \sum_{i=1}^{n}\left(Z_{i}^{*}-\bar{Z}_{n}^{*}\right)\left(Z_{i}-\bar{Z}_{n}\right)
\end{aligned}
$$


Como $V\left(U_{n}\right) \stackrel{P r}{\longrightarrow} \sigma$ (convergência em probabilidade), e $U_{n} \stackrel{d}{\longrightarrow} N(0, \sigma)$ (convergência em distribuição) quando $n \rightarrow \infty$, o Teorema de Slutzky e o Teorema do Limite Central nos garantem que:

$$
\frac{n U^{2}}{\left(\hat{\sigma}_{n}^{* 2}+\psi^{2} \hat{\sigma}_{n}^{2}-2 \psi \hat{\sigma}_{g, h, n}^{2}\right)} \sim \chi^{2}[1]
$$

Portanto, pelo Teorema de Filler, se encontrarmos as raízes da equação quadrática em $\psi$ :

$$
\left(\bar{Z}_{n} \psi-\bar{Z}_{n}^{*}\right)^{2}=\frac{\chi_{1-\beta}^{2}[1]}{n}\left(\hat{\sigma}_{n}^{* 2}+\psi^{2} \hat{\sigma}_{n}^{2}-2 \psi \hat{\sigma}_{g, h, n}^{2}\right)
$$

poderemos construir um intervalo de confiança de nível $1-\beta$ para $\psi$ :

$$
\begin{gathered}
I(n, 1-\beta)=\hat{\psi} \pm \Delta_{n, 1-\beta}, \quad \text { com } \\
\Delta_{n, 1-\beta}=\frac{\chi_{1-\beta}^{2}[1]}{n \bar{Z}_{n}^{2}}\left(\hat{\sigma}_{n}^{* 2}+\hat{\psi}^{2} \hat{\sigma}_{n}^{2}-2 \hat{\psi} \hat{\sigma}_{g, h, n}^{2}\right)
\end{gathered}
$$

Podemos então, fixar o erro $\Delta_{n, 1-\beta}$ para $\psi$ e assim, teremos um critério de parada para o algoritmo de integração com o método de Importance Sampling.

\subsubsection{Exemplo: Modelo Normal}

Para ilustrar a importância da escolha da distribuição no Importance Sampling, retornamos ao modelo normal exposto na Seção 2.3.3. Aplicaremos o FBST para as 6 hipóteses definidas naquela seção.

Nem sempre é possível avaliar a densidade a posteriori no espaço paramétrico todo. Porém, para minimizar o efeito da introdução de vícios na estimação de $\overline{e v}$, basta que a região ignorada na integração numérica possua relevância desprezível.

Neste caso, limitamos a região de integração para os pontos $(\mu, \tau)$ no conjunto $[-3 ; 3] \times[0 ; 10]$, e estimamos $\overline{e v}$ para duas distribuições diferentes no Importance Sampling:

- uma uniforme sobre o retângulo $[-3 ; 3] \times[0 ; 10]$;

- um par de normais truncadas independentes.

A Tabela 3.1 mostra os resultados obtidos e a performance obtida em cada caso para 30 avaliações de $\overline{e v}$ independentes: 
Tabela 3.1: Médias e variâncias de $\overline{e v}$ e do total de pontos avaliados.

\begin{tabular}{|c|rrrr|rrrr|}
\hline & \multicolumn{4}{|c|}{ Uniforme } & \multicolumn{4}{c|}{ Normais Truncadas } \\
\hline Hip. & $\begin{array}{r}\overline{e v} \\
\text { médio }\end{array}$ & desvio & $\begin{array}{r}\text { pontos } \\
(\mathrm{mil})\end{array}$ & desvio & $\begin{array}{r}\overline{e v} \\
\text { médio }\end{array}$ & desvio & $\begin{array}{r}\text { pontos } \\
(\mathrm{mil})\end{array}$ & desvio \\
\hline$H_{0}$ & 0.495 & 0.003 & 383 & 5 & 0.493 & 0.004 & 100 &. \\
\hline$H_{1}$ & 0.187 & 0.004 & 375 & 5 & 0.186 & 0.004 & 207 & 5 \\
\hline$H_{2}$ & 0.306 & 0.003 & 445 & 5 & 0.306 & 0.004 & 330 &. \\
\hline$H_{3}$ & 0.533 & 0.004 & 353 & 5 & 0.533 & 0.004 & 298 & 5 \\
\hline$H_{4}$ & 0.519 & 0.004 & 365 & 5 & 0.519 & 0.004 & 326 & 5 \\
\hline$H_{5}$ & 0.872 & 0.003 & 49 & 2 & 0.871 & 0.004 & 45 & 5 \\
\hline
\end{tabular}

\subsubsection{Método da Variável Indicadora}

Em problemas que tratam da inferência sobre proporções populacionais, podemos observar uma concentração acentuada da posteriori em uma região relativamente pequena no espaço paramétrico, mesmo em amostras pequenas. Essa concentração eventualmente pode provocar uma dificuldade adicional na estimação de $\overline{e v}$ : a insuficiência da precisão de máquina.

Reescrevendo a evidência contra a hipótese, temos:

$$
\psi=\int_{T_{\theta^{*}}} p(\theta) d \theta=\int_{\Theta} \mathbf{1}_{\left\{X_{i} \in T_{\left.\theta^{*}\right\}}\right.} d P(\theta)=E_{p}\left(\mathbf{1}_{\left\{X_{i} \in T_{\theta^{*}}\right\}}\right)
$$

Intuitivamente $\overline{e v}$ representa uma proporção do volume da densidade a posteriori. Portanto, munidos de um método para amostragem exata do espaço paramétrico com a posteriori do nosso problema, podemos simplesmente estimar a fração dos pontos amostrados que caíram no conjunto tangente à hipótese, obtendo um estimador consistente para $\overline{e v}$, pelo Teorema do Limite Central.

$$
\hat{\psi}=\frac{1}{N} \sum_{i=1}^{N} \mathbf{1}_{\left\{X_{i} \in T_{\theta^{*}}\right\}}, \quad \sigma_{\hat{\psi}}^{2}=\frac{1}{N} \sum_{i=1}^{N}\left(\mathbf{1}_{\left\{X_{i} \in T_{\theta^{*}}\right\}}-\hat{\psi}\right)^{2}
$$

Para determinar se um ponto pertence ou não ao conjunto tangente, aplicamos uma transformação que mantenha a monotonicidade na imagem da posteriori (como o log) e comparamos com o valor encontrado para o ponto $\theta^{*}$. Assim nossa variável indicadora pode ser:

$$
\mathbf{1}_{\left\{\log \left(p\left(X_{i}\right)\right)>\log \left(p\left(\theta^{*}\right)\right)\right\}}
$$




\subsection{Biblioteca FBST para o Ambiente R}

A biblioteca desenvolvida ao longo deste trabalho é constituída basicamente de scripts R listados na íntegra no Apêndice.

\subsubsection{Plataforma de Desenvolvimento}

Este ambiente foi desenvolvido e testado com os seguintes recursos.

- Hardware: desktop PC (Pentium IV 3.4Ghz, 1Gb RAM)

- Sistema Operacional: desenvolvido e testado com o sistema operacional linux, distribuição Ubuntu 6.06 LTS (http://www.ubuntulinux.org), testes também foram feitos com a distribuição Debian Sarge (http://www.debian.org).

- R: versão 2.2.1 (http://www.r-project.org) com a utilização das libraries:

$$
\begin{aligned}
& \text { - adapt } \\
& \text { - MASS } \\
& \text { - gdata } \\
& \text { - mvtnorm }
\end{aligned}
$$

- Yacas: versão 1.0.57 (http://yacas.sourceforge.net/)

- ALGENCAN: versão do código Fortran com última atualização em 27 de março de 2006. (http://www.ime.usp.br/ egbirgin/tango/).

\subsubsection{Exemplo passo-a-passo}

A seguir listamos o script que gerou a Tabela 2.2. Nele explicitamos as duas etapas do FBST, a otimização para cada hipótese precisa e a integração de cada conjunto tangente. É importante ressaltarmos a definição da posteriori, das funções de amostragem e das hipóteses precisas fornecidas.

\subsubsection{1 scriptModeloNormal.r}

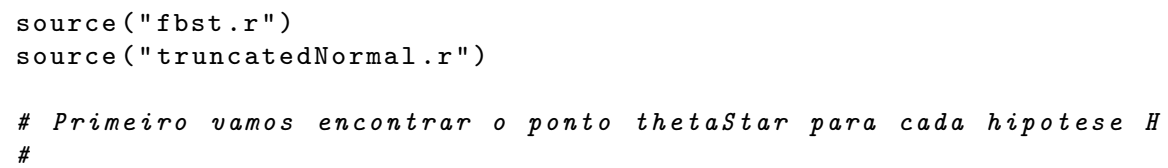




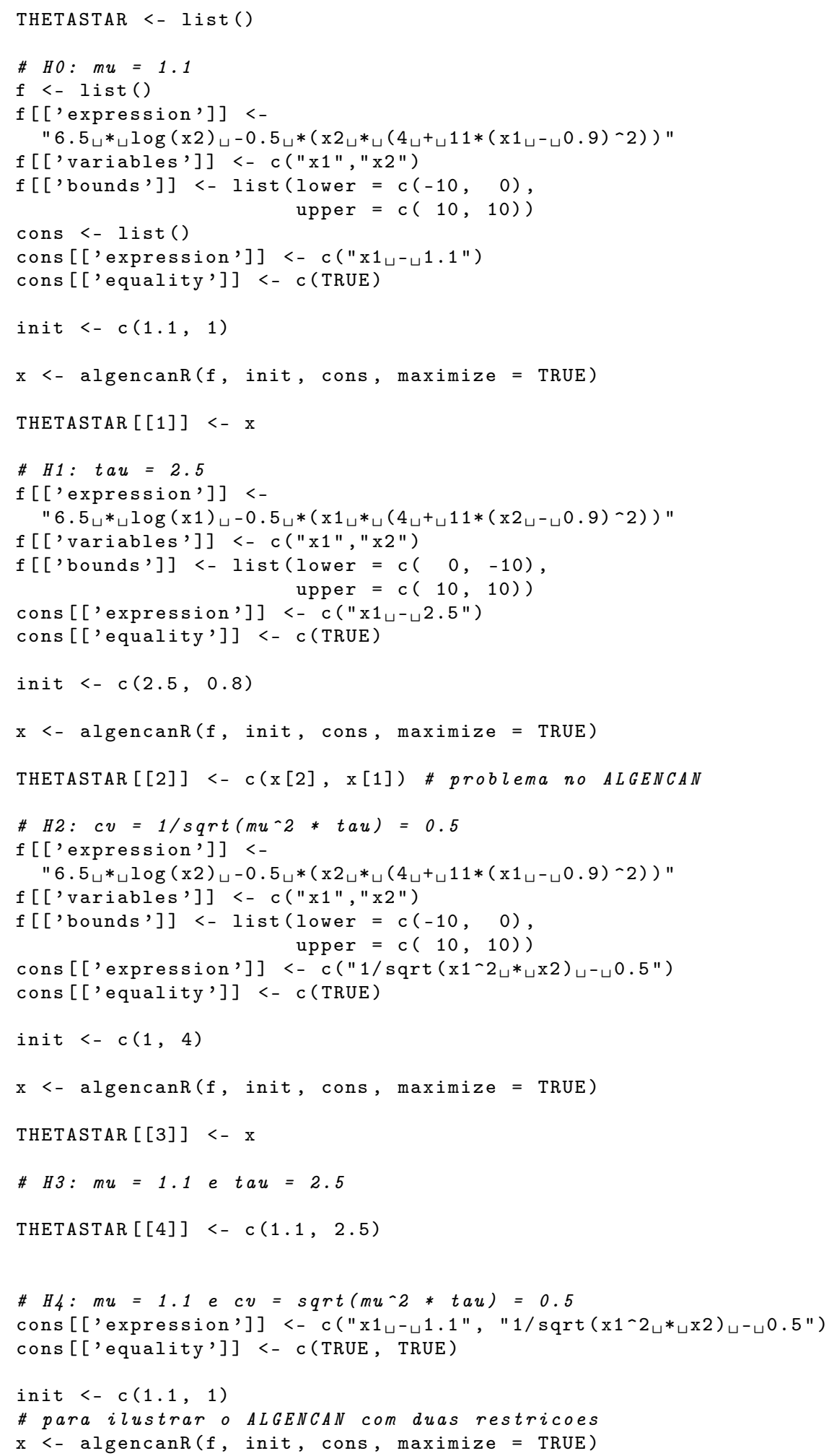




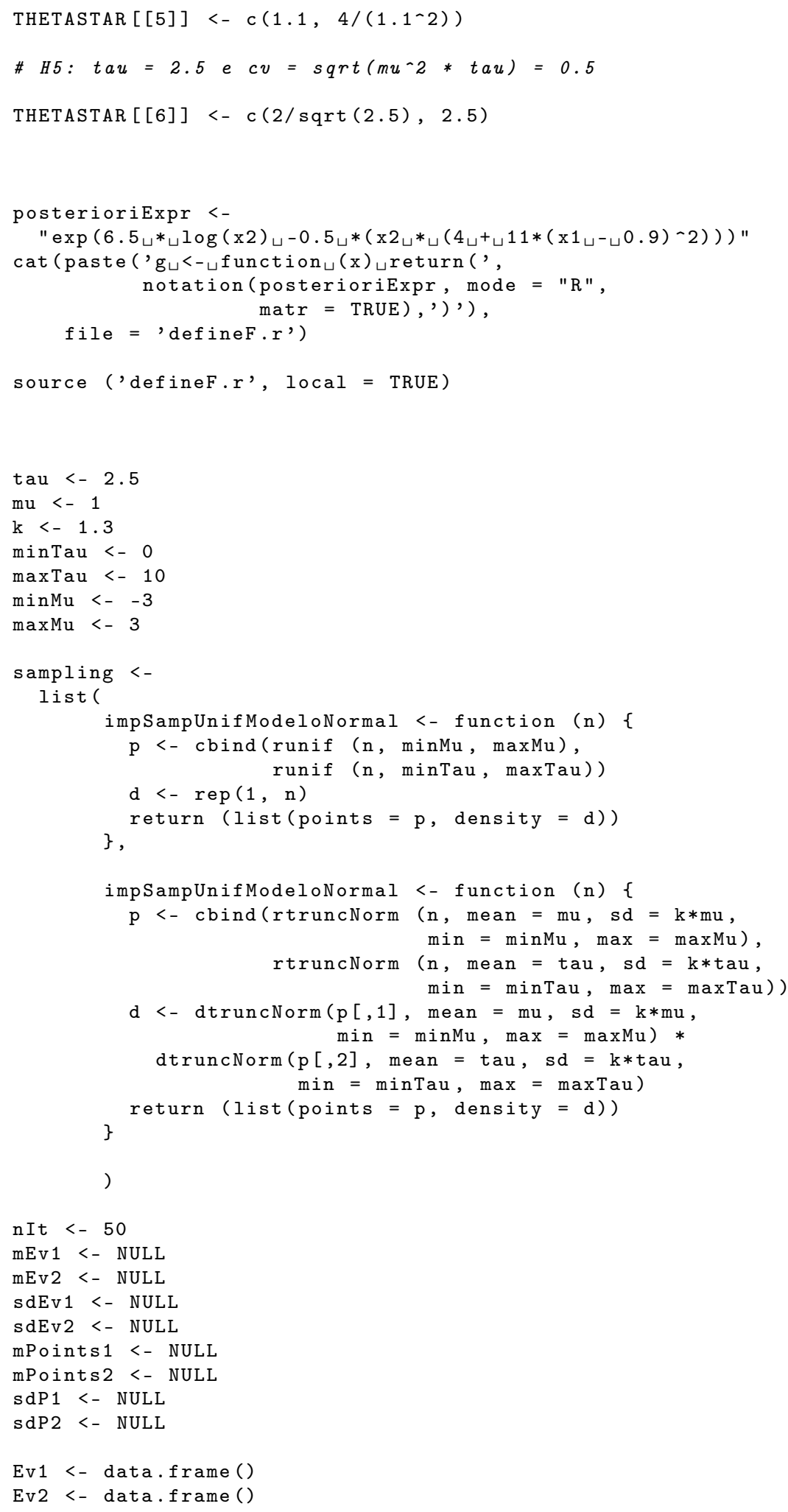




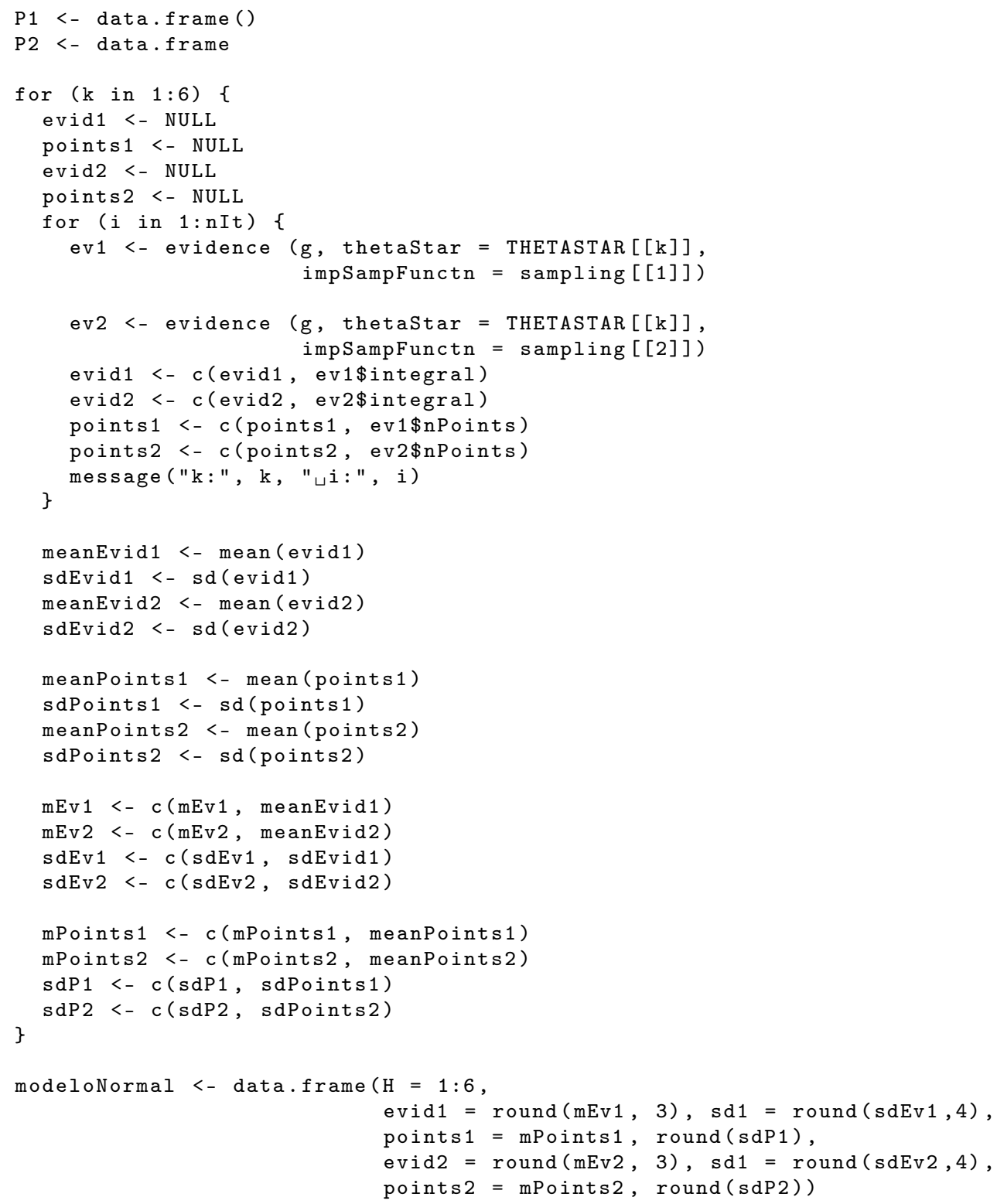

Listing 3.1: Script Modelo Normal

\subsection{Considerações}

A simplicidade da formulação do FBST e das questões por ele levantadas contrastam com a falta de um ambiente integrado e robusto para otimização e integração, etapas fundamentais no FBST. A carência de implementações de métodos genéricos robustos, ágeis e precisos na busca das respostas, deixa 
uma responsabilidade grande nas mãos do usuário. As implementações propostas neste trabalho, requerem do seu utilizador critério e sensibilidade para cada problema proposto.

Um exemplo de dificuldade encontrada no desenvolvimento de aplicações do FBST é a questão dos modelos com dependência entre os parâmetros. Ao longo do desenvolvimento da biblioteca de rotinas, implementamos alguns métodos de amostragem no espaço paramétrico dos modelos Gamma, Weibull e Gompertz. Para enxergar melhor a questão da dependência dos parâmetros na amostra criamos rotinas para visualizar curvas de nível em posterioris de modelos bi-paramétricos e aperfeiçoamos rotinas de ajuste de parâmetro a um modelo proposto (inclusive ao modelo Gompertz, que possui relação exponencial entre os parâmetros).

Superadas as dificuldades expostas, o FBST é uma alternativa eficaz, com boas propriedades teóricas e fácil de ser interpretado como critério num processo de tomada de decisões. 


\section{Capítulo 4}

\section{O Equilíbrio de Hardy-Weinberg e a Evolução Darwiniana}

O problema do equilíbrio de Hardy-Weinberg é clássico nos estudos de genética populacional. Grosso modo, em uma população em equilíbrio, as freqüências genotípicas populacionais podem ser calculadas a partir das freqüências alélicas, e vice-versa. Uma extensa bibliografia trata do teste de equilíbrio de Hardy-Weinberg é, dentre os quais citamos [?], bem como a solução originalmente proposta pelo FBST, [?].

Antes de tratarmos sobre o Equilíbrio de Hardy-Weinberg, a Evolução Darwiniana e aplicações do FBST nessa temática, é importante discutirmos sobre alguns fundamentos e conceitos de genética. Na seção seguinte, veremos o Equilíbrio de Hardy-Weinberg, uma propriedade importante que relaciona as características genéticas entre gerações de uma população. Após isso formalizaremos o teste de equilíbrio com o FBST. Em seguida trataremos um pouco sobre fatores da dinâmica evolutiva que influenciam o comportamento dos perfis genéticos de uma população ao longo do tempo e sua relação com o Equilíbrio de Hardy-Weinberg.

Genética populacional é o estudo das distribuições de freqüências dos alelos e suas mudanças sob a influência de forças evolutivas tais como: seleção natural, mutação, migração e deriva genética. Ela também considera subdivisões populacionais e a estrutura de uma população no espaço.

Gene alelo é qualquer uma das possíveis sequências de DNA em um determinado locus (posição num cromossomo). Em seus estudos, Gregor Mendel, concluiu que na variedade de ervilhas que cultivava, havia dois alelos para a determinação da cor das flores produzidas por elas, sendo um deles chamado de dominante (por forçar a produção de flores de uma cor com sua 
simples presença em algum dos alelos) e o outro de recessivo (por determinar a aparição de outra cor apenas quando os dois alelos fossem recessivos simultaneamente), este é o caso mais simples em espécies diplóides (espécies cujas caracteríticas genéticas são determinadas por pares de cromossomos). Existem locus que podem admitir dezenas de alelos. Um locus famoso que exemplifica o caso de um gene de 3 alelos é o do que caracteriza a classificação do sangue humano no sistema ABO.

\subsection{Equilíbrio de Hardy-Weinberg}

Em espécies diplóides, no caso em que um locus possui dois alelos $A$ e $a$, com freqüências populacionais $p$ e $q$, respectivamente, com $p+q=1$, se a população não estiver sofrendo ação de alguma das forças evolutivas sobre esse locus, as freqüências genotípicas dos pares de alelos $A A, A a$ e $a a$ em uma nova geração de indivíduos podem ser representadas pela Tabela 4.1:

\begin{tabular}{|c|c|c|}
\hline & $A(p)$ & $a(q)$ \\
\hline$A(p)$ & $A A\left(p^{2}\right)$ & $A a(p q)$ \\
\hline$a(q)$ & $A a(p q)$ & $a a\left(q^{2}\right)$ \\
\hline
\end{tabular}

Tabela 4.1: Freqüências genotípicas esperadas no Equilíbrio de Hardy-Weinberg

A Tabela 4.1 indica que esperamos observar na próxima geração as freqüências:

$$
f(A A)=p^{2}, \quad f(a a)=q^{2}, \quad f(A a)=2 p q,
$$

tais que $p^{2}+2 p q+q^{2}=1$.

Sob as hipóteses de:

- cruzamentos aleatórios entre os indivíduos da população;

- número de indivíduos suficientemente grande para evitar grandes flutuações aleatórias entre as freqüências de duas gerações;

- ausência de influência das forças evolutivas como, seleção natural, mutações e migrações.

dizemos que o locus com freqüências alélicas populacionais descritas acima está sob o Equilíbrio de Hardy-Weinberg. Para as freqüências genotípicas de Hardy-Weinberg no caso em que o locus analisado possui mais de 2 alelos em seres diplóides, obtemos as equações de equilíbrio a partir da expansâo 
multinomial de grau 2 das freqüências alélicas populacionais. Tomando um locus com $k$ alelos, os fatores da espansão de $\left(p_{1}+\cdots+p_{k}\right)^{2}$ são:

$$
(\underbrace{p_{1}}_{f\left(A_{1}\right)}+\cdots+\underbrace{p_{k}}_{f\left(A_{k}\right)})^{2}=\underbrace{p_{1}^{2}}_{f\left(A_{1} A_{1}\right)}+\cdots+\underbrace{p_{k}^{2}}_{f\left(A_{k} A_{k}\right)}+\sum_{i \neq j} \underbrace{2 p_{i} p_{j}}_{f\left(A_{i} A_{j}\right)}
$$

onde os $p_{i}=f\left(A_{i}\right), i=1 \ldots k$ são as freqüências alélicas populacionais para o gene $A_{i}$ e $f\left(A_{i} A_{j}\right)$ as freqüências dos genes $A_{i} A_{j}$.

Uma vez em equilíbrio, as relações entre as freqüências genotípicas e as freqüências alélicas devem satisfazer:

$$
f\left(A_{i} A_{j}\right)=f\left(A_{i}\right) f\left(A_{j}\right) \quad \forall i, j \in\{1,2, \ldots, k\} .
$$

A generalização das equações acima para o caso de $n$-ploidia em um locus de $k$ alelos, é dada por:

$$
\begin{gathered}
\left(p_{1}+\cdots+p_{k}\right)^{n}=\sum_{\substack{l_{1}, \ldots, l_{k}: l_{1}+\cdots+l_{k}=n, l_{r} \in\{1,2, \ldots, n\}, r \in\{1,2, \ldots, k\}}}\left(\begin{array}{c}
n \\
l_{1}, \ldots, l_{k}
\end{array}\right) p_{1}^{l_{1}} \ldots p_{k}^{l_{k}}, \quad \\
f\left(A_{i_{1}}, \ldots, A_{i_{k}}\right)=f\left(A_{i_{1}}\right) \ldots f\left(A_{i_{k}}\right) \quad \forall i_{r} \in\{1, \ldots, n\}, r \in\{1, \ldots, k\}
\end{gathered}
$$

\subsection{Teste de Equilíbrio de Hardy-Weinberg com FBST}

A formalização do FBST para o equilíbrio entre as freqüências genotípicas e alélicas na geração de uma população para o caso de organismos diplóides, pode ser feita da seguinte forma:

- Posteriori: Denotemos por $\mathbf{n}$ o vetor de contagem dos genótipos observados em uma amostra:

$$
\mathbf{n}=\left(\begin{array}{cccc}
n_{A_{1} A_{1}} & 0 & \ldots & 0 \\
n_{A_{2} A_{1}} & n_{A_{2} A_{2}} & \ddots & \vdots \\
\vdots & & \ddots & 0 \\
n_{A_{k} A_{1}} & \ldots & \ldots & n_{A_{k} A_{k}}
\end{array}\right)\left(\begin{array}{c}
1 \\
\vdots \\
\vdots \\
1
\end{array}\right)
$$

Admitindo a distribuição a priori uniforme sobre o espaço paramétrico, a distribuição a posteriori para as freqüências genotípicas $\pi_{i j}=f\left(A_{i} A_{j}\right)$ é dada por:

$$
p(\boldsymbol{\pi}) \propto \exp \{\mathbf{n} \cdot \log (\boldsymbol{\pi})\}=\prod_{i, j \in\{1, \ldots, k\}} \pi_{i j}^{n_{A_{i} A_{j}}}
$$


onde $\boldsymbol{\pi}$, é o vetor das freqüências genotípicas $\pi_{i j}$.

- Hipótese: Denotando por $\pi_{i}, i=1, \ldots, k$, as freqüências alélicas populacionais, nossa hipótese é composta pelas equações de equilíbrio:

$$
\pi_{i j}=\pi_{i} \pi_{j} \quad \forall i, j \in\{1,2, \ldots, k\},
$$

e pela restrição do espaço paramétrico:

$$
\sum_{i=1}^{k} \pi_{i}=1
$$

Sob $H$, a posteriori neste caso fica:

$$
p(\boldsymbol{\pi} \mid H) \propto \prod_{\substack{j \in\{1, \ldots, k\} \\ i \in\{j, \ldots, k\}}}\left(\pi_{i} \pi_{j}\right)^{n_{A_{i} A_{j}}}
$$

\subsubsection{Otimização}

Para a otimização sob a hipótese, podemos utilizar o método analítico apresentado a seguir. Note-se que a Equação 4.8 pode ser reescrita separando-se os genótipos homozigotos (alelos iguais) dos heterozigotos (alelos diferentes):

$$
p(\boldsymbol{\pi} \mid H) \propto f(\boldsymbol{\pi} \mid H)=\prod_{j \in\{1, \ldots, k\}} \pi_{j}^{2 n_{A_{j} A_{j}}} \prod_{\substack{j \in\{1, \ldots, k-1\} \\ i \in\{j+1, \ldots, k\}}}\left(2 \pi_{i} \pi_{j}\right)^{n_{A_{i} A_{j}}}
$$

Maximizar $f(\boldsymbol{\pi} \mid H)$ equivale a maximizar seu logaritmo:

$$
\begin{aligned}
\log (f(\boldsymbol{\pi} \mid H)) & =l(\pi)=\sum_{j \in\{1, \ldots, k\}} 2 n_{A_{j} A_{j}} \log \left(\pi_{j}\right)+\sum_{\substack{j \in\{1, \ldots, k-1\} \\
i \in\{j+1, \ldots, k\}}} n_{A_{i} A_{j}} \log \left(2 \pi_{i} \pi_{j}\right) \\
& =\sum_{j \in\{1, \ldots, k\}} 2 n_{A_{j} A_{j}} \log \left(\pi_{j}\right)+\sum_{\substack{j \in\{1, \ldots, k-1\} \\
i \in\{j+1, \ldots, k\}}} n_{A_{i} A_{j}}\left(\log (2)+\log \left(\pi_{i}\right)+\log \left(\pi_{j}\right)\right) \\
& =h \log (2)+\sum_{j \in\{1, \ldots, k\}} n_{j} \log \left(\pi_{j}\right),
\end{aligned}
$$

tal que,

$$
\begin{aligned}
h & =\sum_{\substack{j \in\{1, \ldots, k-1\} \\
i \in\{j+1, \ldots, k\}}} n_{A_{i} A_{j}}, \\
n_{j} & =\sum_{i \in\{1, \ldots, j\}} n_{A_{j} A_{i}}+\sum_{i \in\{j, \ldots, k\}} n_{A_{i} A_{j}} .
\end{aligned}
$$


Pela restrição 4.7, temos:

$$
l(\pi)=h \log (2)+\sum_{j \in\{1, \ldots, k-1\}} n_{j} \log \left(\pi_{j}\right)+n_{k} \log \left(1-\sum_{j \in\{1, \ldots, k-1\}} \pi_{j}\right) .
$$

As componentes do gradiente de $l(\pi)$ são dadas por:

$$
\frac{\partial l}{\partial \pi_{i}}(\pi)=\frac{n_{i}}{\pi_{i}}-\frac{n_{k}}{\left(1-\sum_{j=1}^{k-1} \pi_{j}\right)}
$$

Logo, o ponto ótimo sob a hipótese $H$ é o vetor $\pi$ que satisfaz:

$$
A . \pi=b ; \quad A=\left(\begin{array}{cccc}
n_{1}+n_{k} & n_{1} & \ldots & n_{1} \\
n_{2} & n_{2}+n_{k} & & n_{2} \\
\vdots & & \ddots & \vdots \\
n_{k-1} & n_{k-1} & \ldots & n_{k-1}+n_{k}
\end{array}\right) ; \quad b=\left(\begin{array}{c}
n_{1} \\
\vdots \\
n_{k-1}
\end{array}\right) .
$$

\subsubsection{Integração}

Neste problema, devemos utilizar o Método da Variável Indicadora descrito no capítulo anterior. A amostragem da distribuição Dirichlet definida em (4.5) é simples de ser obtida e podemos aplicar a transformação do logaritmo para calcular $\overline{e v}$.

\subsection{Evolução Darwiniana}

Nesta seção vamos abordar alguns fatores importantes no processo de evolutivo que podem ser detectados pelo teste:

Deriva Genética é a variação das freqüências alélicas observada entre gerações de uma mesma população. Essa variação é um fenômeno de natureza aleatória que pode ocorrer principalmente em populações pequenas, por exemplo, indivíduos que produzem um número maior de descendentes do que outros fazem aumentar a freqüência dos seus alelos.

Cruzamentos Não Aleatórios São os cruzamentos entre indivíduos onde ocorre a influência de fatores genéticos, físicos ou sociais na escolha do parceiro para acasalamento. 
Mutações são mudanças no material genético. Elas podem ser derivadas de uma série de fatores, entre eles:

- erros na cópia do DNA (ou RNA) durante a divisão celular,

- exposição a radiação ou agentes químicos capazes de provocá-las,

- ações de vírus,

- aleatoridades em processos celulares internos.

Em organismos pluricelulares, as mutações podem ser transmitidas ou não a seus descendentes.

Seleção Natural é o processo pelo qual os seres vivos com traços ou características mais favoráveis à sobrevivência e reprodução, transmitem essas boas características às gerações seguintes tornando-as mais frequentes em sua espécie, produzindo ao longo de sucessivas gerações adaptações ou novas espécies.

Migração é o processo de cruzamento entre indivíduos de populações diferentes, que sofreram ao longo do tempo, um distanciamento em suas freqüências alélicas por conta de separação geográfica.

Todos os fatores listados acima contribuem para a variação das freqüências alélicas populacionais de um locus genético ao longo do tempo. Como sabemos, os genes são os responsáveis pelas proteínas, os atores atuantes na dinâmica dos processos celulares, Beadle e Tatum (1941) mostraram em seus experimentos a relação direta entre os genes e as enzimas envolvidas em processos metabólicos, propondo a hipótese conhecida como:

\section{Um gene, uma enzima.}

Como responsáveis pela produção das proteínas dentro da célula, os genes determinam as características do indivíduo, que por sua vez influenciam processos de interação dele com a própria população e outras espécies (reprodução, interações sociais, alimentação, etc...) e com o ambiente em que vive (fatores geográficos, climáticos e etc...). Essas interações, ao longo das gerações, selecionam as características mais favoráveis para a perpetuação, adaptação e diversificação das espécies, ou de acordo com o paradigma da Evolução Darwiniana, a sobrevivência dos mais adaptados pela competição entre as espécies. 
Portanto, testar o Equilibrio de Hardy-Weinberg é importante porque, se o locus não estiver em equilibrio, isto quer dizer que o produto daquele gene, dá ao indivíduo uma característica que lhe confere vantagem ou desvantagem em relação a outros. Para que isso seja verdade os efeitos da Deriva Genética e dos Cruzamentos Não Aleatórios não podem ser significativos, e se eles não forem relevantes, podemos concluir que as forças evolutivas (Mutações, Seleção Natural e Migrações) estão atuando sobre a população. 


\section{Capítulo 5}

\section{Contribuições}

\subsection{Teste de Paternidade}

O exame genético de paternidade é usualmente empregado em processos judiciais para reconhecimento de paternidade. O problema estatístico é inferir se um determinado indivíduo, o Demandante, é filho de um segundo indivíduo, o Demandado. Este é o chamado cáculo (de probabilidade) de paternidade ou de vínculo genético de filiação.

Para o teste de paternidade, devem ser conhecidos os genótipos dos indivíduos envolvidos ou de seus parentes. A maioria dos métodos de cálculo de paternidade conhecidos envolvem as frequências alélicas da população e se baseiam na genética mendeliana - que pressupõe o Equilíbrio de HardyWeinberg para os loci analisados.

Em nosso trabalho, implementamos o teste de Equilibrio de Hardy-Weinberg para múltiplos alelos em um mesmo locus em organismos diplóides. Esta implementação está sendo utilizada na tese de doutorado de Fábio Nakano, aluno do programa de Bioinformática da USP. Os conceitos do Equilibrio de Hardy-Weinberg são apresentados no Capitulo 4, e a implementação computacional é apresentada no Apêndice A.2

\section{$5.2 \quad$ Hipóteses Separadas}

Um problema clássico em estatística consiste em escolher qual dentre duas (ou mais) distribuições de probabilidade melhor se ajusta a um conjunto de dados observados. Em muitos casos, análises gráficas ou testes de ajuste simples (por exexemplo o chi-quadrado) são suficientes para a escolha. Todavia, em domínios onde se exigem bons ajustes, surgem questões importantes: 
- Existe evidência de que os ajustes fornecidos pelas distribuições candidatas sejam significativamente diferentes?

- Qual a distribuição que melhor se ajusta aos dados?

- Escolhendo-se uma das distribuições, existe alguma evidência de não aderência dos dados àquela distribuição, mas sim a uma outra?

- Supondo que uma das distribuições seja a verdadeira, qual é a evidência fornecida pelos dados?

- Se nenhuma das distribuições for a verdadeira, qual é a evidência fornecida pelos dados?

Testes de hipóteses separadas, como são comumente chamados problemas dessa natureza, foram originalmente desenvolvidos por [Cox, 1961], [Cox, 1962], e desde então diversas abordagens têm sido utilizadas. Na maioria dos trabalhos com este tema busca-se confrontar a hipótese nula, de que os dados provêm de uma certa distribuição $\mathrm{F}$, contra a hipótese alternativa, de que os dados provêm de uma distribuição $G$.

Em sua tese de doutorado, em andamento, Marcelo de Souza Lauretto propõe a formulação do problema de hipóteses separadas como um problema de seleção em modelos de misturas, através do FBST, vide [Lauretto and Stern, 2005a, ?]. Mais especificamente, considera-se uma mistura de $m$ componentes onde cada componente $k$ possui uma função de densidade $f_{k}\left(. \mid \psi_{k}\right)$ de família distinta das demais componentes e a densidade de probabilidade da observação $x^{j}$ é

$$
f\left(x^{j} \mid w_{1} \ldots w_{k}, \psi_{1} \ldots \psi_{k}\right)=w_{1} f_{1}\left(x^{j} \mid \psi_{1}\right)+w_{2} f_{2}\left(x^{j} \mid \psi_{2}\right)+\ldots+w_{k} f_{m}\left(x^{j} \mid \psi_{k}\right) .
$$

A densidade de probabilidade dos dados completos será

$$
f(X \mid \theta)=\prod_{j=1}^{n}\left[w_{1} f_{1}\left(x^{j} \mid \psi_{1}\right)+w_{2} f_{2}\left(x^{j} \mid \psi_{2}\right)+\ldots+w_{k} f_{m}\left(x^{j} \mid \psi_{k}\right)\right] .
$$

Sob essa formulação, testar se os dados são provenientes da $k$-ésima distribuição equivale a testar a hipótese $H: w_{k}=1, w_{j}=0$ para $j \neq k$.

Em colaboração com Marcelo Lauretto, implementamos um ambiente integrado para cálculo da evidência em alguns dos problemas mais estudados de hipóteses separadas, dentre os quais:

- Weibull $\times$ Log-Normal;

- Gompertz × Weibull. 
Embora este trabalho ainda esteja em andamento, alguns resultados experimentais já foram obtidos, e mostram a adequabilidade do FBST para este problema. Na Tabela 5.1 apresentamos uma análise da convergência dos erros para a seleção de modelos Weibull $\times$ Log-Normal em função do tamanho da amostra. Cada linha corresponde a uma amostra simulada (com parâmetros explícitos na tabela) e contém as taxas de erro do tipo I (percentual de rejeições do modelo verdadeiro) e do tipo II (percentual de aceitações do modelo falso). As taxas de erro foram obtidas simulando-se 200 amostras de cada caso e a aceitação/rejeição da hipótese para cada amostra foi definida fixando-se o nível de significância de $10 \%$.

Tabela 5.1: Erros dos Tipos I e II para testes de hipóteses separadas Weibull vs. Log-Normal

\begin{tabular}{|c|c|c|c|c|c|}
\hline \multicolumn{2}{|c|}{} & \multicolumn{4}{|c|}{$\mathbf{n}$} \\
\hline Amostra & Erro & $\mathbf{4 0}$ & $\mathbf{6 0}$ & $\mathbf{8 0}$ & $\mathbf{1 0 0}$ \\
\hline Log-Normal(0; 0,1) & Tipo I & $4 \%$ & $5 \%$ & $4 \%$ & $4 \%$ \\
& Tipo II & $43 \%$ & $17 \%$ & $9 \%$ & $6 \%$ \\
\hline Log-Normal(0; 0,5) & Tipo I & $5 \%$ & $6 \%$ & $4 \%$ & $4 \%$ \\
& Tipo II & $37 \%$ & $23 \%$ & $14 \%$ & $8 \%$ \\
\hline Log-Normal(0; 1) & Tipo I & $7 \%$ & $7 \%$ & $6 \%$ & $5 \%$ \\
& Tipo II & $41 \%$ & $23 \%$ & $6 \%$ & $6 \%$ \\
\hline Weibull(1; 1) & Tipo I & $5 \%$ & $7 \%$ & $5 \%$ & $6 \%$ \\
& Tipo II & $40 \%$ & $20 \%$ & $10 \%$ & $6 \%$ \\
\hline Weibull(5; 1) & Tipo I & $7 \%$ & $5 \%$ & $7 \%$ & $5 \%$ \\
& Tipo II & $38 \%$ & $23 \%$ & $10 \%$ & $2 \%$ \\
\hline Weibull(10; 1) & Tipo I & $8 \%$ & $6 \%$ & $5 \%$ & $5 \%$ \\
& Tipo II & $34 \%$ & $16 \%$ & $8 \%$ & $4 \%$ \\
\hline
\end{tabular}

Os resultados obtidos mostram o comportamento esperado: as taxas de erro do tipo I mantêm-se abaixo do nível de significância estipulado (10\%) enquanto as taxas de erro do tipo II convergem para 0. 


\section{Referências Bibliográficas}

[Aitchison and Shen, 1980]

[Aitkin, 1991]

[Anderson, 1935]

[Atkinson, 1970]

[Andreani et al, 2005]

[Birgin et al, 2004]

[Berger and Pierichi, 1996]
J.Aitchison, S.M.Shen (1980) Logisticnormal distributions: some properties and use. Biometrika, 67, 261-272.

M.Aitkin (1991). Posterior Bayes factors (with discussion). J.R.Statist.Soc B, 53, 111-142.

E.Anderson (1935). The Irises of the Gaspé Peninsula. Bulletin of the American Iris Society, 59, 2-5.

A.C.Atkinson (1970). A Method for Discriminating Between Models. J. Royal Stat. Soc. B, 32, 323-354. Journal of Computational Physics 22, 245-268.

R.Andreani, E.G.Birgin, J.M.Martİnez and M.L.Schuverdt (2005), Augmented Lagrangian methods under the Constant Positive Linear Dependence constraint qualification, Mathematical Programming

E.G.Birgin, R.Castillo and J.M.Martİnez (2004), Numerical comparison of Augmented Lagrangian algorithms for nonconvex problems, Computational Optimization and Applications, vol 31, pags 31-56

J.O.Berger, L.R.Pericchi (1996). The intrinsic Bayes factor for linear model. in: J.M.Bernardo, J.O.Berger, A.P.Dawid and A.F.M.Smoth (Eds.), Bayesian Statistics 5, Oxford: University Press, 25-44. 
[Biernacki, 1998]

[Birgin et al, 1998]

[Borges and Stern, 2005]

[Celeux et al, 1996]

[Cox, 1961]

[Cox, 1962]

[Dougherty et al, 2002]

[DeGroot, 1970]
C.Biernacki, G.Govaert (1998). Choosing Models in Model-based Clustering and Discriminant Analysis. Technical Report INRIA-3509-1998.

E.G.Birgin, R.Castillo, J.M.Martinez (2004). Numerical comparison of Augmented Lagrangian algorithms for nonconvex problems. to appear in Computational Optimization and Applications.

W.S.Borges and J.M.Stern (2005), On the truth value of complex hypothesis CIMCA2005 - International Conference on Computational Intelligence for Modelling Control and Automation

G.Celeux, D.Chauveau, J.Diebolt (1996). On Stochastic Versions of the EM Algorithm. An Experimental Study in the mixture Case. Journal of Statistical Computation and Simulation, 55, 287-314.

D.R.Cox (1961). Tests of Separate Families of Hypotheses. In Proceedings of the Fourth Berkeley Symposium on Mathematical Statistics and Probability, Vol. I. Berkeley, CA: University of California Press.

D.R.Cox (1962). Further Results on Tests of Separated Families of Hypotheses. J.R. Statist. Soc. B 24, 406-423.

E.R.Dougherty, J.Barrera, M.Brun, S.Kim, R.M.Cesar, Y.Chen, M.Bittner, J.M.Trent (2002). Inference from Clustering with Application to Gene-Expression Microarrays. Journal of Computational Biology, 9(1), 105-126.

M.H.DeGroot (1970). Optimal Statistical Decisions. NY: McGraw-Hill. 
[Dempster et al, 1977]

[Fraley, 1999]

[Gavrilov, 2001]

[Gentle, 1998]

[Gilks, 1996]

[Häggström, 2002]

[Irony et al, 2001]

[Johnson, 1987]

[Lauretto et al, 2003]

[Lauretto and Stern, 2005a]
A.P.Dempster, N.M.Laird, D.B.Rubin (1977). Maximum Likelihood from Incomplete Data via the EM Algorithm. J. of the Royal Statistical Society B. 39, 1-38.

C.Fraley, A.E.Raftery (1999). Mclust: Software for Model-Based Cluster Analysis. J. Classif.,16,297-306.

L.A.Gavrilov, N.S.Gavrilova (2001). The reliability of aging and longevity. J. Theor. Biol. 213, 527-545.

J.E.Gentle (1998). Random Number Generator and Monte Carlo Methods. NY: Springer.

W.R.Gilks, S.Richardson, D.J.Spiegelhalter (1996). Markov Chain Monte Carlo in Practice. NY: CRC

O.Häggström (2002). Finite Markov Chains and Algorithmic Applications. Cambridge Univ.

T.Z.Irony, M.S.Lauretto, C.A.B. Pereira, J.M. Stern (2001). A Weibull Wearout Test: Full Bayesian Approach. In: Y.Hayakawa; T.Irony; M.Xie. (Org.). Series in Quality, Reliability \& Engineering Statistics: System and Bayesian Reliability, v. 5, p. 287-300.

M.E.Johnson (1987). Multivariate Statistical Simulation. NY: Wiley.

M.Lauretto, C.A.B.Pereira, J.M.Stern, S.Zacks (2003). Comparing Parameters of Two Bivariate Normal Distributions Using the Invariant FBST. Brazilian Journal of Probability and Statistics, 17, 147-168.

M.S.Lauretto, J.M.Stern (2005a). FBST for Mixture Model Selection. American Institute of Physics Conference Proceedings, 803, 121-128. 
[Lauretto and Stern, 2005b]

[McLachlan, 2000]

[Madruga, 2001]

[Madruga et al, 2003]

[Magalhães et al, 2005]

[Martinez, 2000]

[Meeker, 1998]

[Meng and Wong, 1996]

[O'Hagan, 1995]
M.S.Lauretto, J.M.Stern (2005b). Testing Significance in Bayesian Classifiers. Frontiers In Artificial Intelligence, to appear.

G.McLachlan, D.Peel (2000). Finite Mixture Models. NY: Wiley.

M.Madruga, L.G.Esteves, S.Wechsler (2001). On the Bayesianity of Pereira-Stern Tests. Test,10,291-299.

M.R.Madruga, C.A.B.Pereira, J.M.Stern (2003). Bayesian Evidence Test for Precise Hypotheses. Journal of Statistical Planning and Inference, 117,185-198.

J.P.Magalhães, J.A.S.Cabral, D.Magalhães (2005). The influence of genes on the aging process of mices: A statistical assessment of the genetics of aging. Genetics 169:265-274.

J.M.Martinez (2000). BOX-QUACAN and the Implementation of Augmented Lagrangian Algorithms for Minimization with Inequality Constraints. Computational and $A p$ plied Mathematics. 19, 31-56.

W.Q.Meeker, L.A.Escobar (1998). Statistical Methods for Reliability Data. Wiley Series in Probability and Statistics.

X.L.Meng, W.H.Wong (1996). Simulating Ratios of Normalizing Constants via a Simple Identity: A Theoretical Exploration. Statistica Sinica, 6, 831-860.

[Montoya-Delgado et al, 2001] L.E.Montoya-Delgado, T.Z.Irony, C.A.B.Pereira, M.Whittle (2001). Unconditional exact test for the Hardy-Weinberg law. Genetics 875-883.

A.O'Hagan (1995). Fractional Bayes factor for model comparison (with discussion). J.R.Statist.Soc. B, 57, 99-138. 
[Ormoneit and Tresp, 1995]

[Pereira, 2005]

[Pereira and Stern, 1999]

[Pereira and Stern, 2001]

[Robert, 1996]

[Spall, 2003]

[Stern, 2001]
[Stephens, 1997]

D.Ormoneit, V.Tresp (1995). Improved Gaussian Mixtures Density Estimates Using Bayesian Penalty Terms and Network Averaging. Advances in Neural Information Processing Systems 8, 542-548. MIT.

B.B.Pereira (2005). Separate Families of Hypotheses. In: Peter Armitage, Theodore Calton (Org.) Encyclopedia of Biostatistics 2 ed. v.7, 4881-4886.

C.A.B.Pereira, J.M.Stern (1999). Evidence and Credibility: Full Bayesian Significance Test for Precise Hypotheses. Entropy Journal, 1, 69-80.

C.A.B.Pereira, J.M.Stern (2001). Model Selection: Full Bayesian Approach. Environmetrics, 12, 559-568.

C.P.Robert (1996). Mixture of Distributions: Inference and Estimation. in Gilks (1996).

[Ricklefs and Scheuerlein, 2001] R.E.Ricklefs, A.Scheuerlein (2001). Comparison of aging-related mortality among birds and mammals. Experimental Gerontology 36, 845-857.

[Ricklefs and Scheuerlein, 2002] R.E.Ricklefs, A.Scheuerlein (2002). Biological implications of the Weibull and Gompertz models of aging. Journal of Gerontoloty, 57(2), B69-B76.

J.C.Spall (2003). Introduction to Stochastic Search and Optimization. Hoboken: Wiley.

M.Stephens (1997). Bayesian Methods for Mixtures of Normal Distributions. Oxford Univ.

J.M.Stern (2001). The Full Bayesian Significant Test for the Covariance Structure Problem, ISAS-01, Int.Conf.on Systems Analysis and Synthesis, 7, 60-65. 
[Stern, 2003]

[Stern, 2004a]

[Stern, 2004b]

[Stern, 2005]

[Stern and Pereira, 2005]

[Stern and Zacks, 2002]

[Yeung, 2001]
J.M.Stern (2003). Significance Tests, Belief Calculi, and Burden of Proof in Legal and Scientific Discourse. Laptec'03, Frontiers in Artificial Intelligence and its Applications, 101, 139-147.

J.M.Stern (2004a). Paraconsistent Sensitivity Analysis for Bayesian Significance Tests. SBIA'04, Lecture Notes Artificial Intelligence, 3171, 134-143.

J.M.Stern (2004b). Uninformative Reference Sensitivity in Possibilistic Sharp Hypotheses Tests. MaxEnt 2004, American Institute of Physics Proceedings, 735, 581588.

J.M.Stern (2005). Cognitive Constructivism, Eigen-Solutions, and Sharp Statistical Hypotheses. Third Conference on the Foundations of Information Science. FIS2005, $61,1-23$

J.M.Stern, C.A.B.Pereira (2005). FBST Asymptotics. Under preparation.

J.M.Stern, S.Zacks (2002). Testing the Independence of Poisson Variates under the Holgate Bivariate Distribution. The Power of a New Evidence Test. Statistical and Probability Letters, 60, 313-320.

K.Y.Yeung, C.Fraley, A.Murua, A.E.Raftery, W.L.Ruzzo (2001). Modelbased clustering and data transformations for gene expression data. Bioinformatics Vol. 17 no 10, 977-987. 


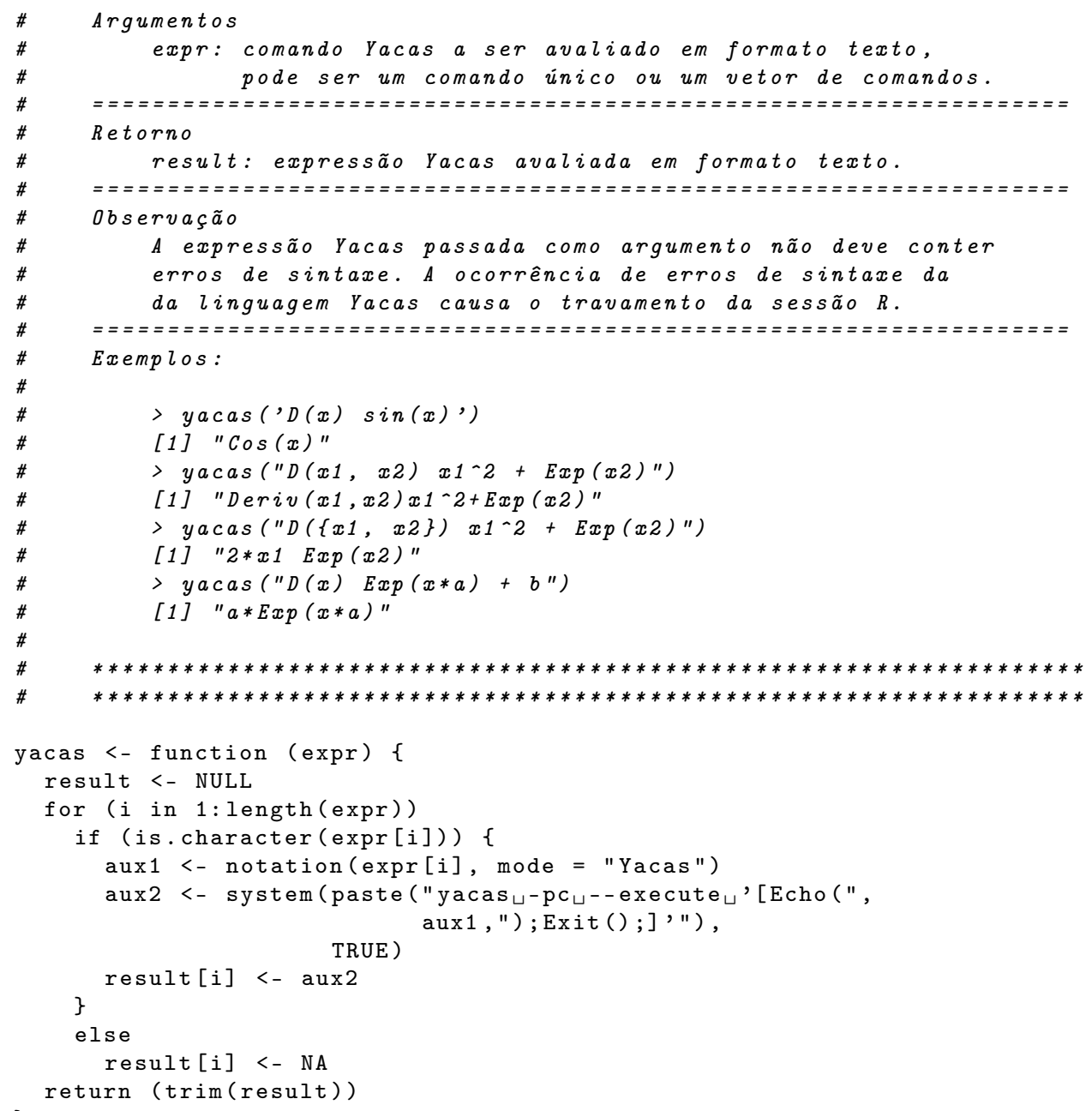




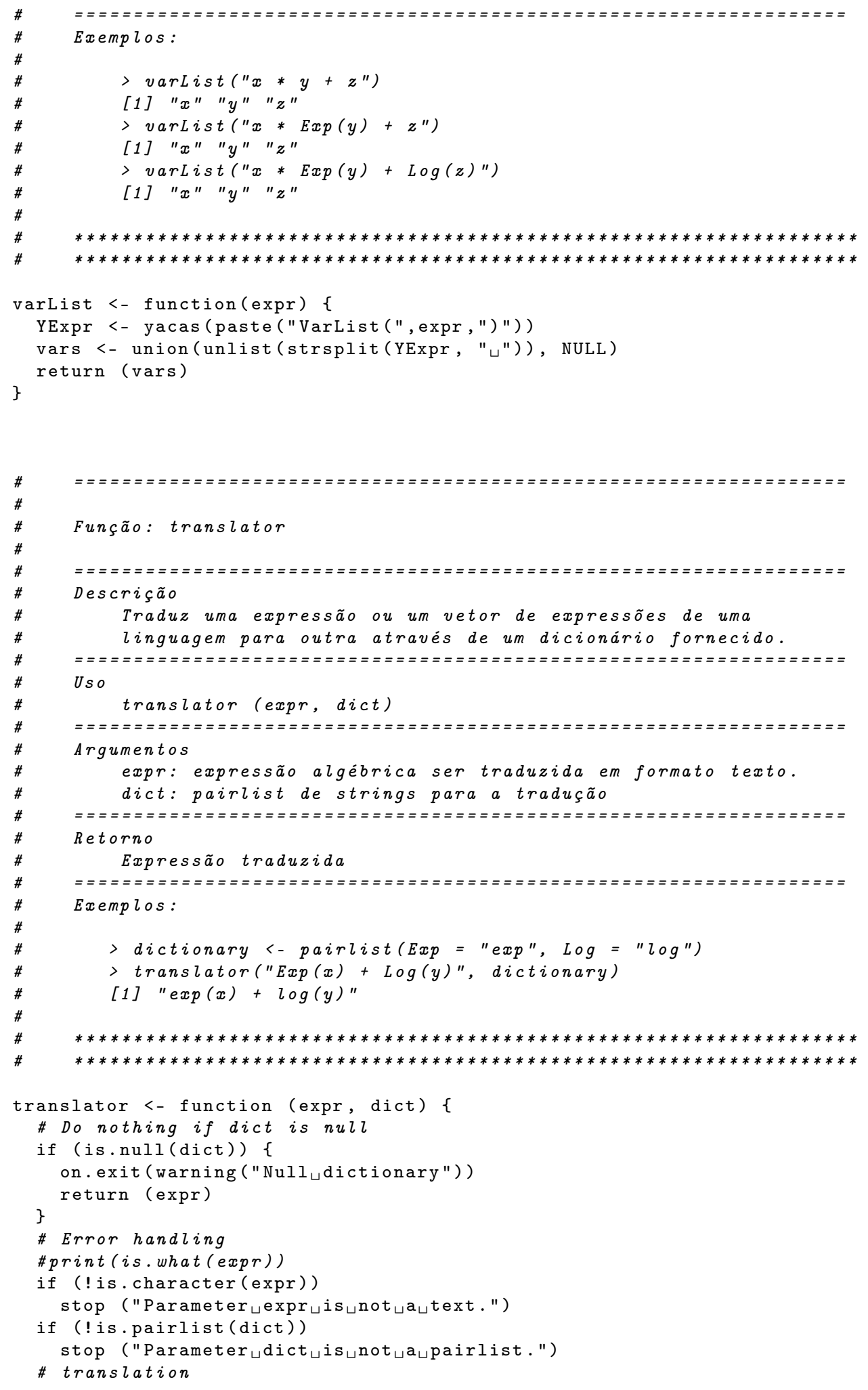


newExpr <- expr

for (text in names(dict)) newExpr <- gsub(text, dict [text], newExpr) \} return (newExpr)

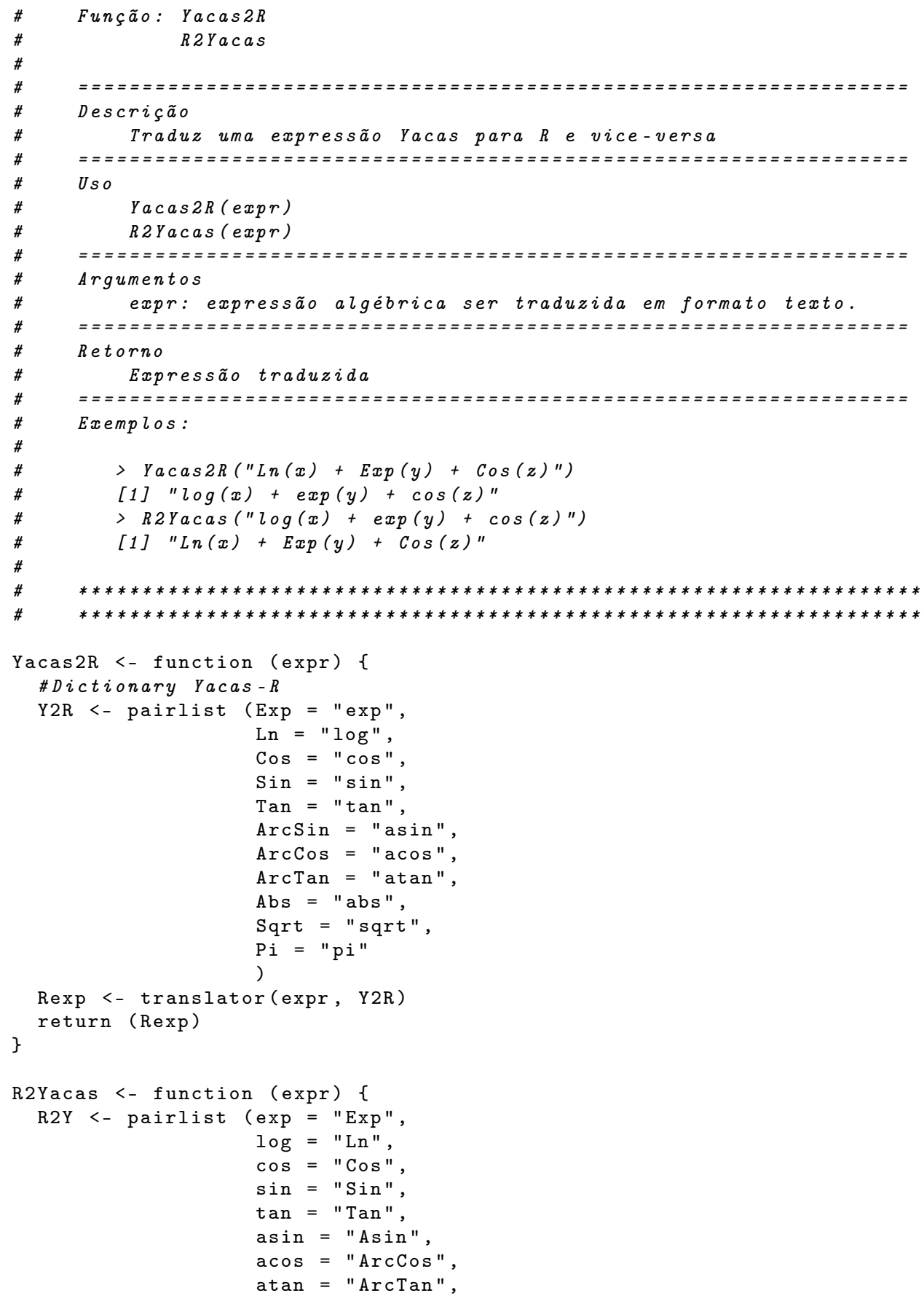




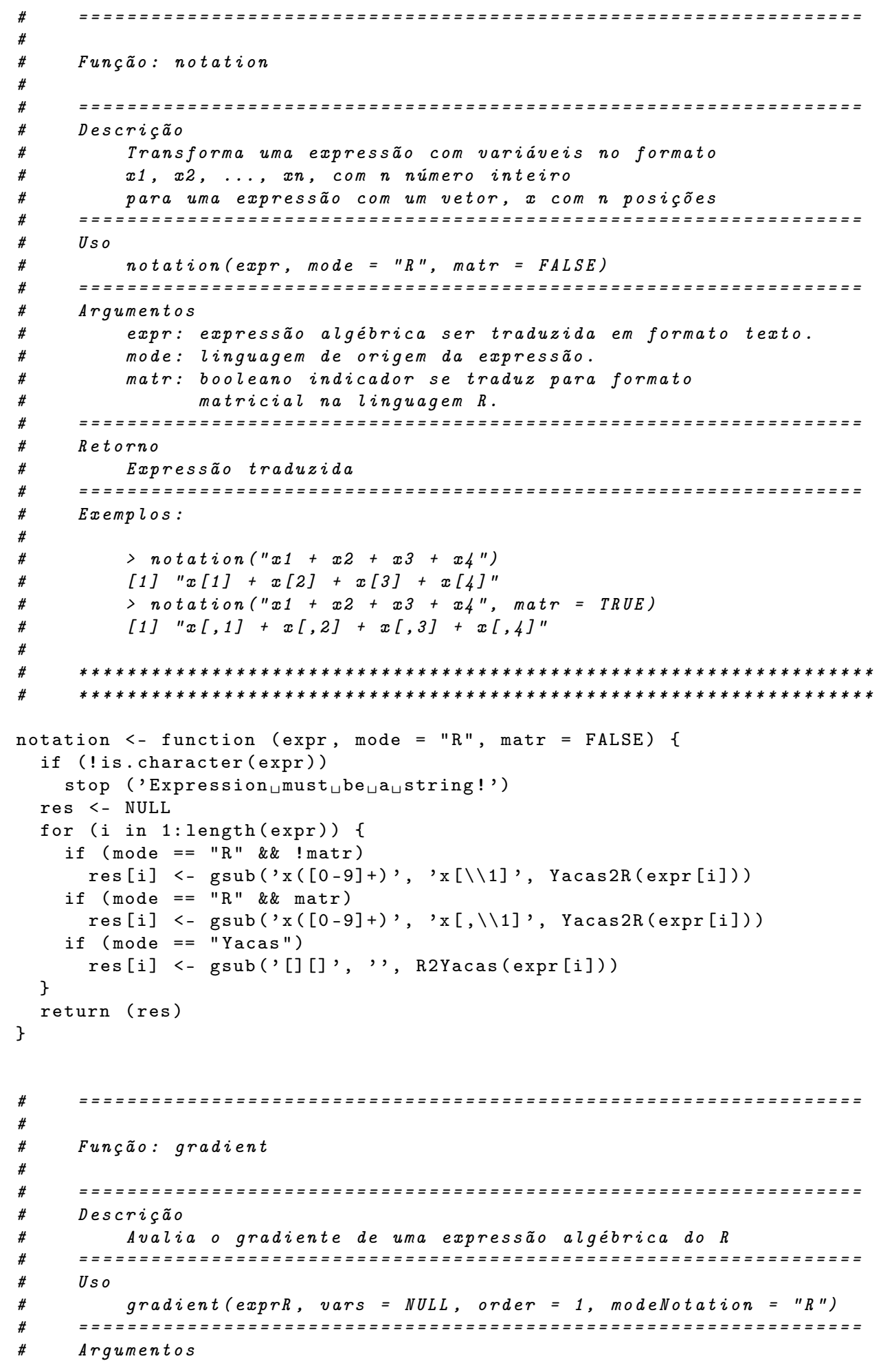




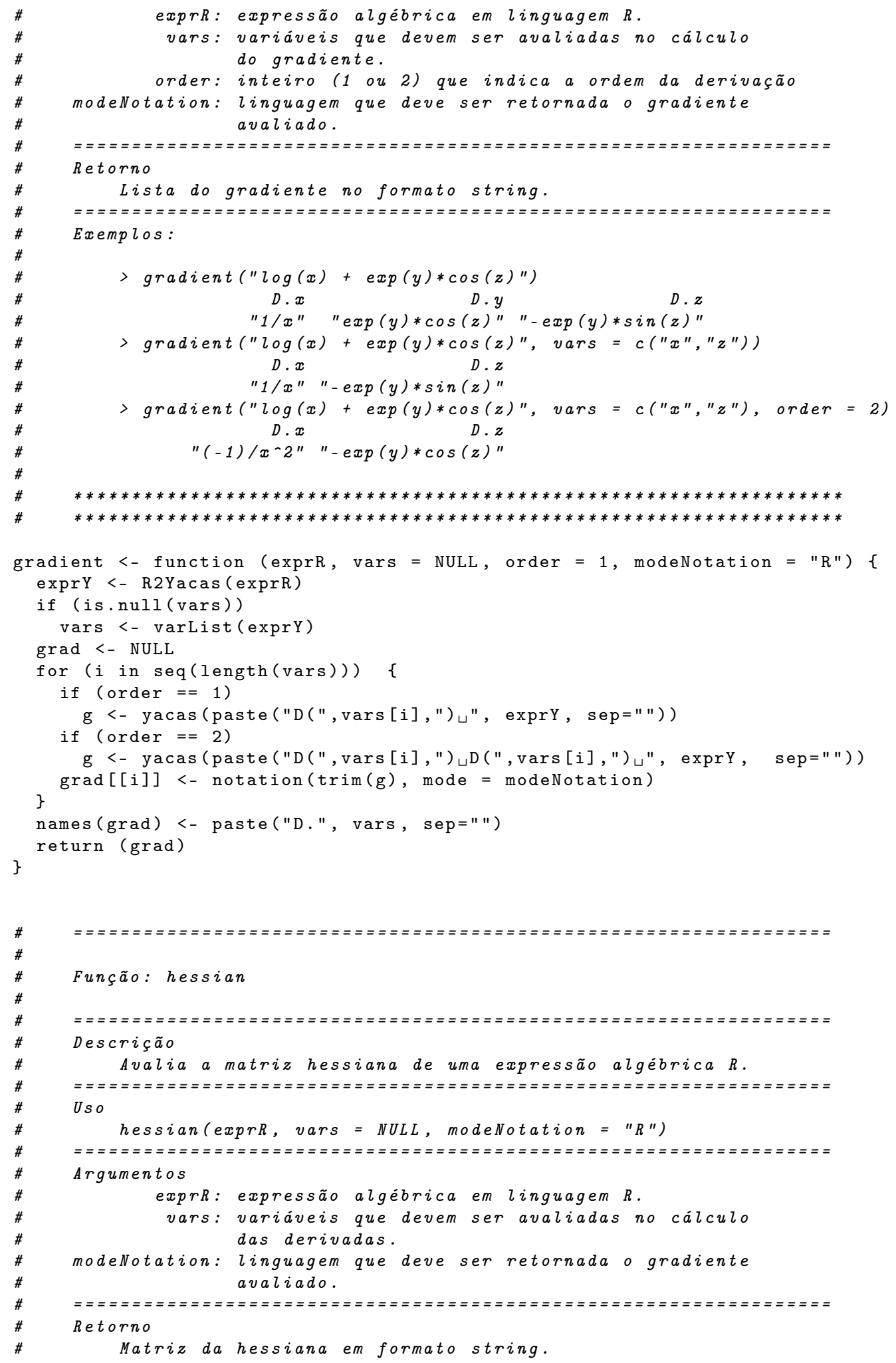




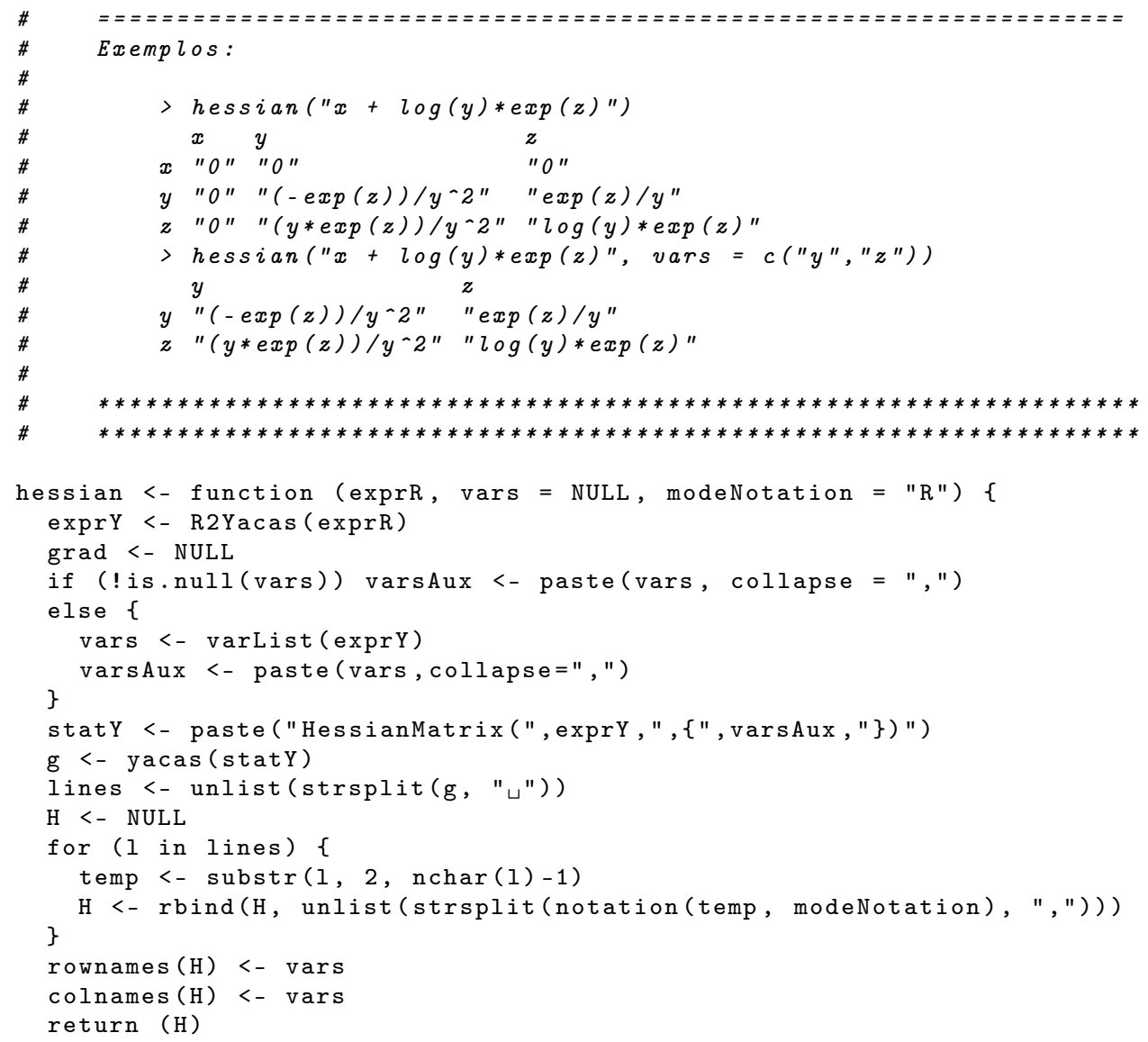




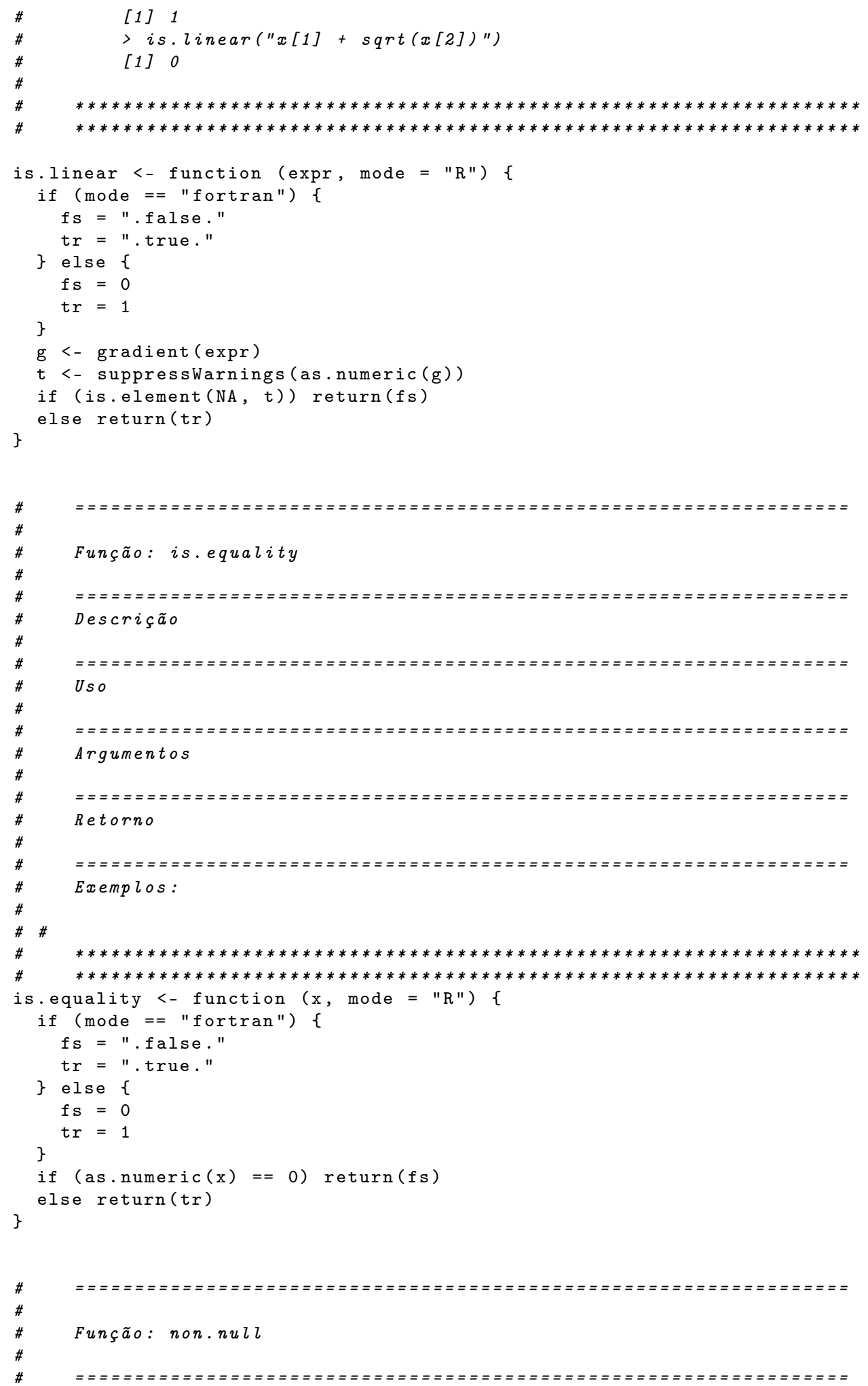


Descrição

Conta o número de elementos não nulos de uma matriz.

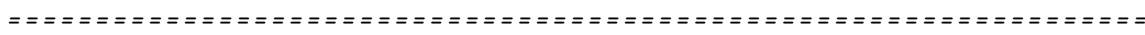

Uso

non. null(mat)

Argumentos

mat: matriz numérica.

Retorno

inteiro positivo

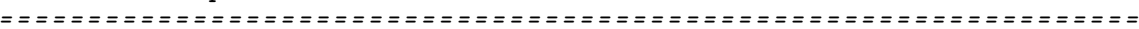

Exemplos:

$>A<-c b i n d(c(1,2), c(3,4))$

$>n \circ n \cdot n u l l(A)$

[1] 4

$>A<-c b i n d(c(0,2), c(3,0))$

$>$ non.null (A)

[1] 2

$>A<-c b i n d(c(0,2), c(N A, 0))$

$>n \circ n \cdot n u l l(A)$

[1] 2

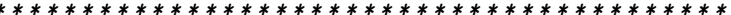

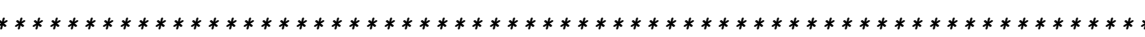

non.null<- function (mat) \{

A <- suppressWarnings (as.numeric (mat))

NAs <- sum(as.numeric (is.na(A)))

numbers <- sum(as.numeric $(A \quad !=0)$, na.rm = TRUE)

\}

return (NAs + numbers)

Função: indices

Descrif̧ão

Indica a ordem em que uma variável aparece numa expressão algébrica.

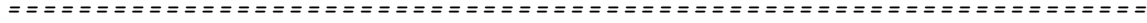

Uso

indices (expr, vars)

$=======$
Argumentos

expr: expressão algébrica.

vars: variáveis da expressão que devem ser indexadas.

Retorno

Vetor de inteiros que associa as variáveis indicadas à ordem em que elas ocorrem na expressão algébrica.

= = = = = = = = = = = = = = = = = = = = = = = = = = = = = = = = = = = = = = = = = = = = =

Exemplos:

$>$ indices(" $a * x+b / \log (y) ", c(" x ", " y "))$

[1] 24

$>\operatorname{indices}(" a * x+b / \log (y) ", c(" a "))$

[1] 1 


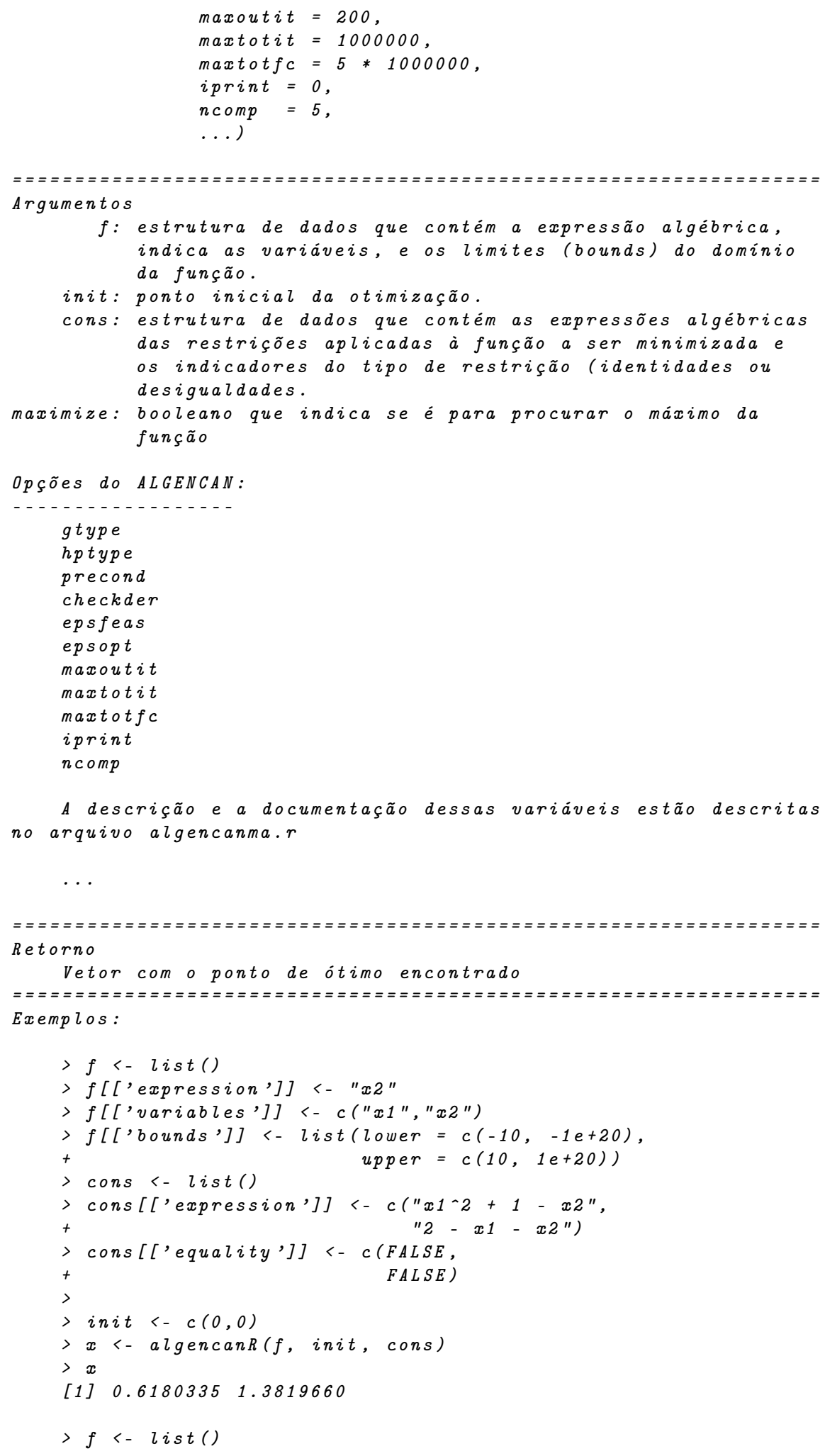




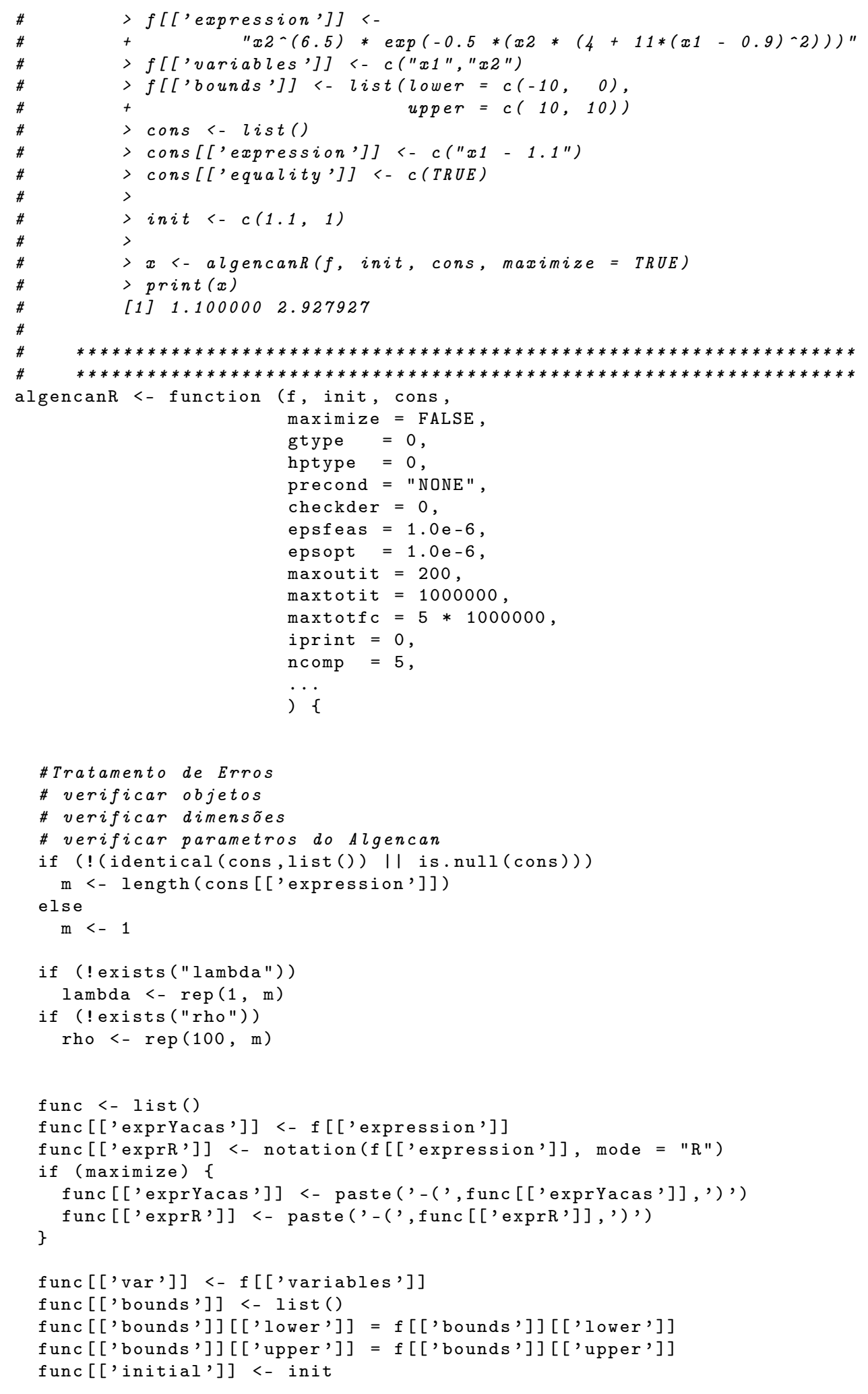




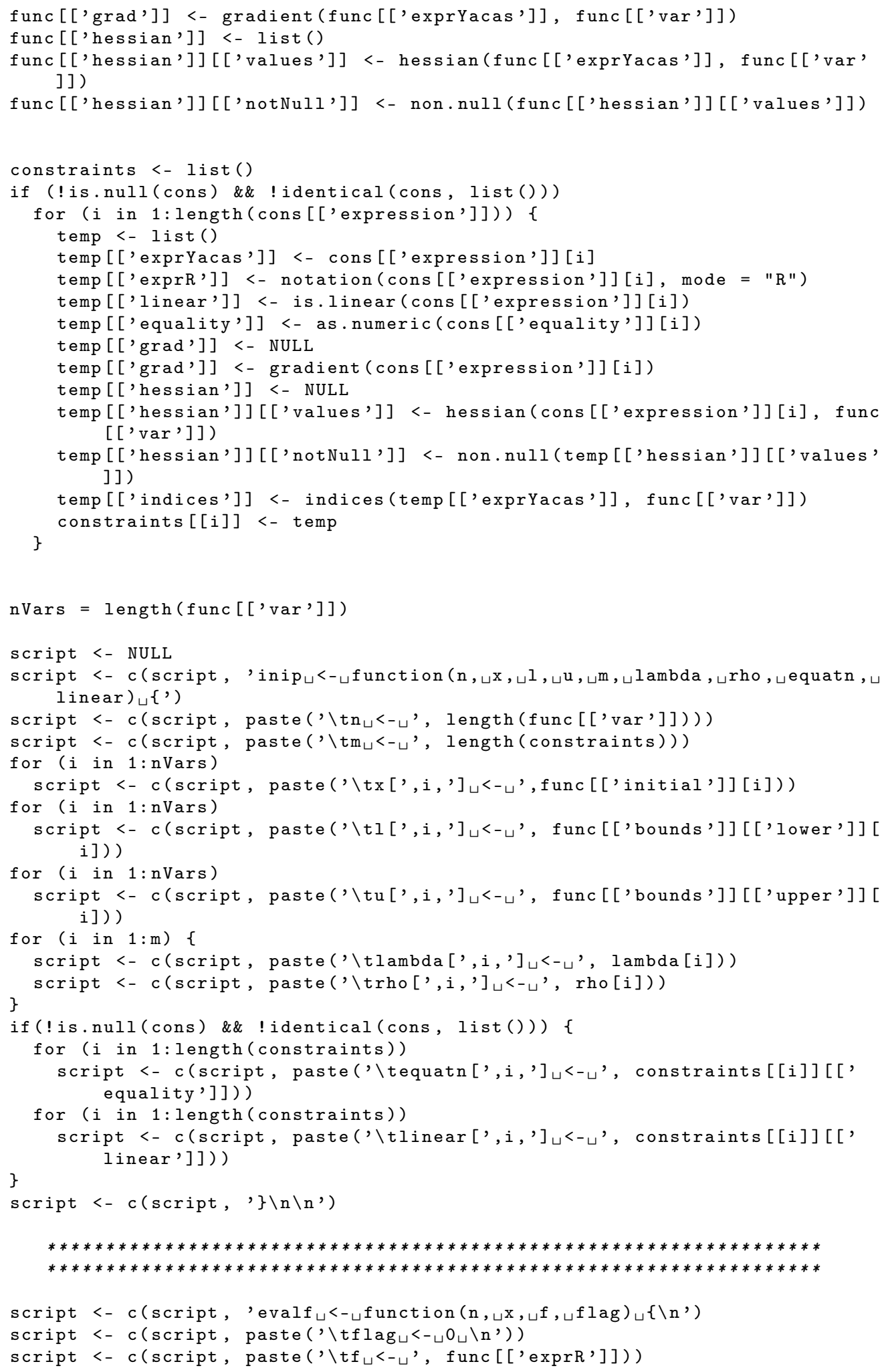




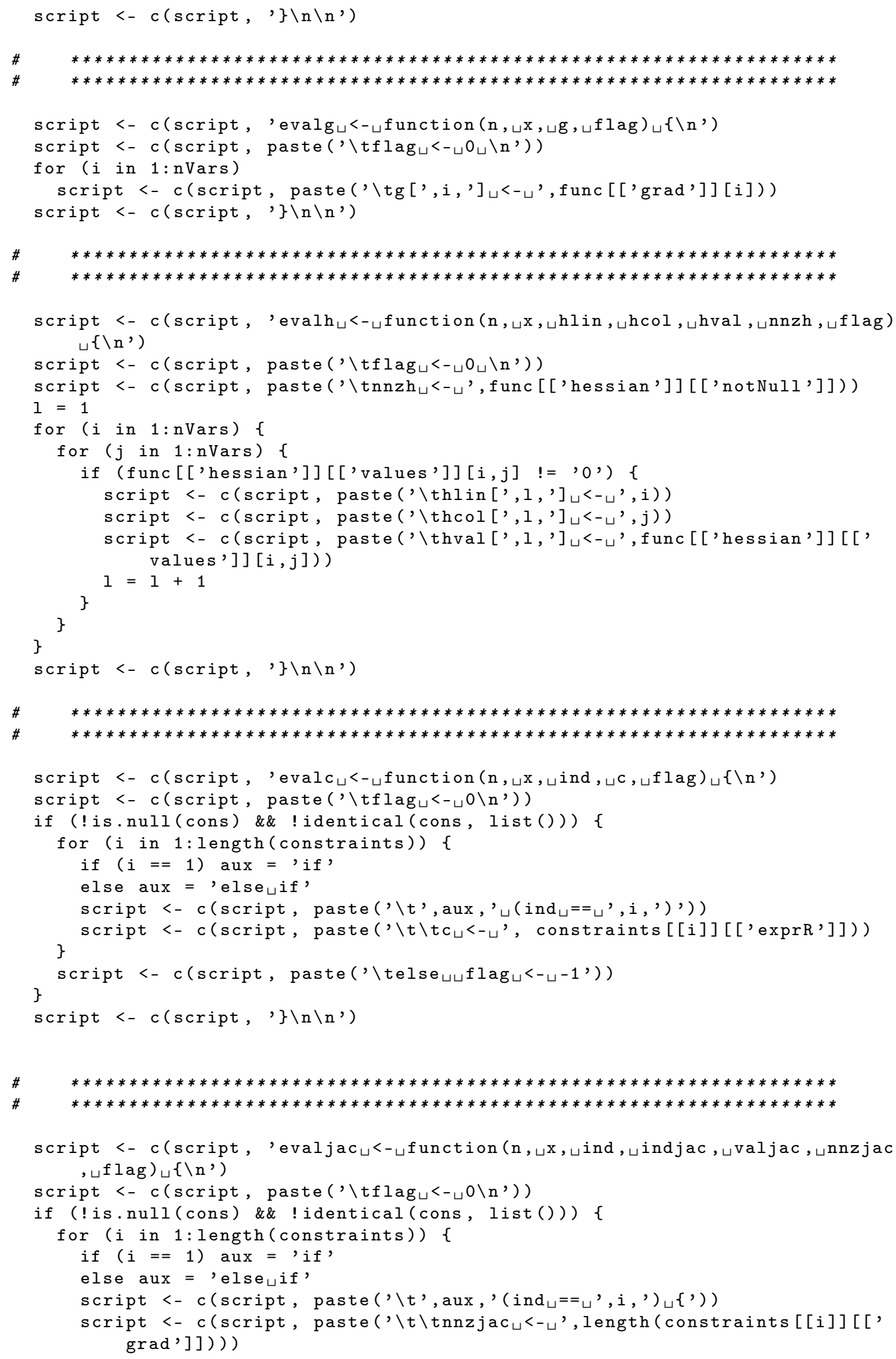




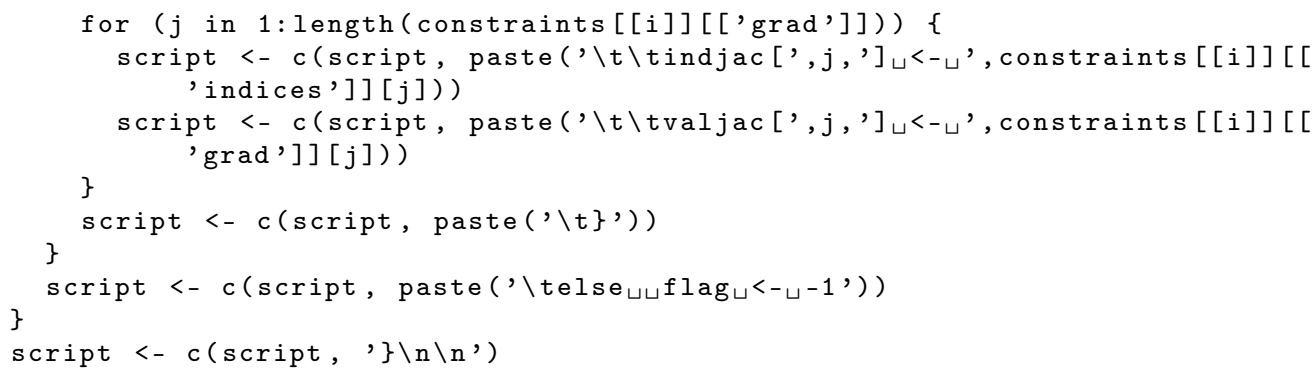

script <- c(script, ,endp $\sqcup<-\sqcup$ function $(n, \sqcup x, \sqcup l, \sqcup u, \sqcup m, \sqcup l a m b d a, \sqcup r h o, \sqcup$ equatn, linear) $\left\{^{\prime}\right.$ ') 


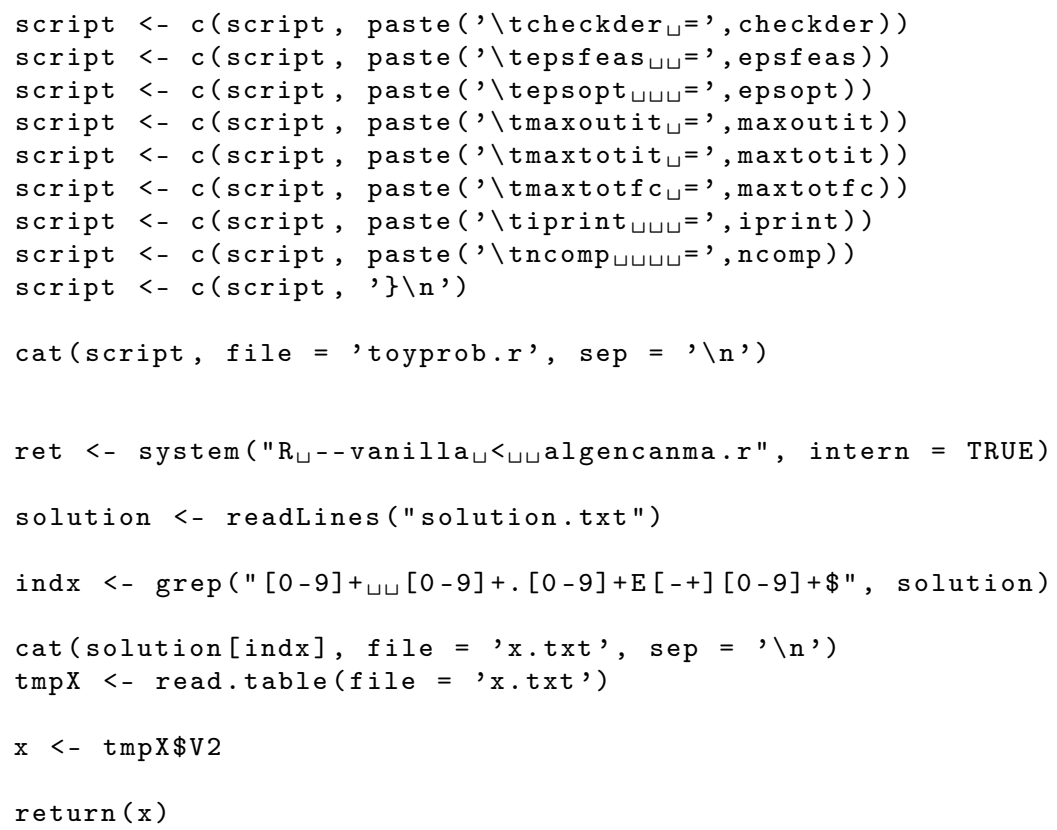

Listing A.1: yacas.r

\section{A.2 fbst.r}

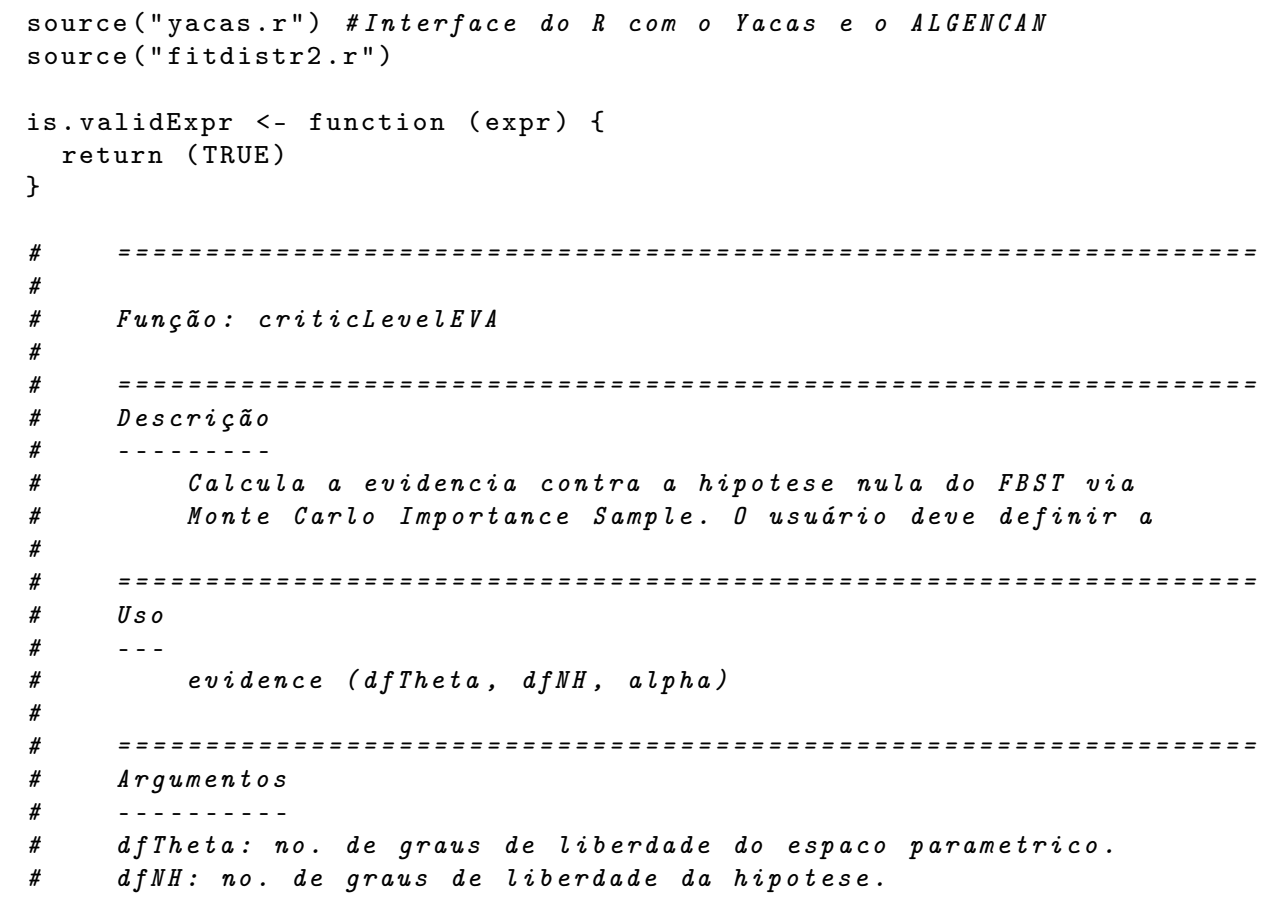

\# 


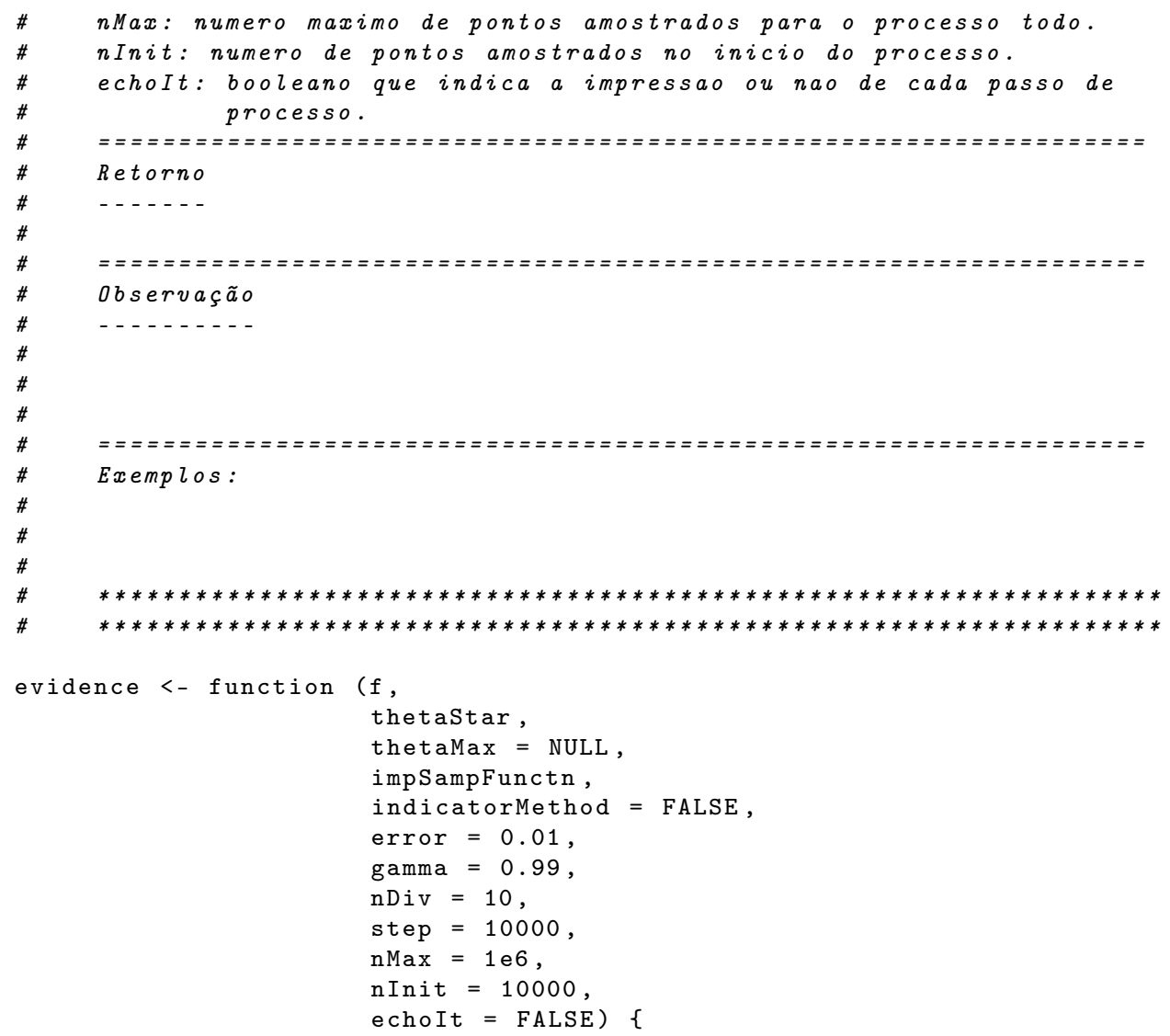




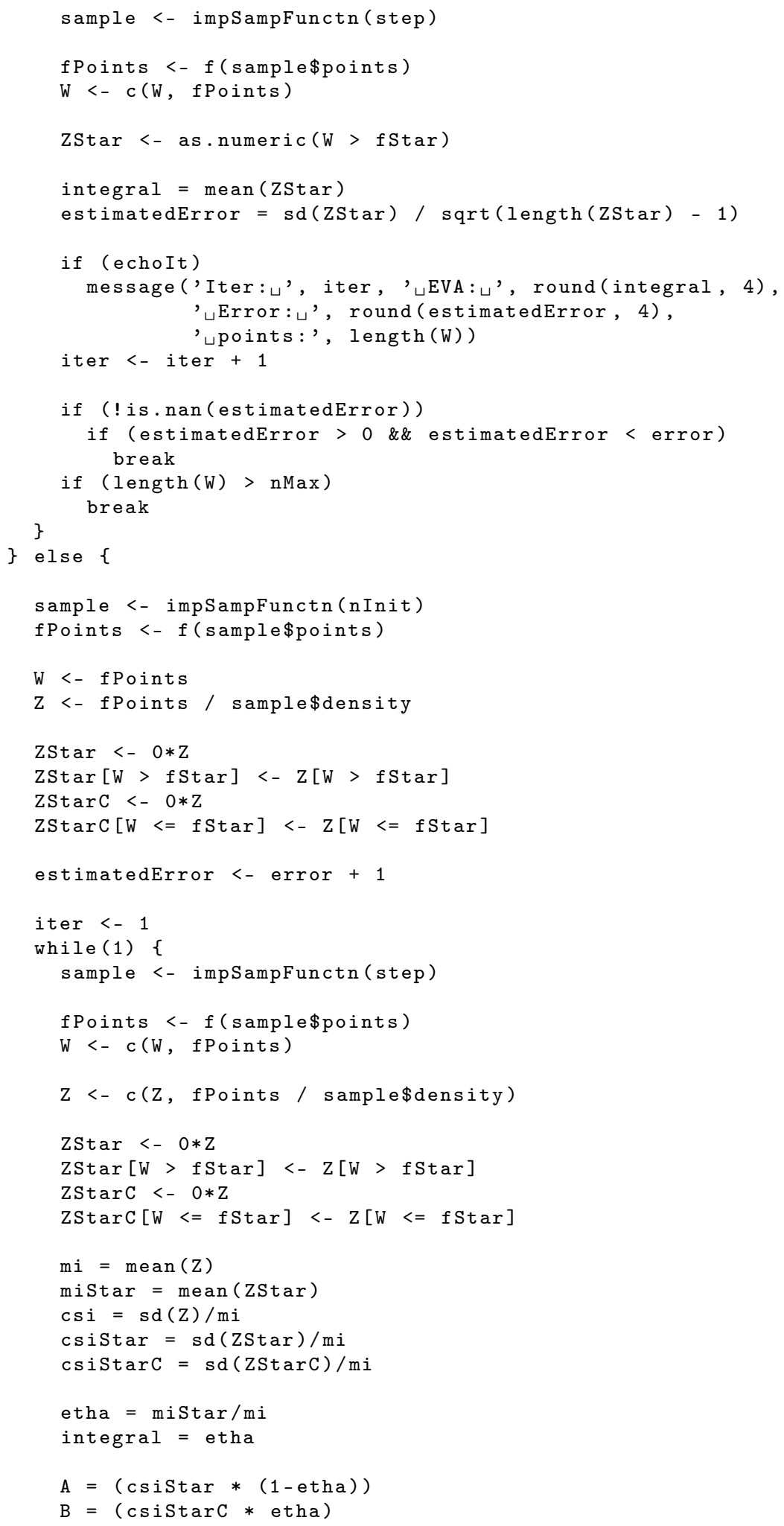




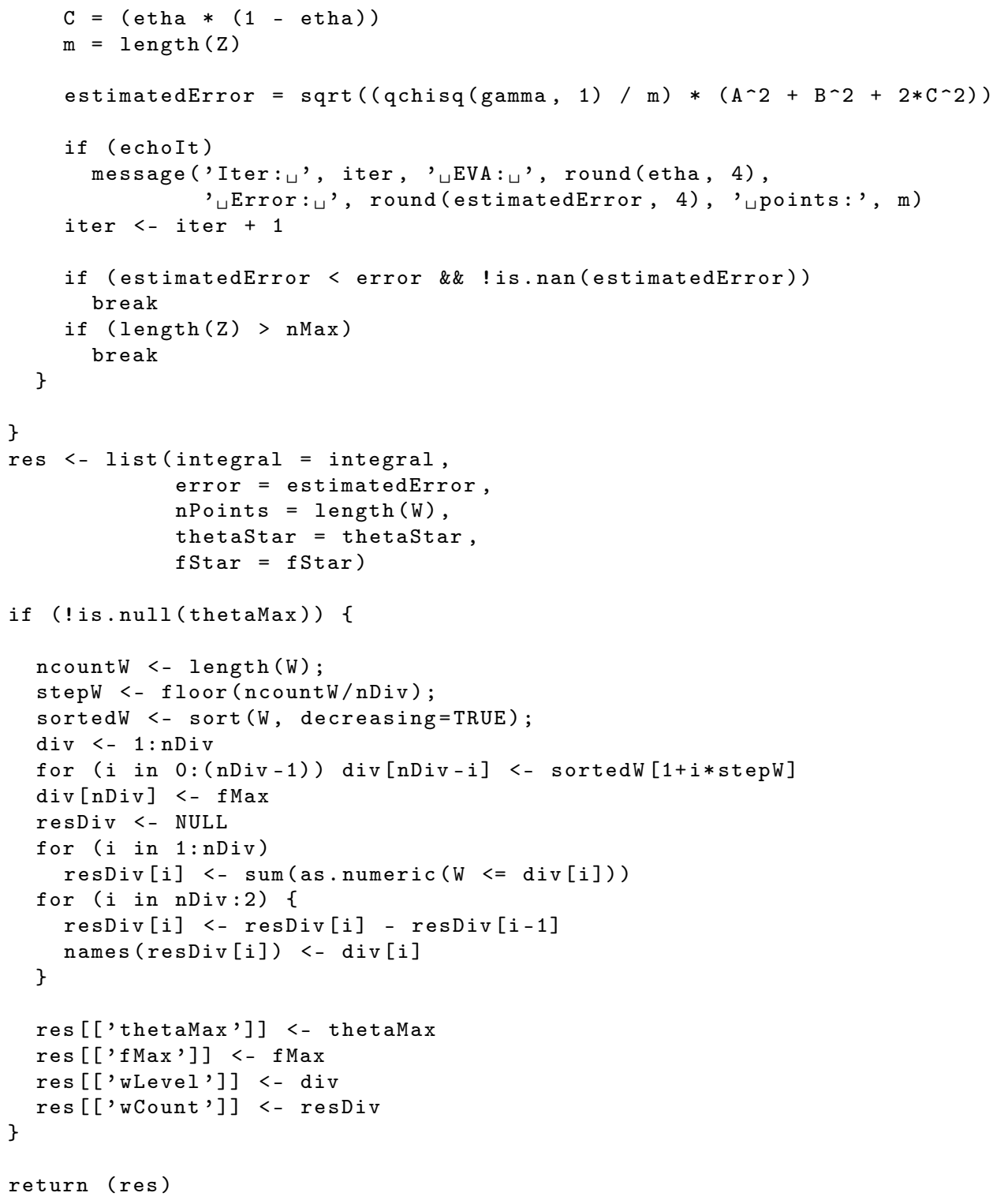


Para o cálculo do valor de evidência do FBST, são necessários dois passos fundamentais:

- o primeiro consiste na busca do ponto de máxima verossimilhança sobre a hipótese nula (HO), denominado theta*. - O segundo é a avaliação da integral da verossimilhança, sobre a região dos pontos do espaço paramétrico que possuem valores na imagem superiores ao valor da imagem no ponto thet $a *$.

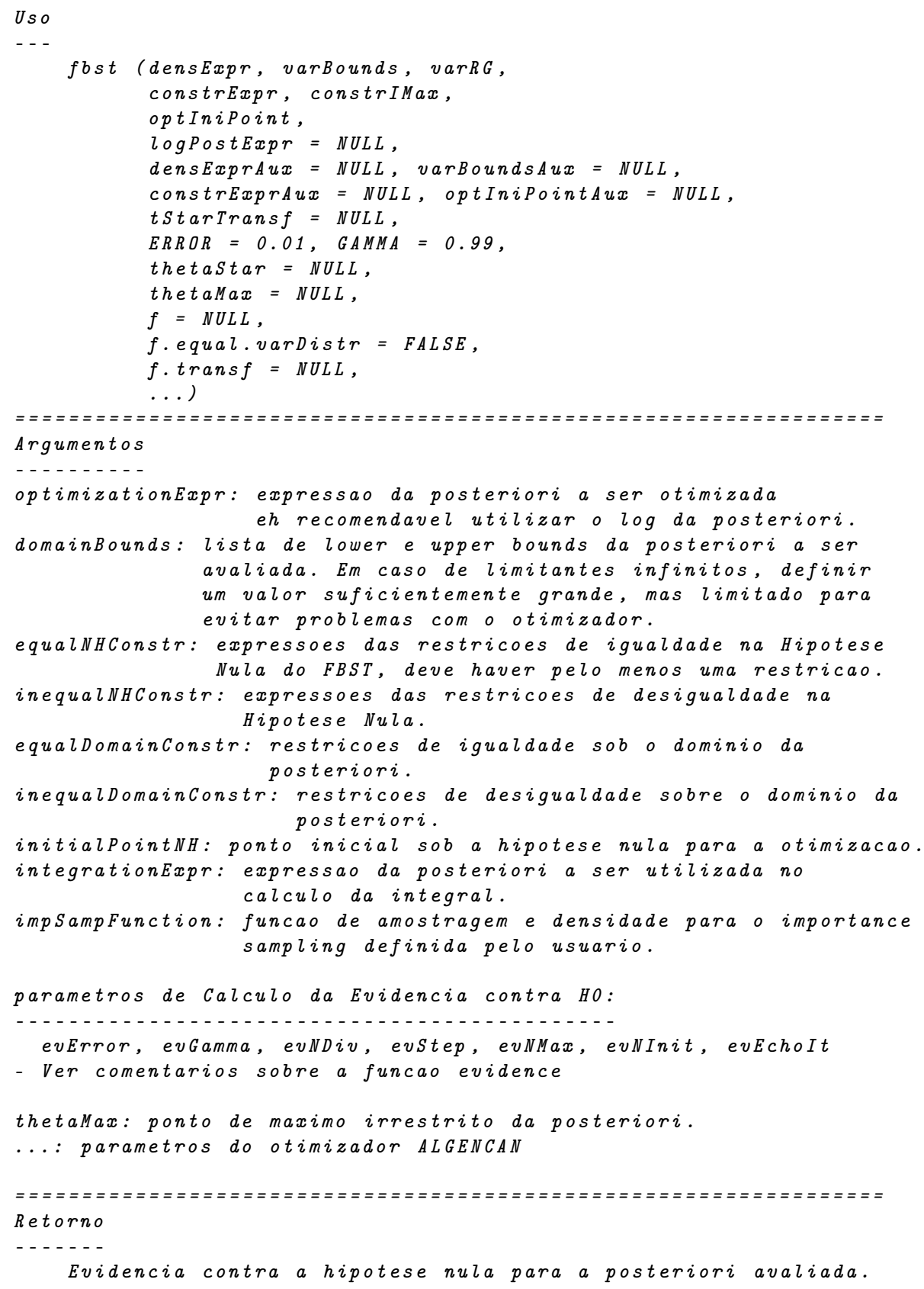


fbst <- function (optimizationExpr,

domainBounds,

equalNHConstr

inequalNHConstr = NULL,

equalDomainConstr = NULL,

inequalDomainConstr = NULL,

initialPointNH,

integrationExpr = paste("exp(", optimizationExpr,")"),

impSampFunction,

indicatorMethod $=$ FALSE,

evError $=0.01$,

evGamma $=0.99$,

evNDiv $=10$,

evstep $=1000$

evNMax $=5$ e 5 ,

evNInit $=9000$,

evEchoIt $=$ FALSE,

thetaMax = NULL,

...) \{

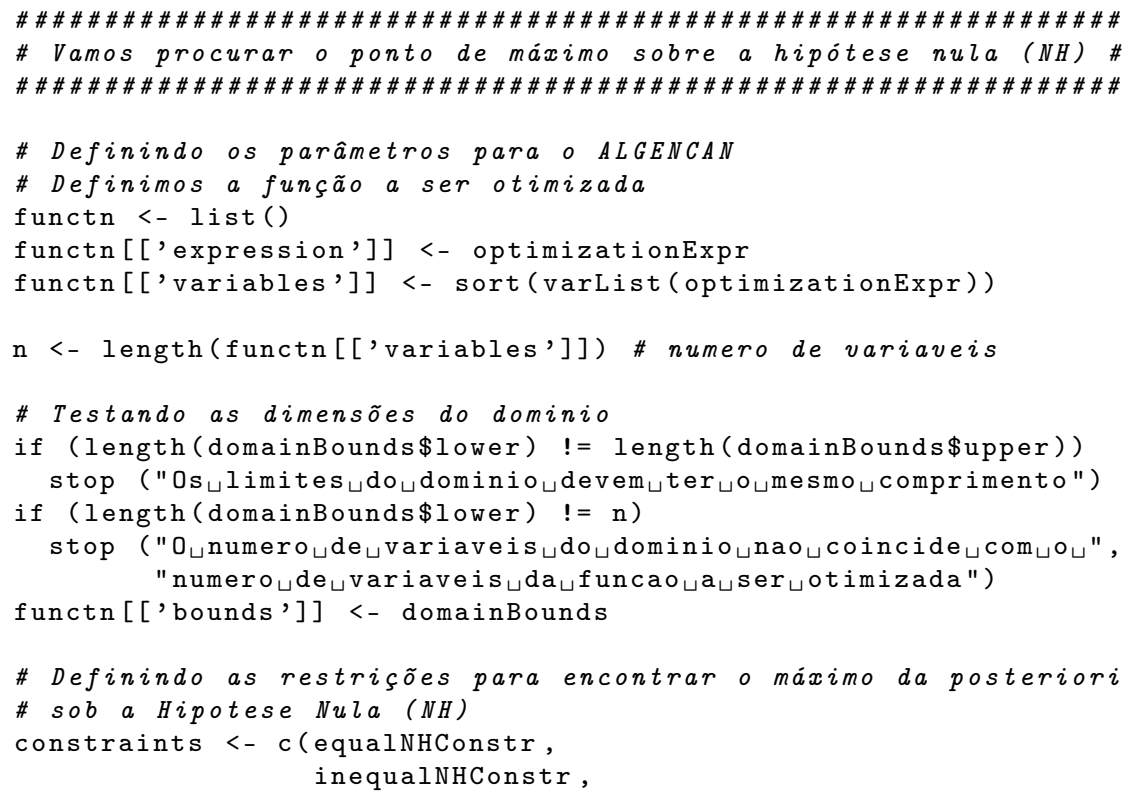


equalDomainConstr,

inequalDomainConstr)

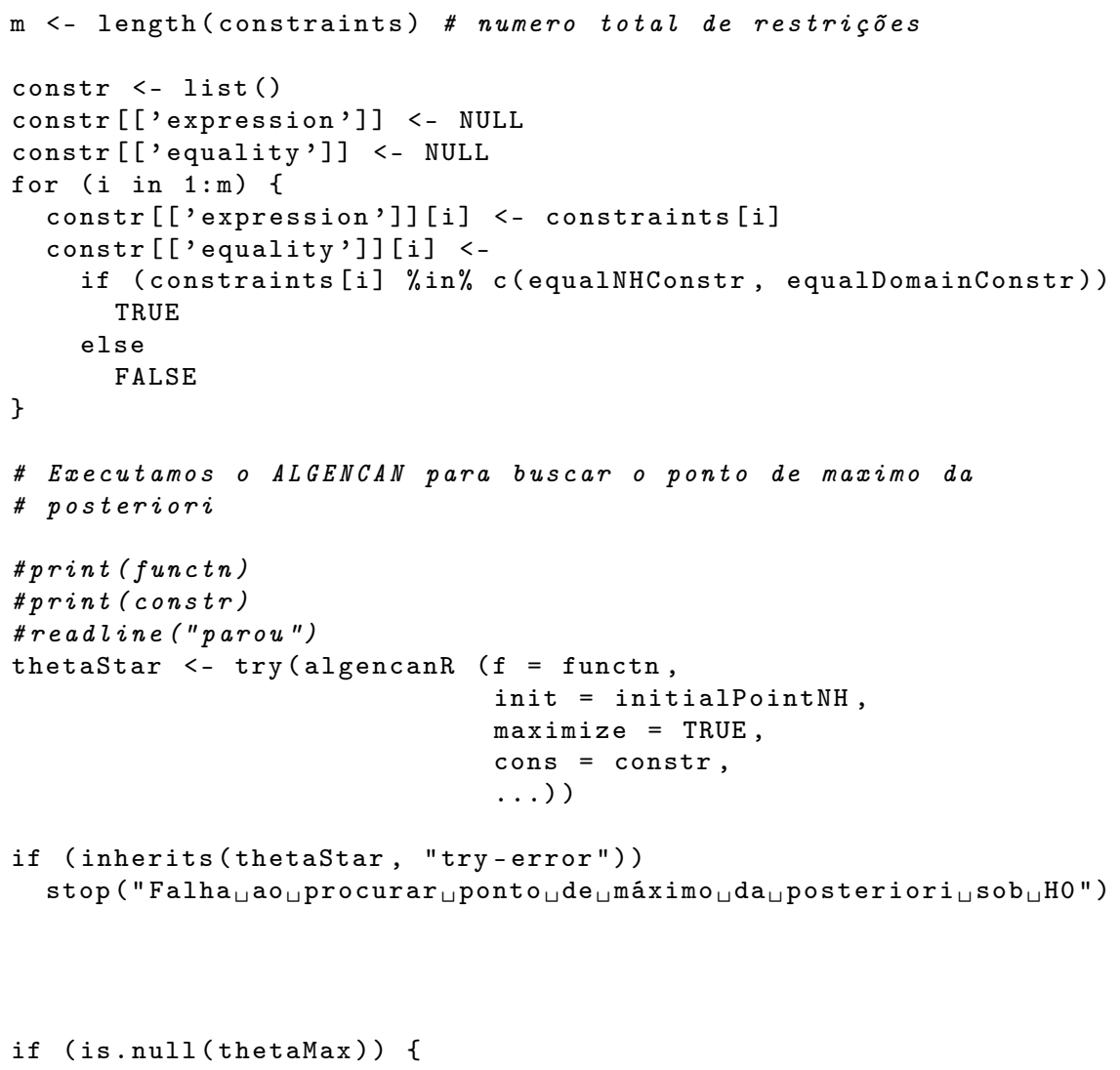




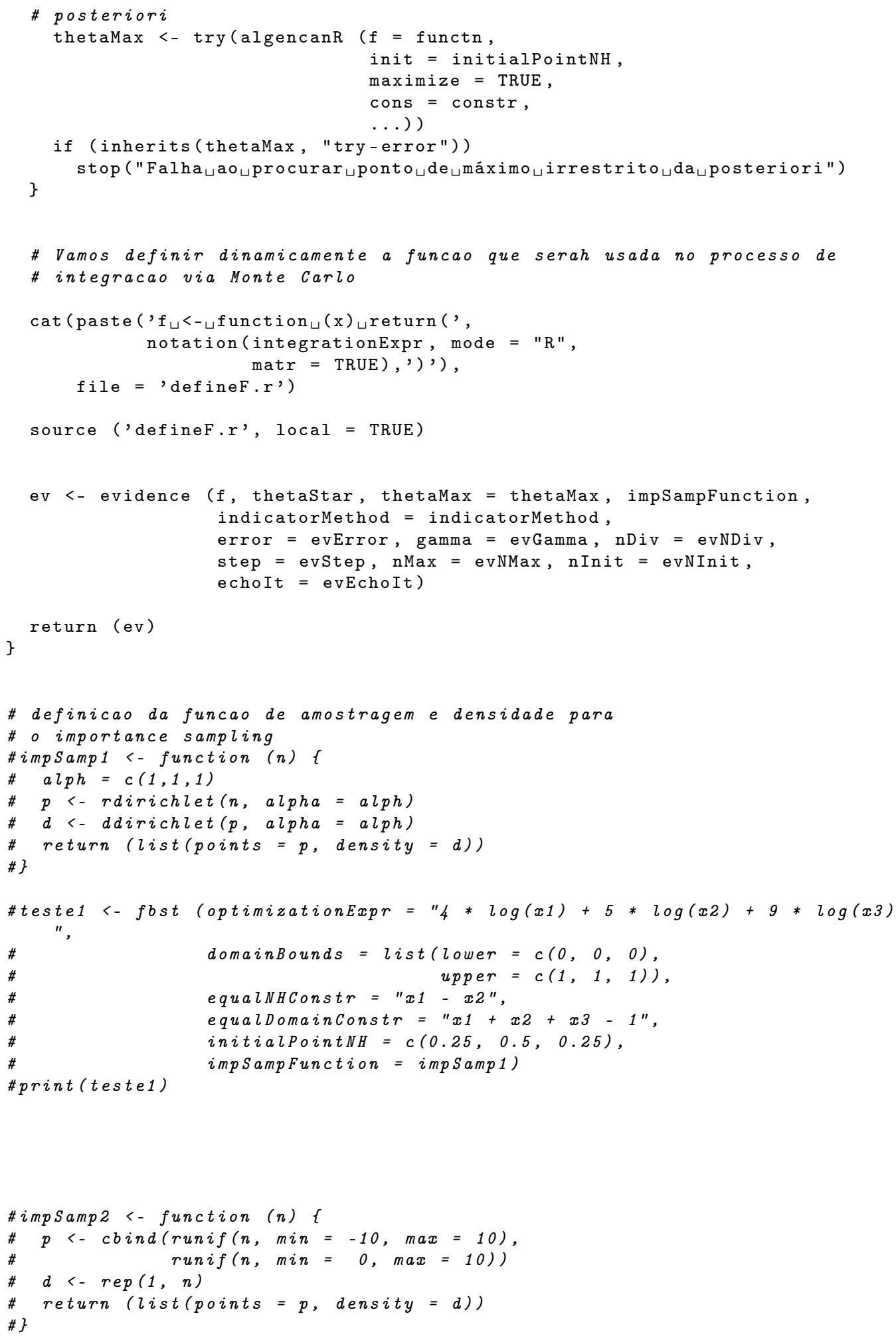




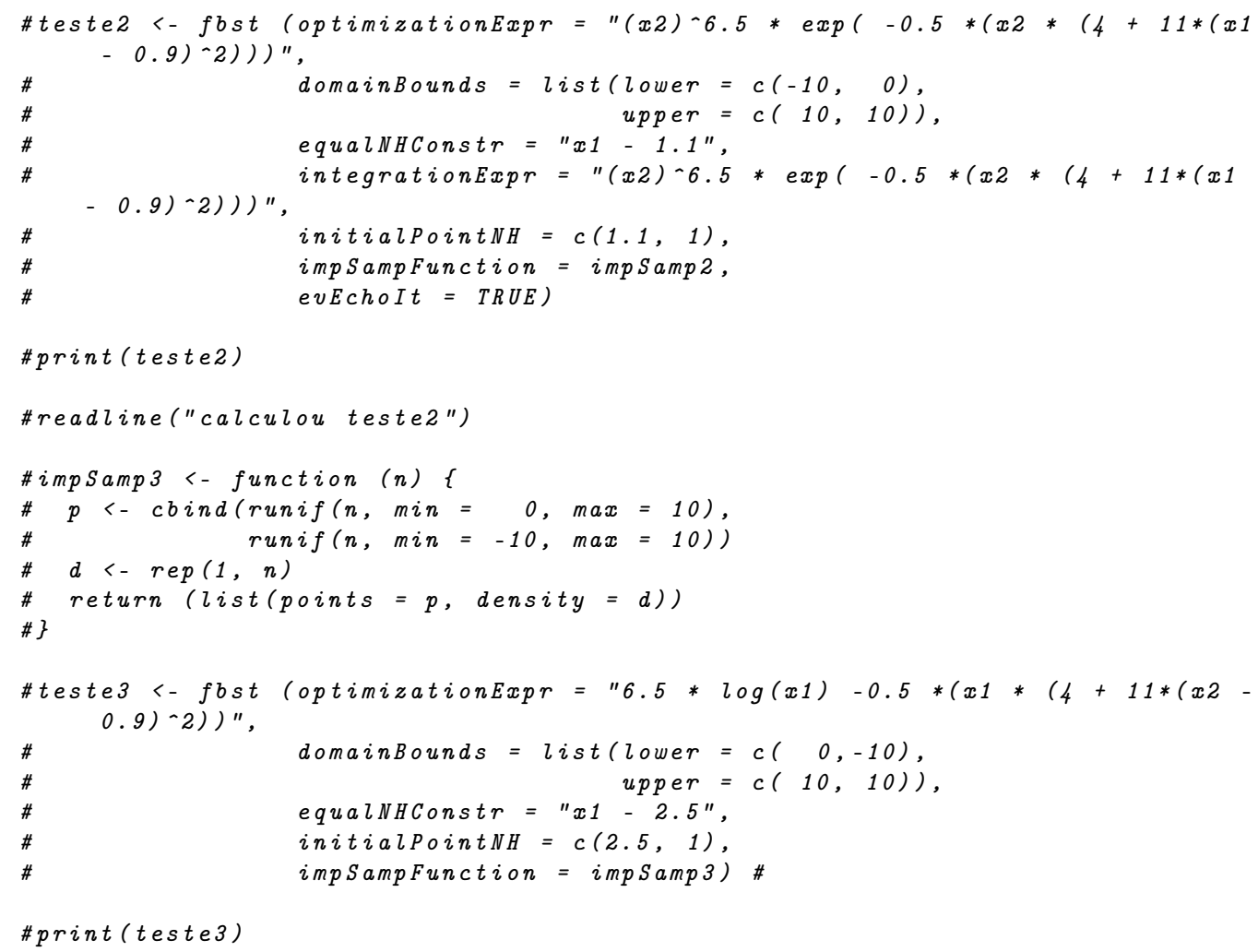




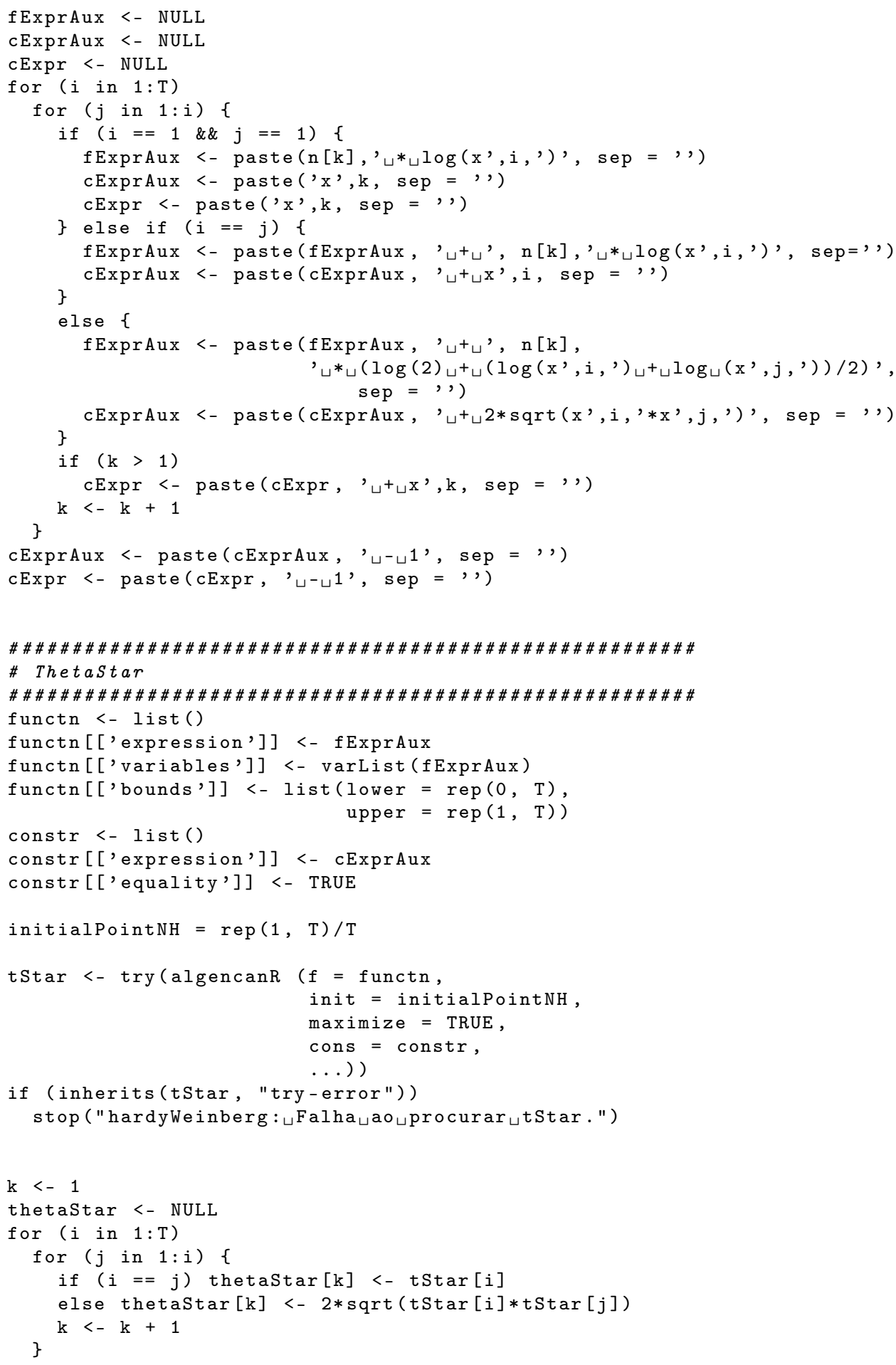




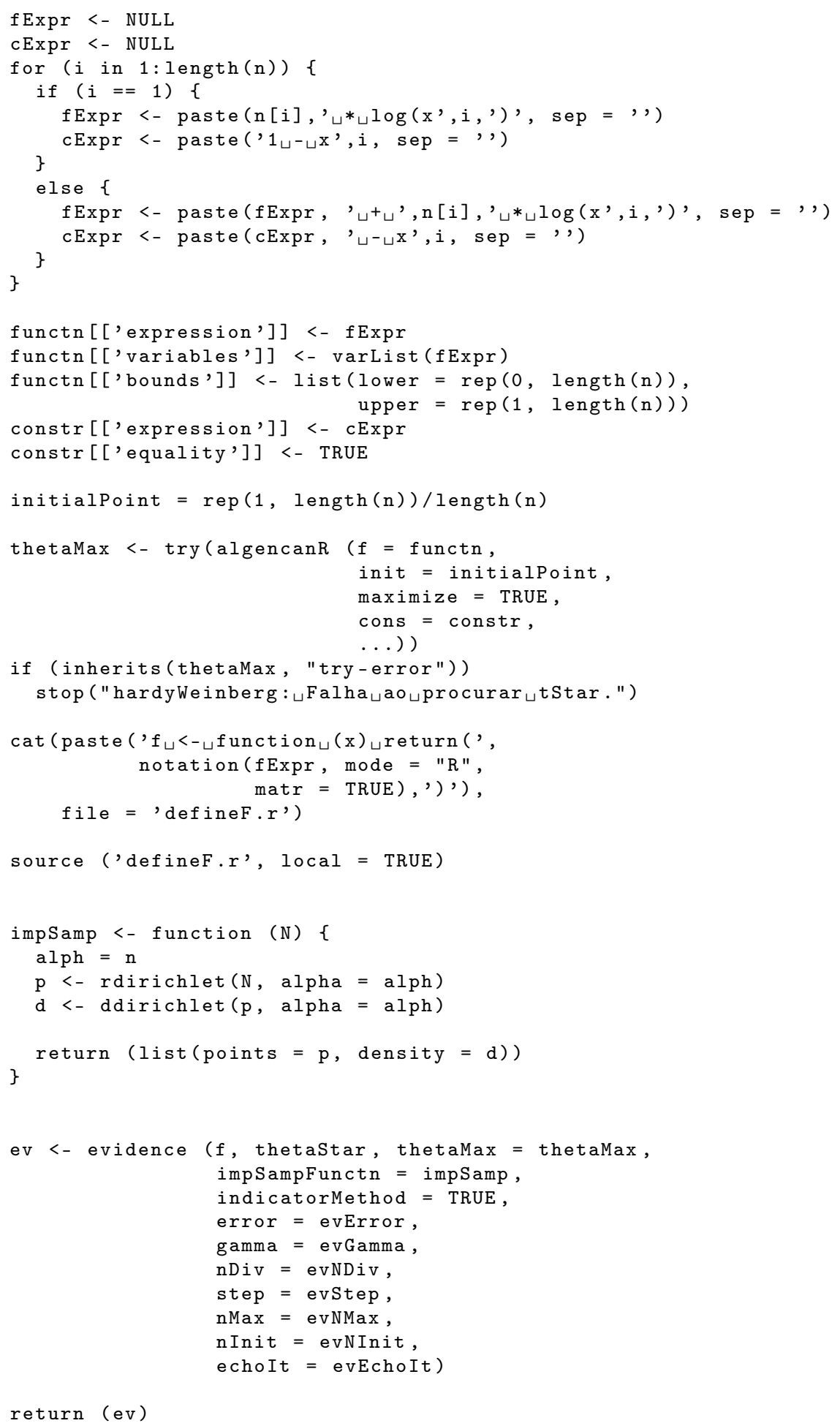




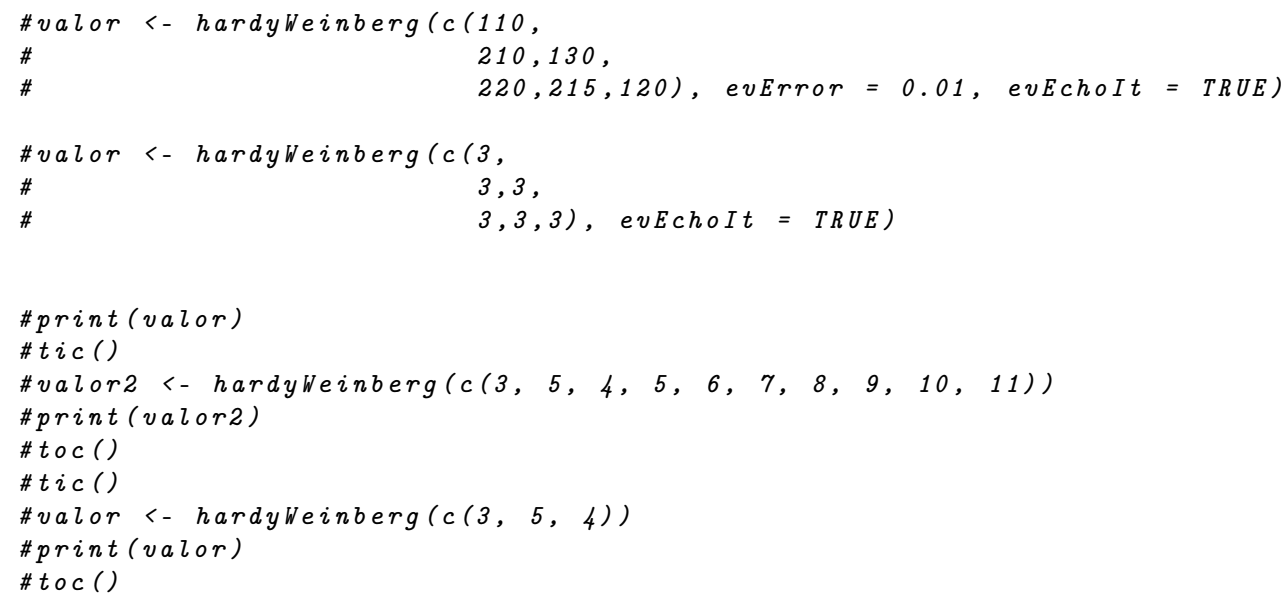

Listing A.2: fbst2.r

\section{A.3 fitdistr2.r}

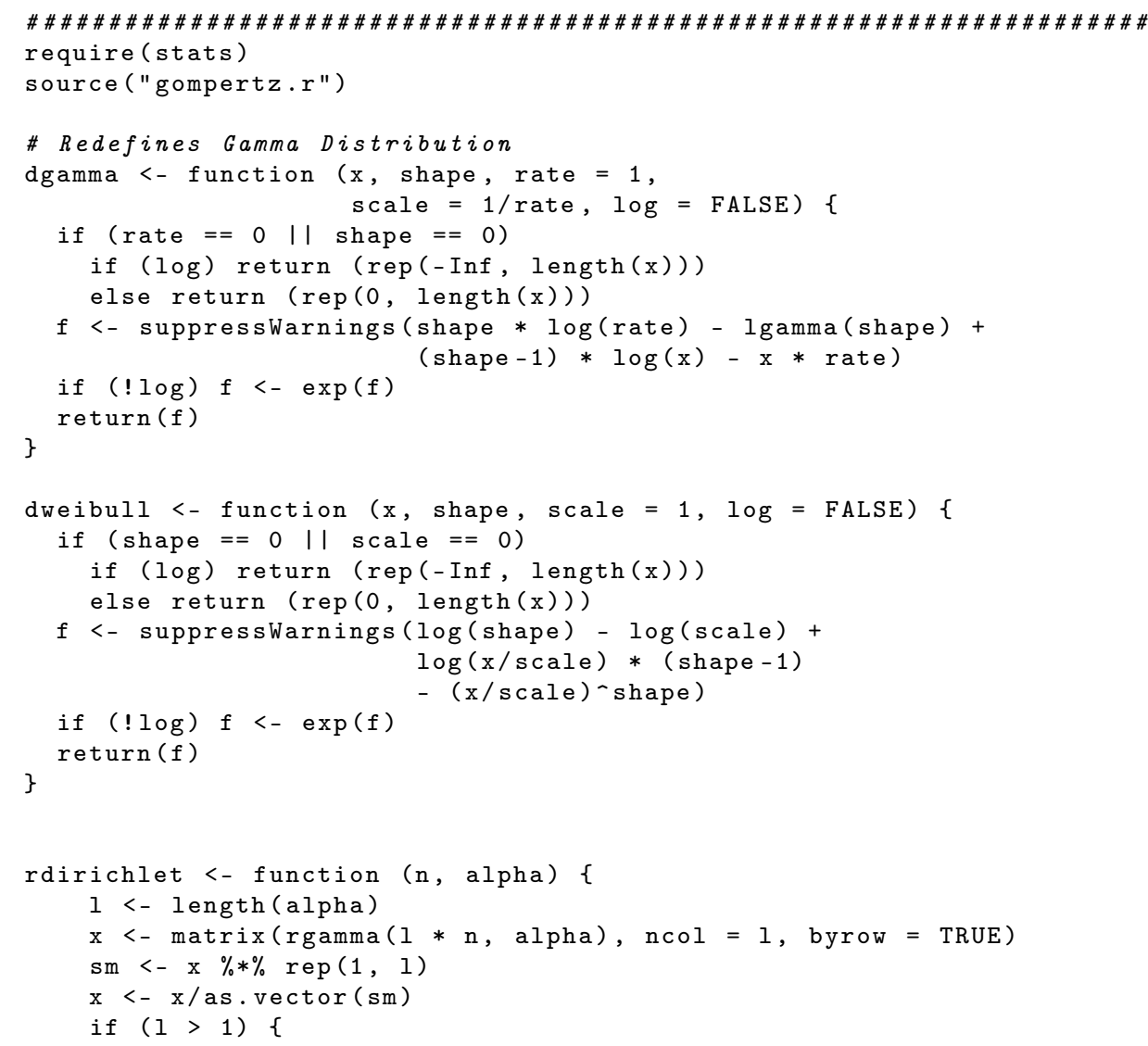




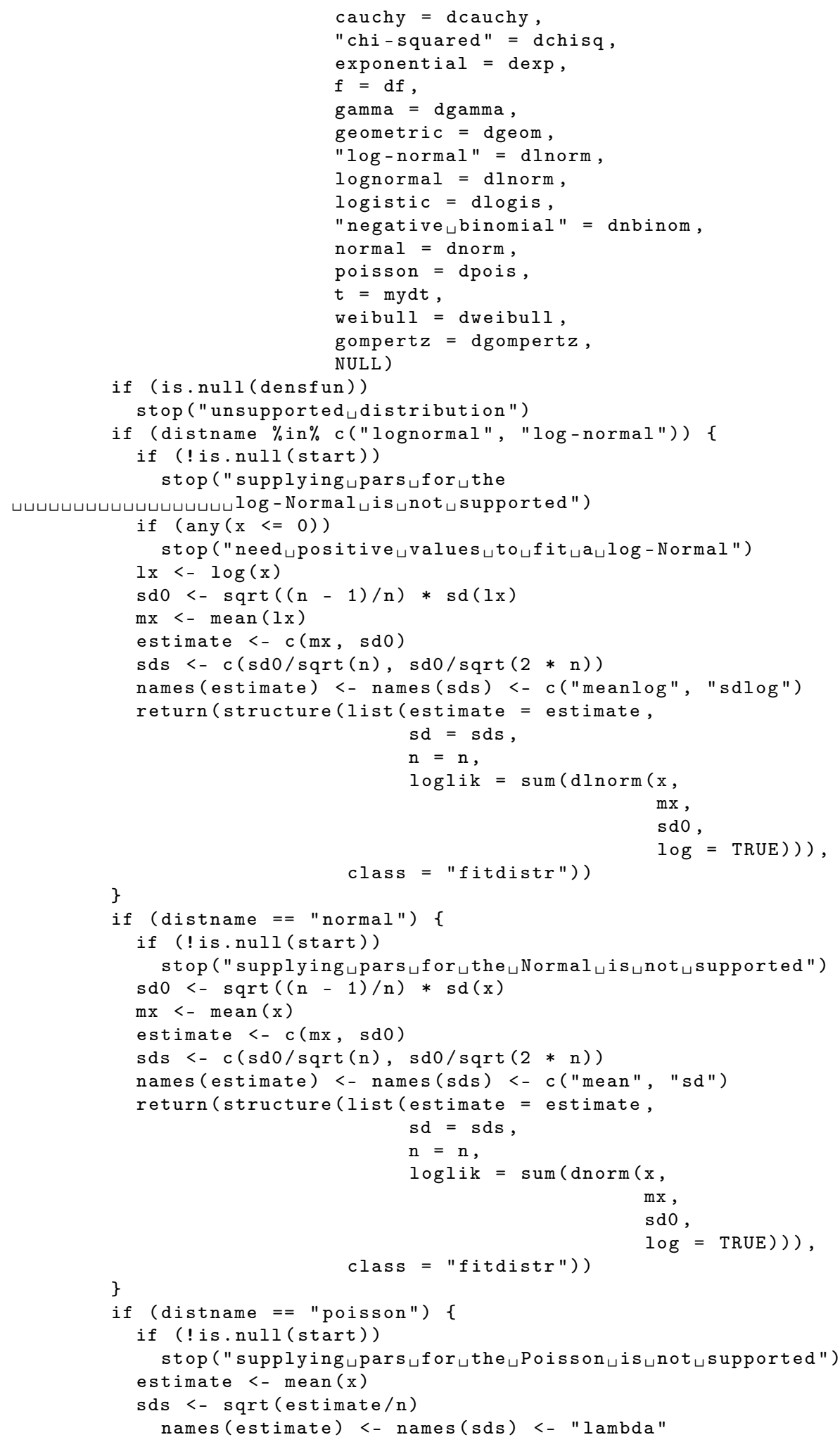




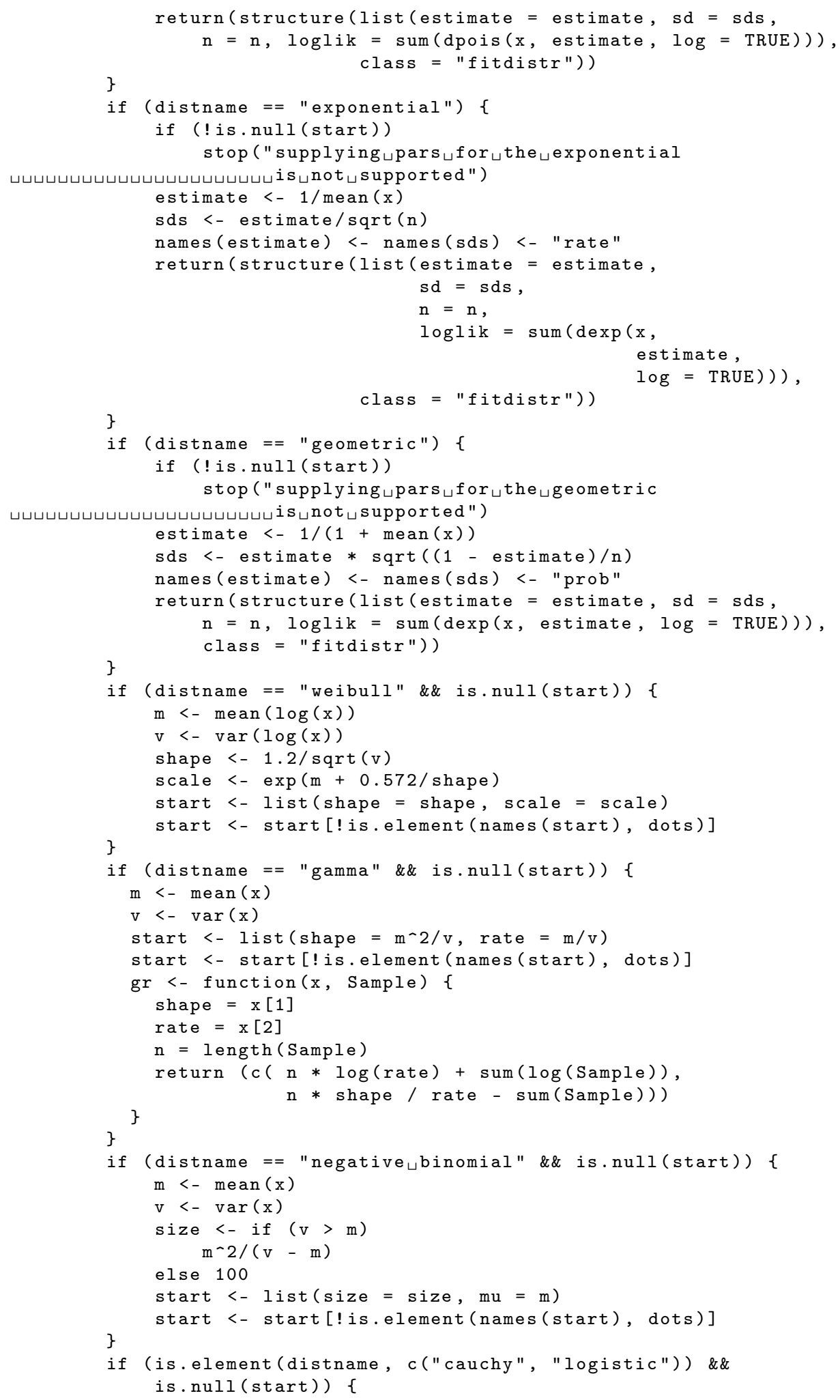




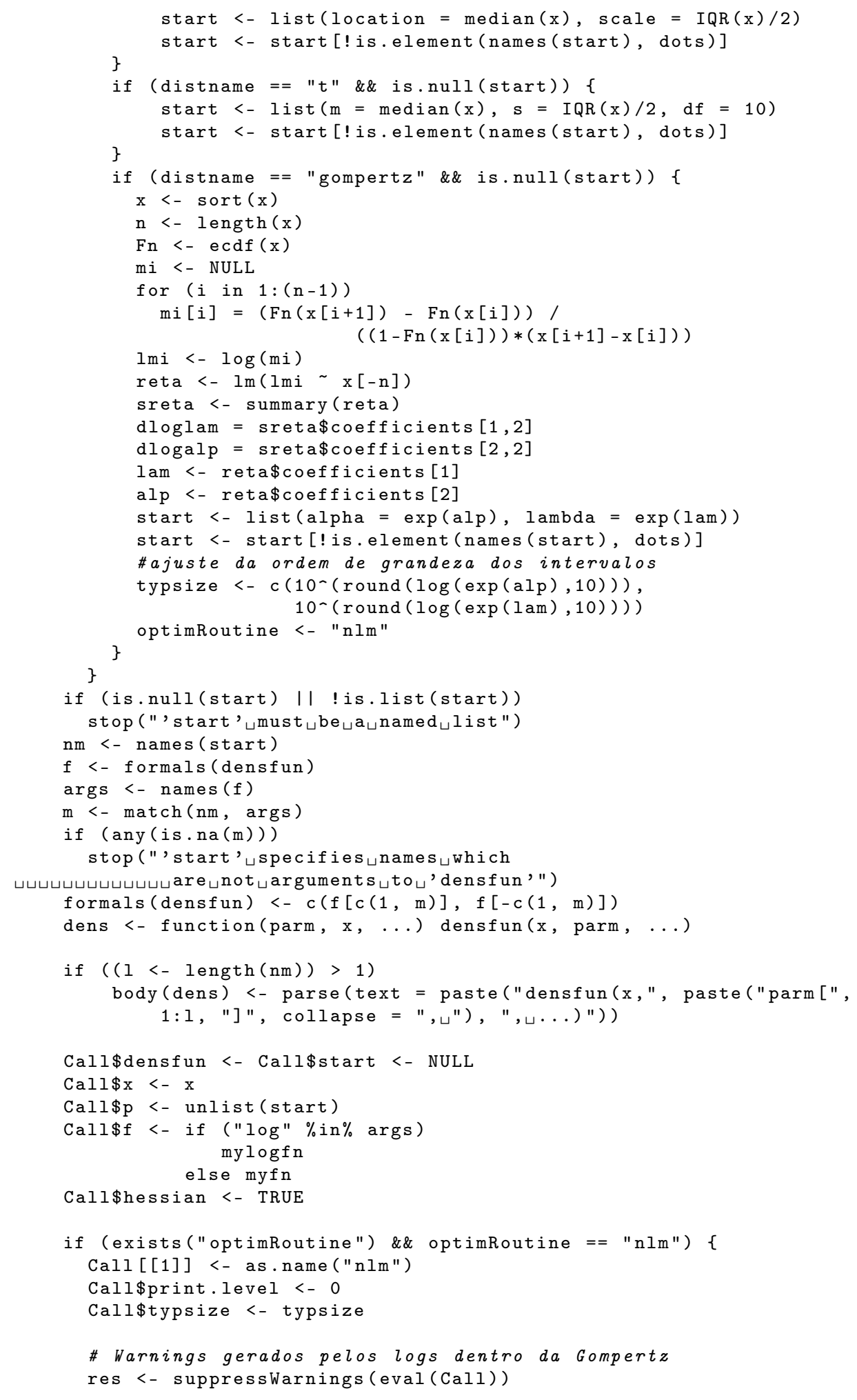




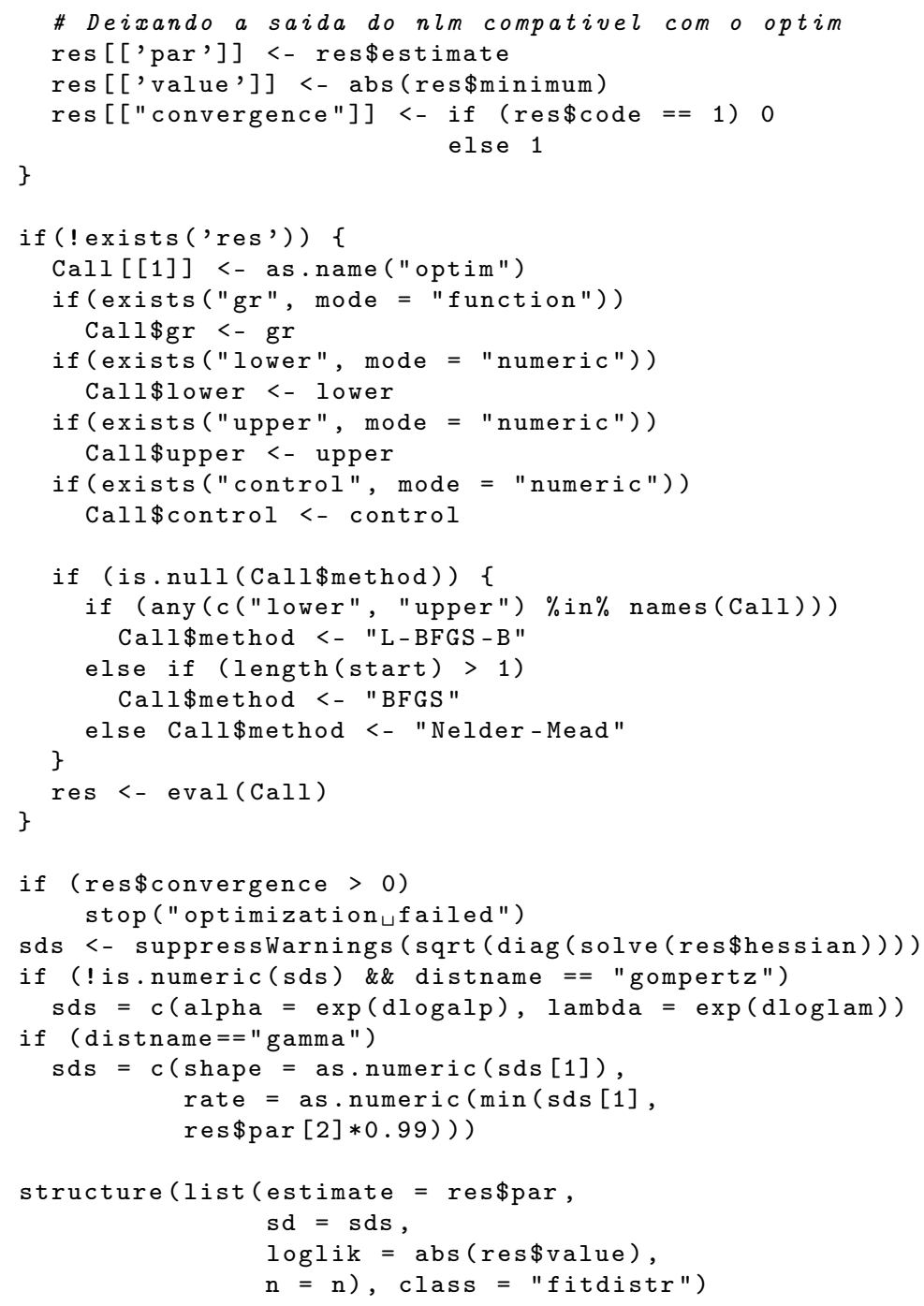

Listing A.3: fitdistr2.r

\section{A.4 plotasurf.r}

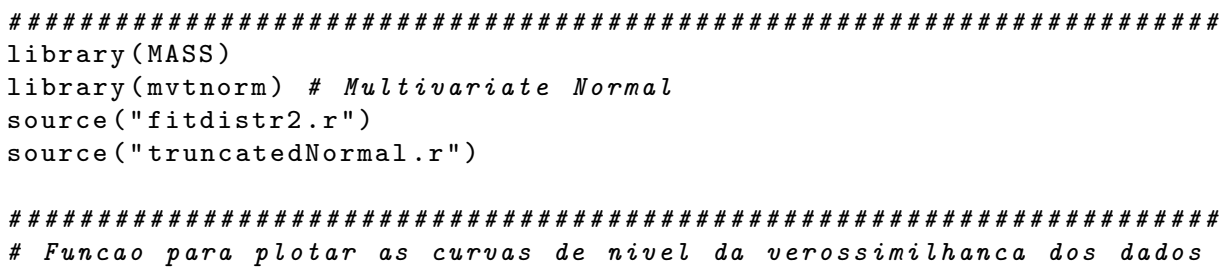




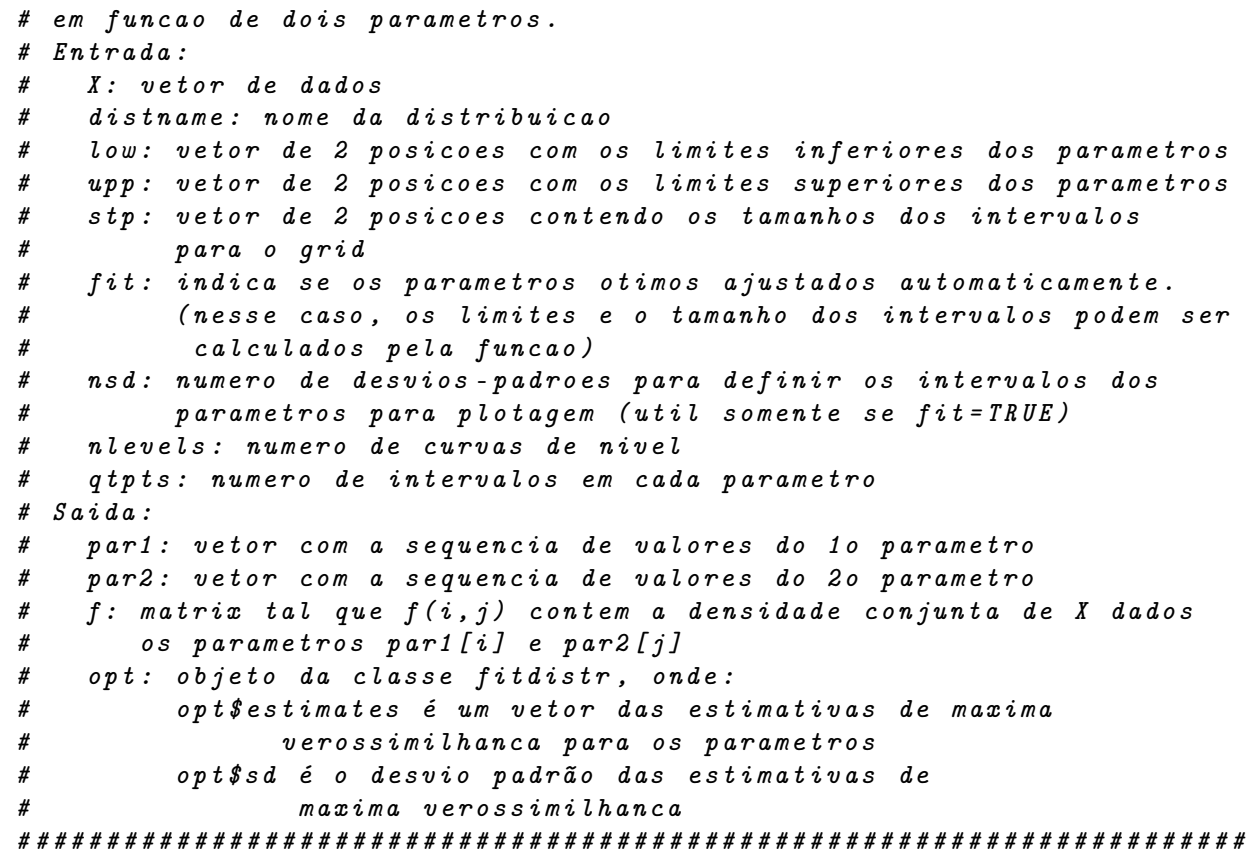

paramLikeContour <- function (X, distname, low $=$ NULL, upp $=$ NULL, stp $=$ NULL fit $=$ TRUE, nsd $=3$, distmin $=0$, nlevels $=10$, qtpts $=200$ priori $=$ NULL) \{

if (! is.character (distname))

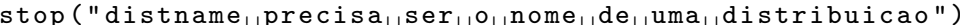

densfun <- switch(tolower(distname),

beta = "dbeta",

\#cauchy = "dcauchy",

"chi-squared" = "dchisq"

\#exponential = "dexp",

$f=" d f "$,

gamma = "dgamma",

"log-normal" = "dlnorm",

lognormal = "dlnorm",

logistic = "dlogis"

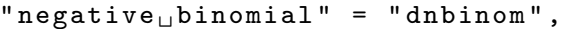
normal = "dnorm",

$\# t=$ "mydt"

uniform = "dunif",

weibull = "dweibull",

gompertz = "dgompertz", NULL )

if (is.null (densfun))

stop ("unsupported $d_{\text {distribution") }}$

if (is.null(low))

epsilon <- 1 e-50

low <- switch (tolower (distname),

beta = c(epsilon, epsilon), 


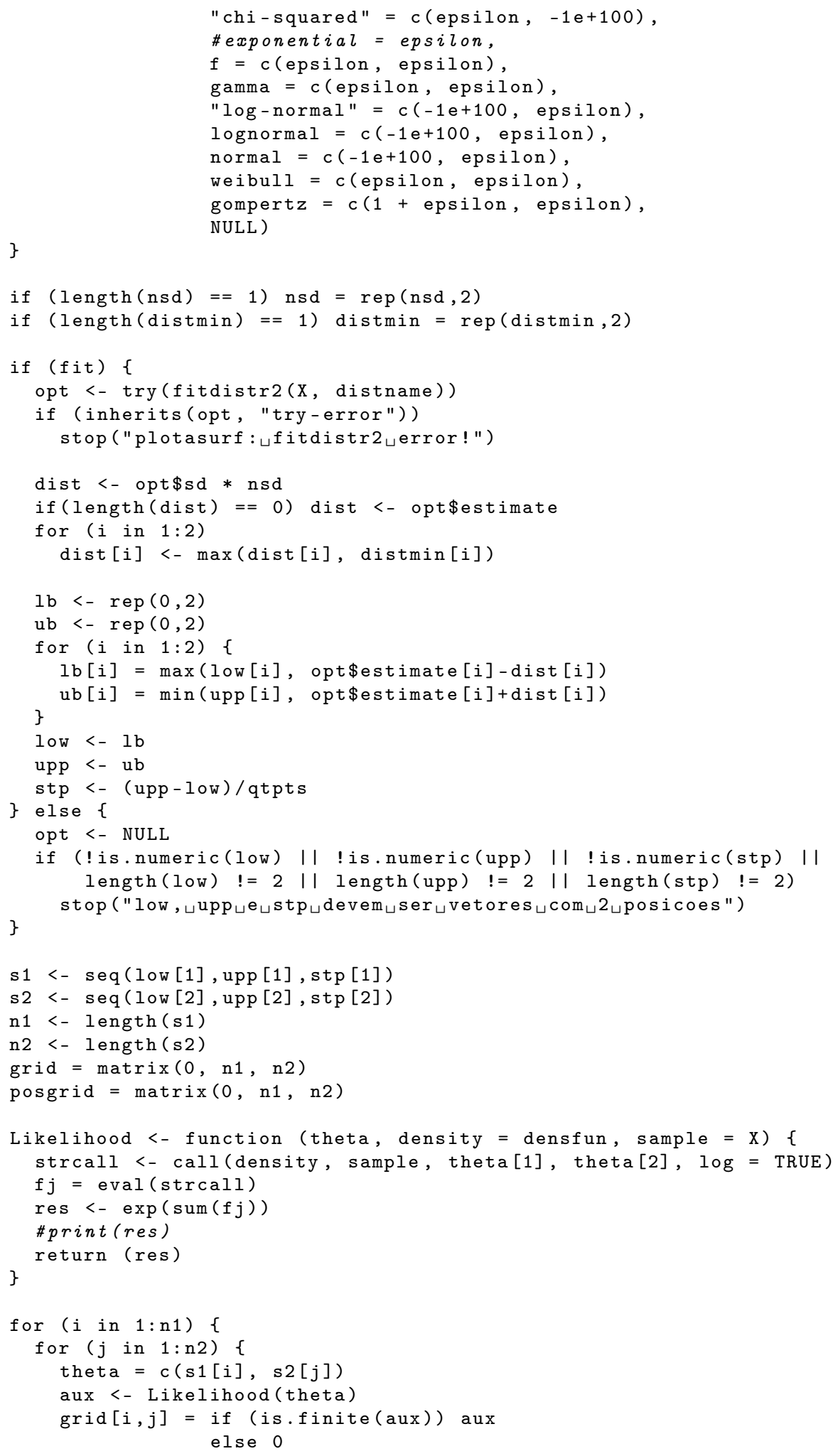




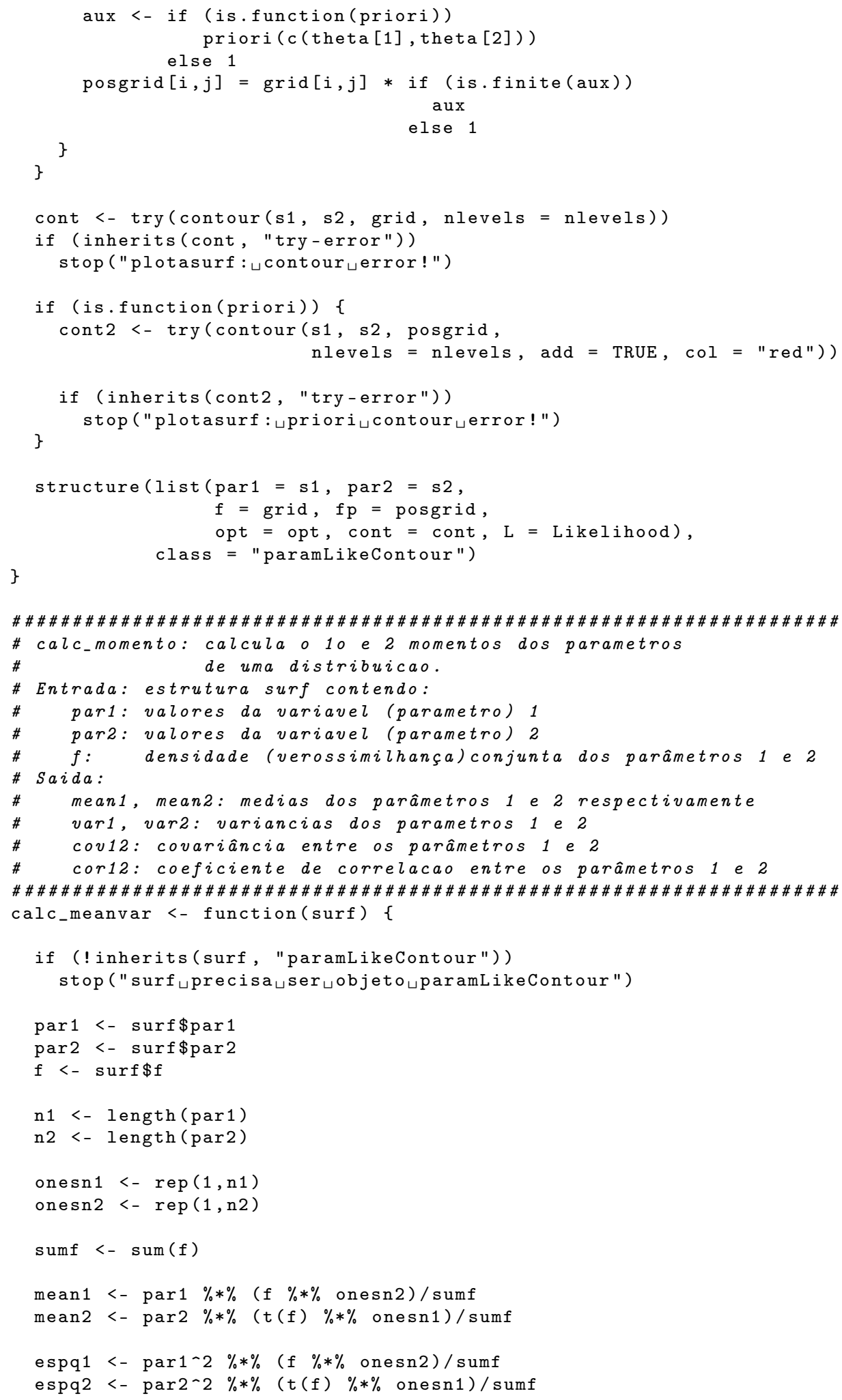




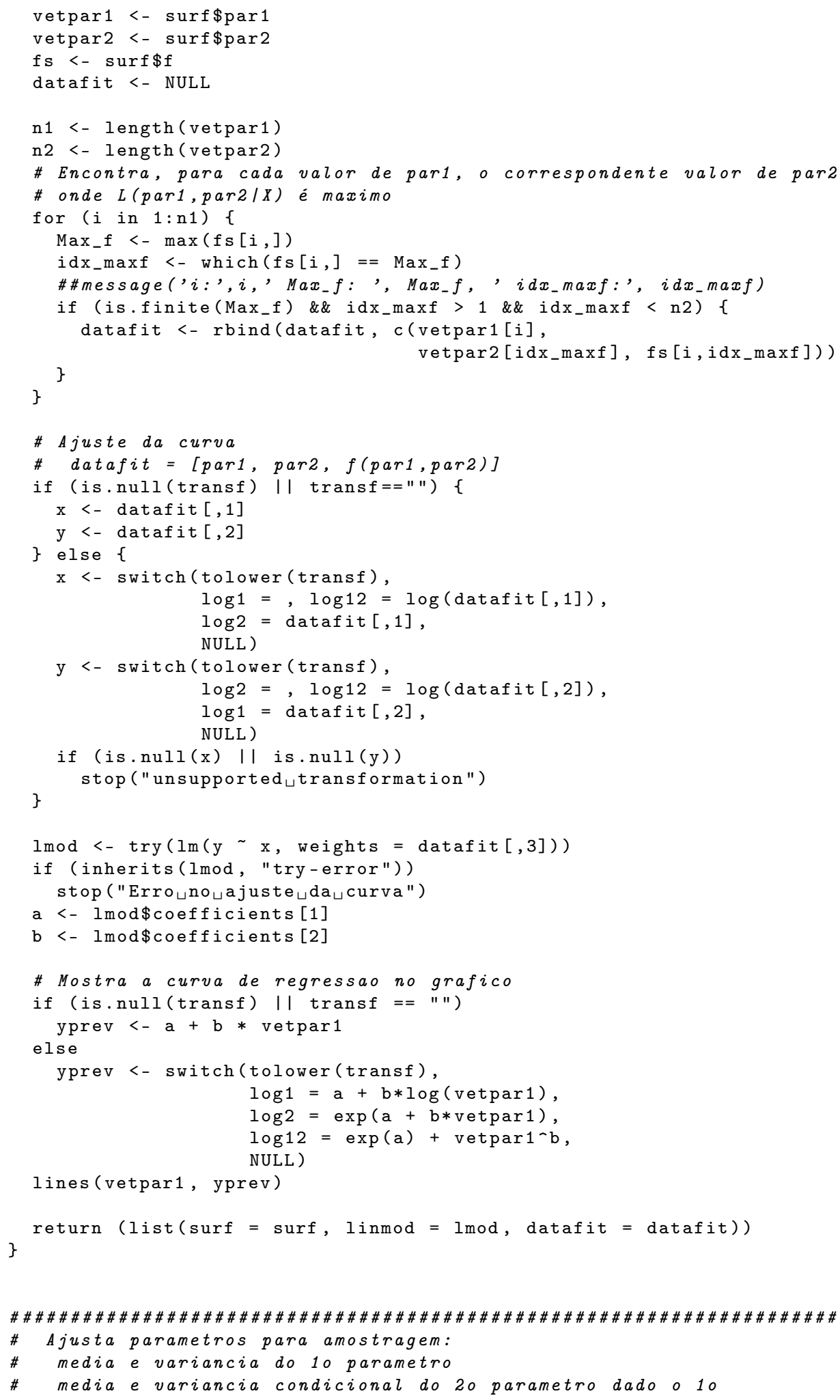




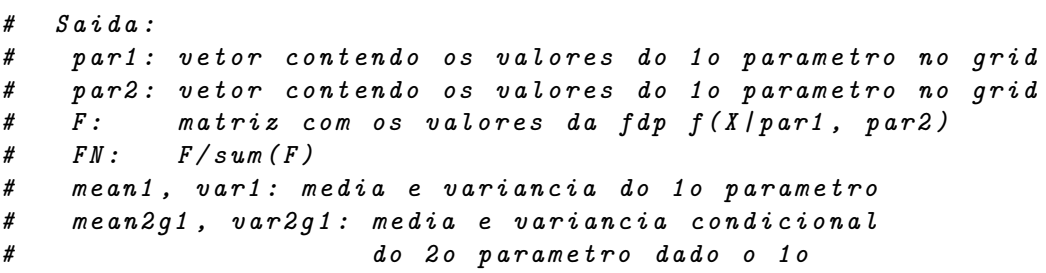




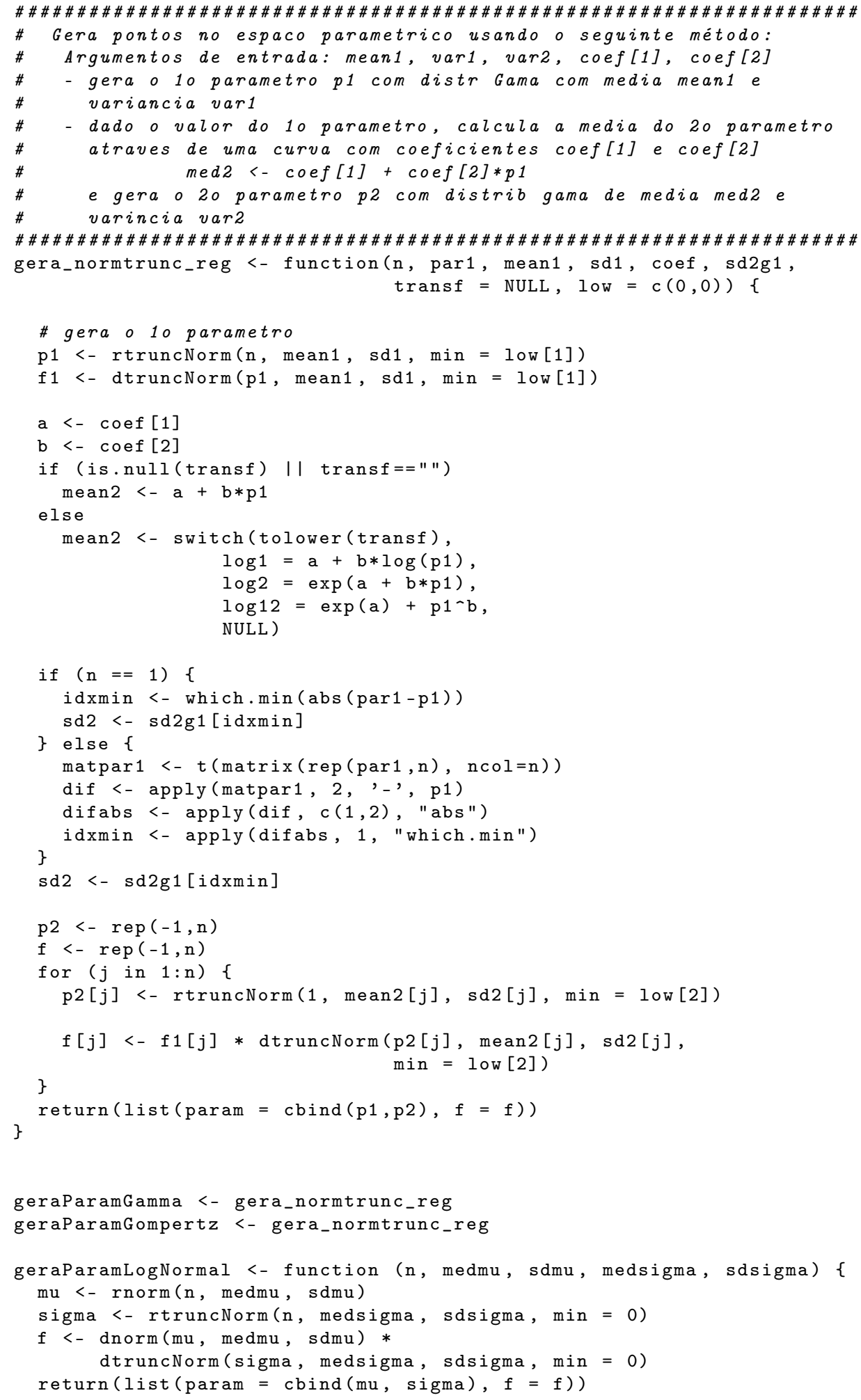


Listing A.4: plotasurf.r

\section{A.5 gompertz.r}

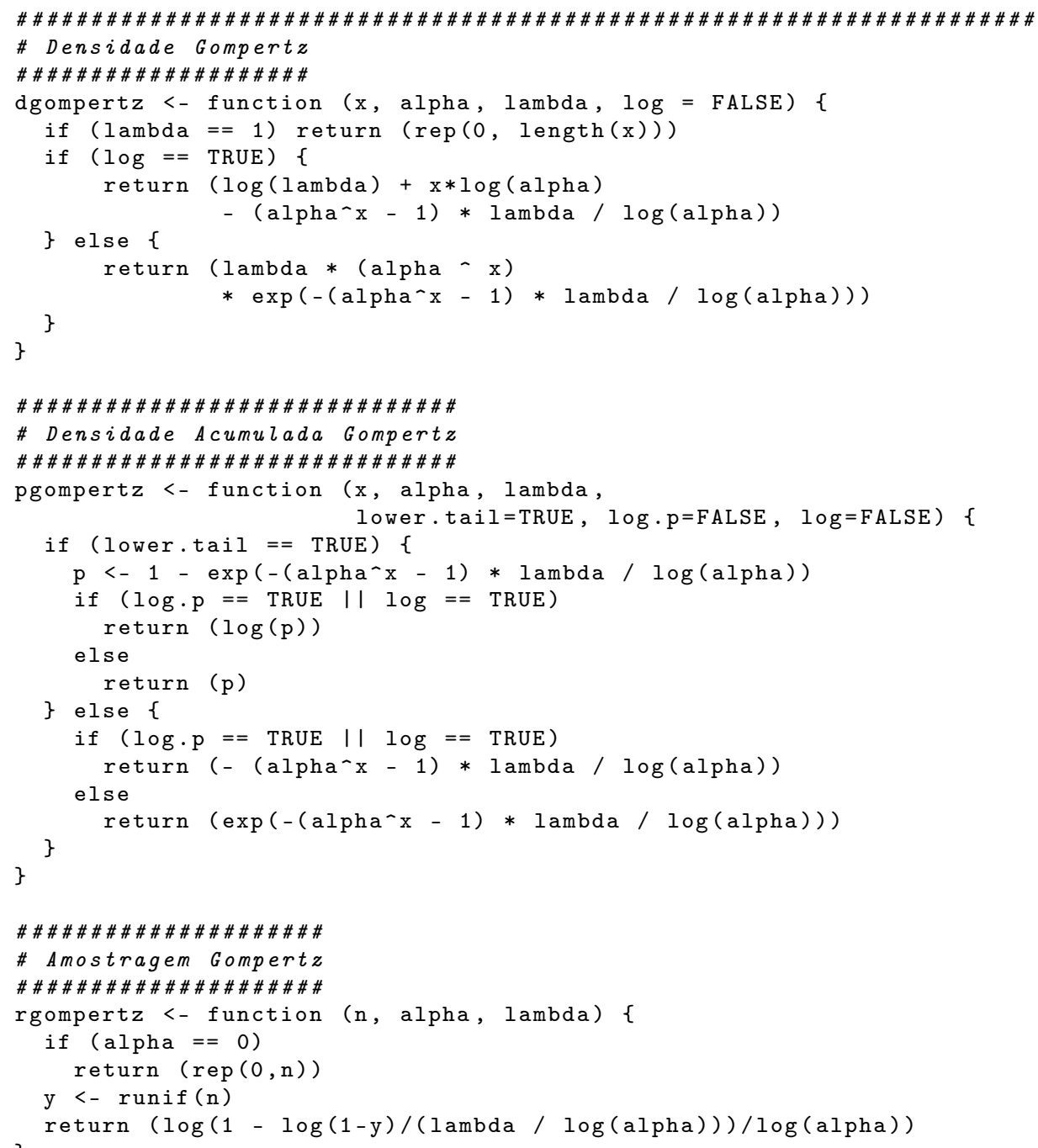


Listing A.5: gompertz.r

\section{A.6 truncatedNormal.r}

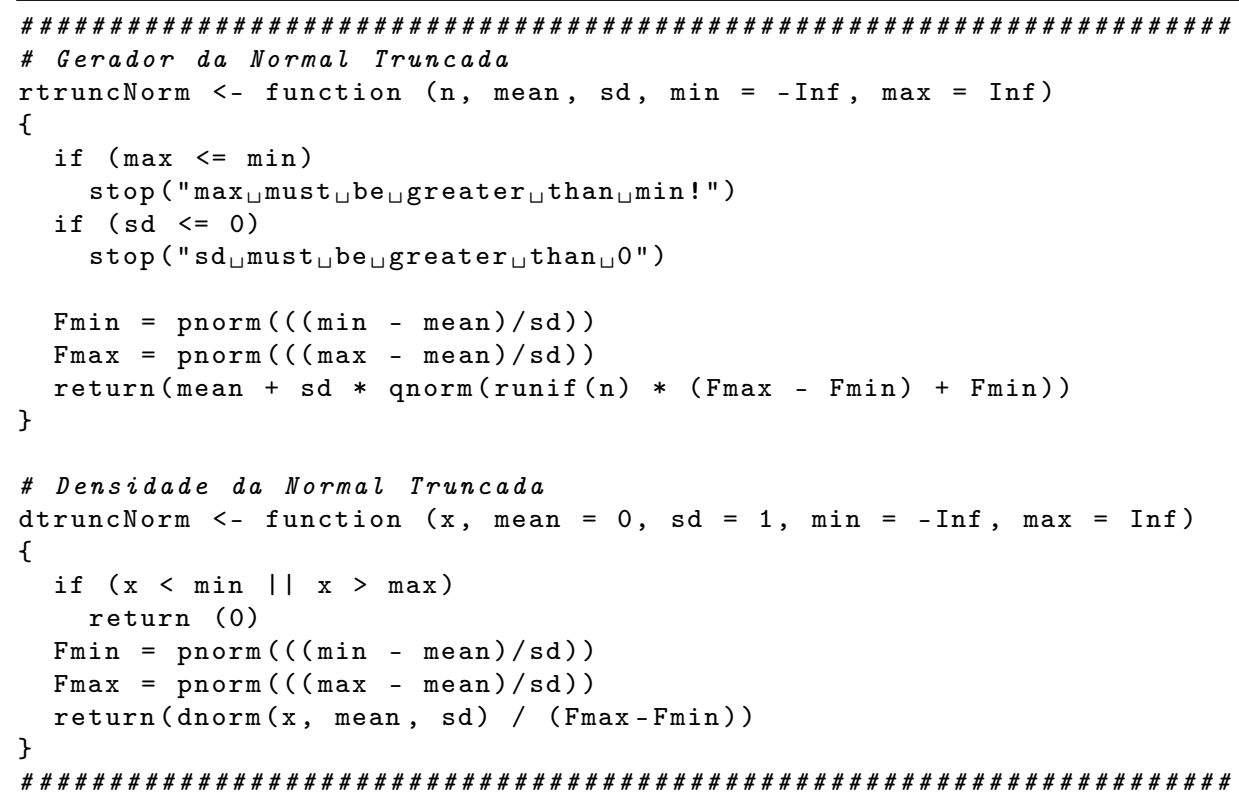

Listing A.6: truncatedNormal.r 